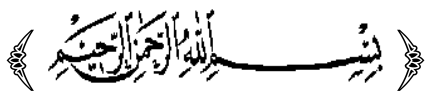

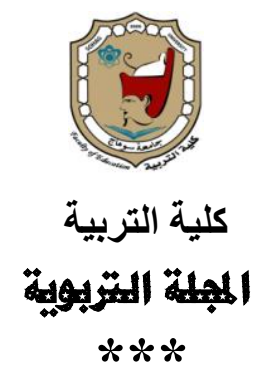

تصور علاجي مقترح قائم على مهارات التواصل

الرياضي لعلاج صعوبات تعلم الدوال المثلثية لدى طلاب المرحلة الثانوية

\title{
alan.
}

د/إبـابالسيد شحاتهمحد

مدرس المناهج وطرق تدريس الرياضيات

كلية التربية بالوادي الجديد - جامعة أسيوط

المجلة التزبوية ـ العدد السادس والثلاثون ـ أبريل عا مr مr 
تتسم الرياضيات بطبيعتها الخصبة التي تجعل منها مجالاً لتدريب المتعلمين على أساليب التفكير السليم وحل المشكلات من خلال تنمية قراتهم على التفكير والاستدلال وإدراك

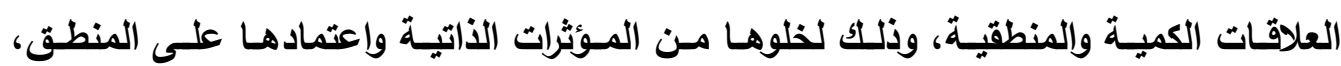
والحقائق والبراهين لذلك فهي تلعب دوراً كبيراً في كل جوانب الحياة.

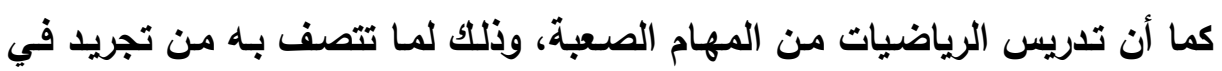
المفاهيم والعلاقات، وتجدر الإشارة إلى أنه لا توجد طريقة مثلى لتدريسها تناسب كلد التل المواقف والدروس التي تقدم من خلال هذه المادة، لذلك فقد بذلت جهوداً عالمية من أجل تطوير تعليم وتعلم الرياضيات، وهذه الجهود جاءت استجابة للعديد من الدعوات التي دعا إليها خبراء التربية في جميع أنحاء العالم لإعادة النظر في مقردات الرياضيات وأهداف وإستراتيجيات

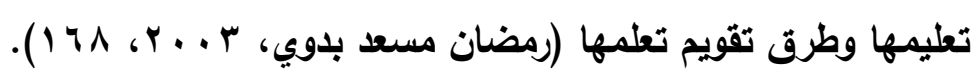

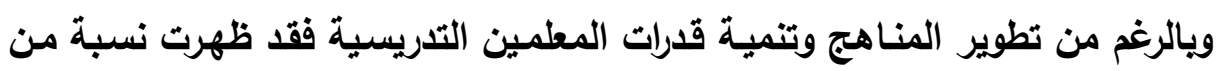

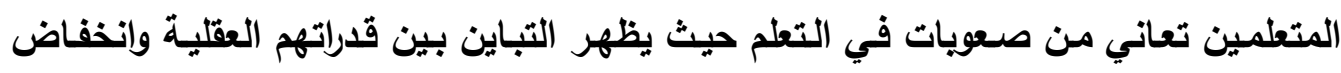
مستوى تحصيلهم الدراسي، ويرجع السبب في ذلتك إلى اضطراب في العمليات الذهنية مثل فئل

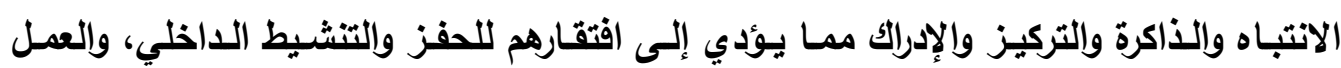

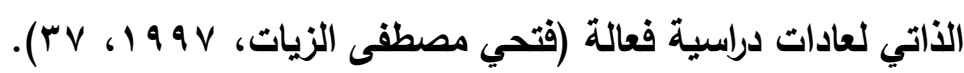

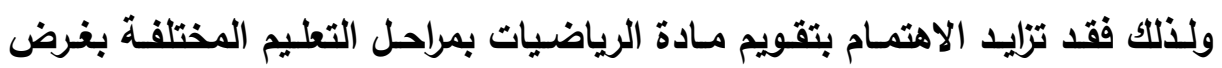
التعرف على الصعويات التي تعوق تعلم الطلاب لها وتشخيص أسبابها وإلعمل على علاجها

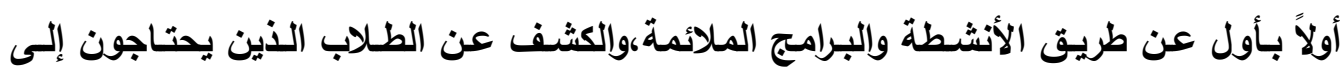

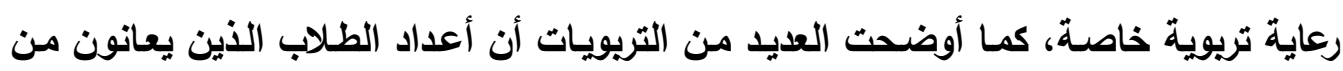
صعويات تعلم مادة الرياضيات في تزايـ مستمر خلال السنوات الأخيرة حتى أصبحوا يمثلون أكبر الفئات في مجال التربية الخاصة(Cawley, et al., 1992, 40-43). وتعـد صـويات تعلـم الرياضسيات مـن المشـكلات التـي تواجـه كـل مـن المعلمسين والمتعلمين، وذلك لأن من هذه الصعويات ما هو مرتبط بطبيعة الرياضيات ويأسلوب تدريسها تونها

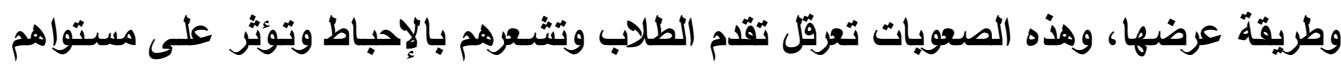




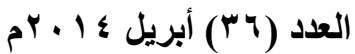

التعليمي في جميع المواد الدراسية المختلفة كما تؤدي إلى عزوف البعض منهم عن المدرسة وفقدانهم الدافعية والاهتمام الضروريين لإنجاز المهام الدراسية والتريوية المختلفة.

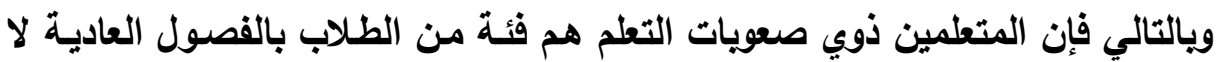

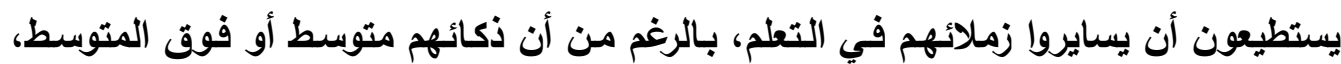

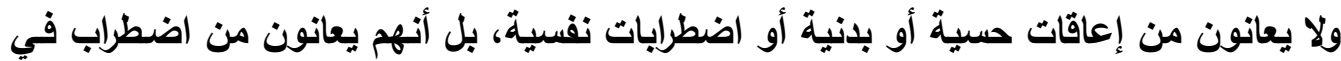
واحدة أو أكثر من العمليات المتضمنة في فهم واستخدام اللغة المكتويـة أو المنطوقة وأن هذه بهن الاضطرابات يستدل عليها من التناقض الدال بين التحصيل والقدرة في واحدة على الأقل من مجالات اللغة المستقبلة والقدرة على التعبير اللغوي وتجهيز اللغة ولا يتضمن هذا التعريف فئـة الطلاب ذوي مشكلات التعلم الناتجـة مـن الإعاقـات السـمعية، أو البصـرية، أو البدنيـة،

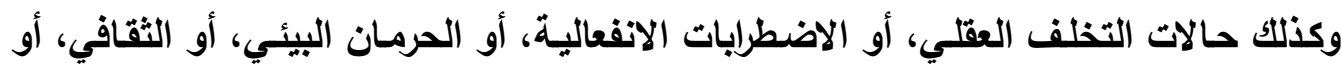

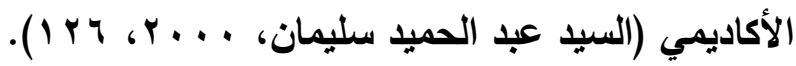

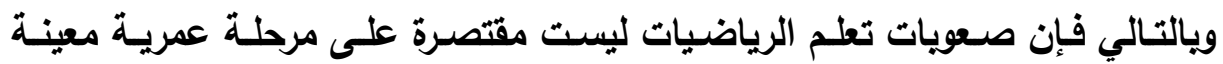
بالرغم من أنها تختلف في أشكالها وفق المرحلة العمرية، لألك يفترض معالجتها بشكل مبكر وإلا فإنها قد تستمر إلى مراحل عمرية متقدمة. كما أوضحا مونتاجيو وأبليجات (Mantague and Applegate, 1993, 19-32) أن هنـاك قصـوراً لـدى الطـلاب ذوي صـعويات التتعلم في تمثيـل المشـكلة وفهمهـــا ووضـع إستراتيجية للحل ومراجعة الحل، وقصور في تحويل المشكلات اللفظية إلى صيغة رياضية،

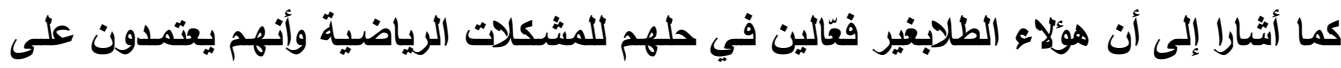
أسلوب المحاولة والخطأ عند حلهم المشكلة. ويمكن ملاحظة تعدد خصائص ذوي صعويات التعلم بشكل عام، وذوي صعويات تعلم الرياضيات بشكل خاص، ويمكن تقسيم هذه الخصائص إلى فئتين هما: أ- خصائص تتناول مفاهيم وعمليات الرياضيات وتتمثل في أن الطلاب يجدون صعوية في تحديد العلاقات المكانية، كما يجدون صعوية في إجراء مقارنات، والانتقال من عملية إلى في إن

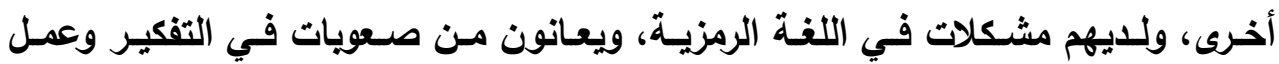

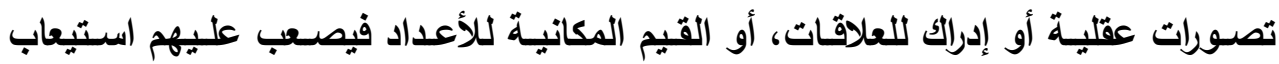
المفاهيم الرياضية (Gearheart, 1985, 370), (Harding, 1986, 123). 


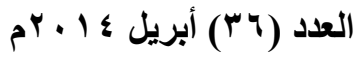

بـ خصائص مرتبطة بالقدرة على المشكلات وتتمثل في قصور الطلاب الواضح في العمليات

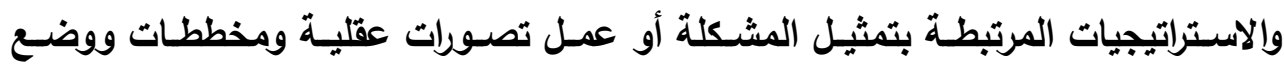
افتراضـات وخطط للحل، فهم أقل مقدرة على فحص المعطيات وتحديد المطلوب وفهم المشكلة وتوظيف مداخل فعالة في الحل، كما أن ليس لليهم القدرة على حل المشكلات

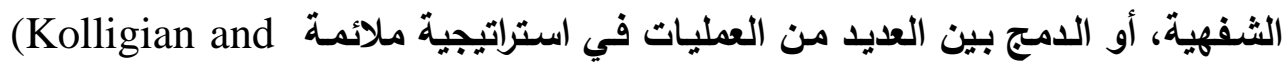

.Stenberg, 1987, 9)

وقد أظهرت العديد من الدراسـات وجود صعويات تعلم في مقرر الرياضيات بالمراحل

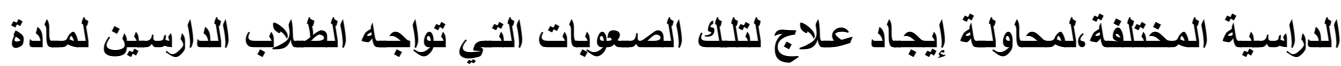
الرياضيات من خلال استراتيجيات ويرامج مناسبة، ومن هذه الدراسات:

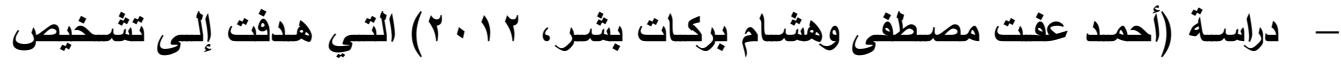
صعويات تعلم الرياضيات لاى طلاب المرحلة المتوسطة، ووضع تصور لبرنـامج علاجي برهي مناسب في ضوء الصعويات التي تظهرها نتائج التطبيق، وقد تكونت عينة الدراسـة من

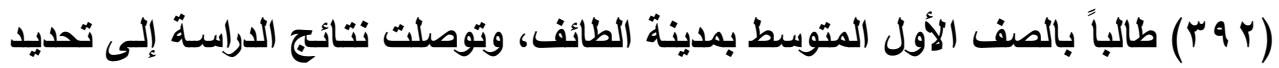

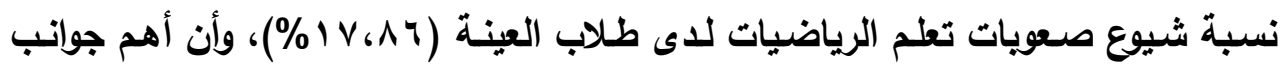
صعويات التعلم تمثلت في العمليات المركبة والمجردات.

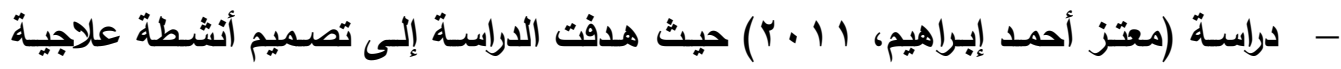
للتلاميذ ذوي صعويات التعلم في الرياضيات بالصفوف الثثلاثة الأولحى بالمرحلة الابتدائية،

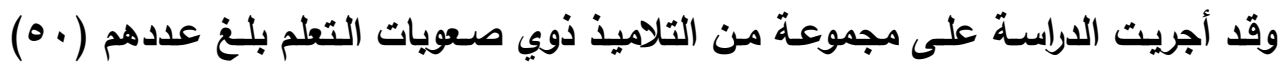

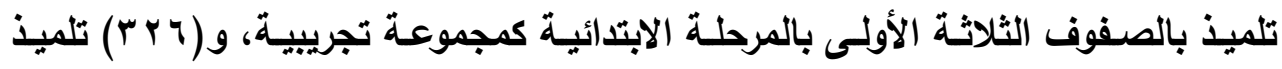
بالصفوف الثلاثة الأولى بالمرحلة الابتدائية كمجموعة ضابطة وقد توصلت الدراسـة إلى الى وجـود فـروق دالـة إحصـائياً عنــ مسـتوى (1 +.، ·) بـين تلاميذ المجمـوعتين التجريبيـة

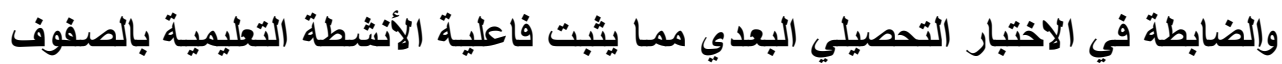

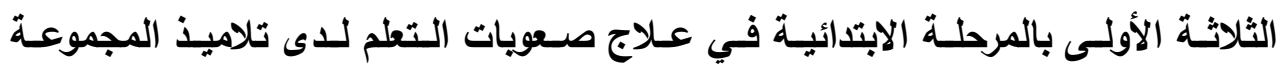
التجريبية. - - دراسة جاردرن ومونتاجيو(Gardern and Montague, 2003) التي هدفت إلى التحقق من استخدام التخيل البصري عند حل المشكلات الرياضية لدى التلاميذ ذوي صعويات 


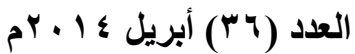

التعلم ومتوسـطي التحصيل والموهـويين مـن تلاميذ الصـف السـادس، لـدى عينـة مسن

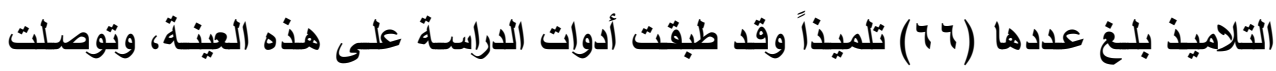
الدراسة إلى أن التلاميذ الموهويين يستخدمون التمثيل المكانية البصرية بأهمية أكثر من

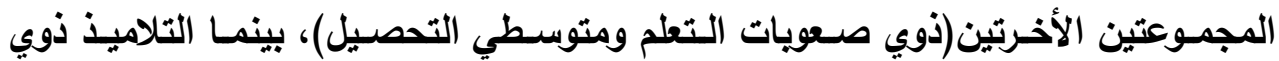
صعويات التعلم يستخدمون التمثيلات التصويرية بأهمية أكثر من نظائرهم، لذا فإن نجاح حل المشكلة الرياضية يرتبط إيجابياً باستخدام التمثيلات التصويرية. - دراسـة كوزمينسكي و كوزمينسكي (Kozminski and Kozminski, 2002) التي هدفت إلى بحث أثر المحادثات بين المعلمين والطلاب ذوي صعويات التعلم في تحسبن

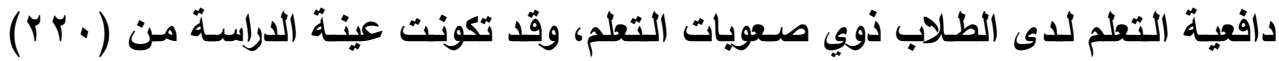
طالب ذوي صعويات التعلم من طلاب المرحلـة الإعداديـة، وقد توصلت الدراسـة إلى أن المحادثات بين المعلم والطلاب ذوي صعويات التعلم كان لها أثر بالغ في تحسين أسلوب النجاح والفشل وكذلك دافعية التعلم لدى التلاميذ ذوي صعويات التعلم.

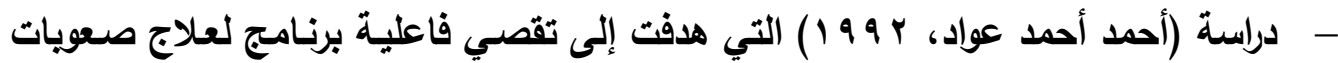
التعلم لادي تلاميذ المرحلة الابتدائية، وقد تكونت عينة الدراسـة من مجموعة من تلاميذ

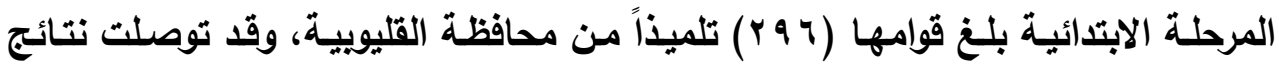
الاراسـة إلى أن نسبة انتثـار صـويات تعلـم الرياضيات في مدارس محافظة القليويبـة

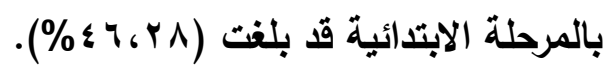

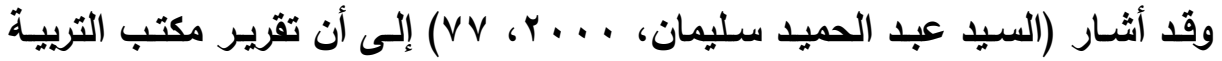
الأمريكي قد حدد أن مجتمع ذوي صعويات التعلم قد تزايد بنسبة ( • 1 \%\%) في عام (999 199) منذ صدور تعريف المجلس الاستثاري (NACHC) في عام (9vV I ) وحتى التاريخ المشار

وممـا سـبق يتضـح أهميـة دراسـة الصـويات التـي تواجـه الطلابفي تعلـم الرياضـيات بالمراحل الدراسية المختلفة، كما نجد أن عدم فهم اللغـة المكتويـة والمقرويوة، وعدم القدرة على تمثيـل المشـكلة الهندسية بصـور مختلفـة، وعدم القـرة على تحليل وتقويم الحلـول

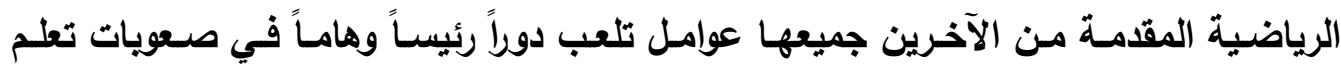




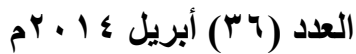

الرياضيات لـى الطلاب وهـي جزء مـن مهارات التواصل الرياضـي التي يفتقدها كثير من الطلاب أثناء دراستهم لمقرر الرياضيات بفروعه المختلفة بالمراحل الدراسية المختلفة.

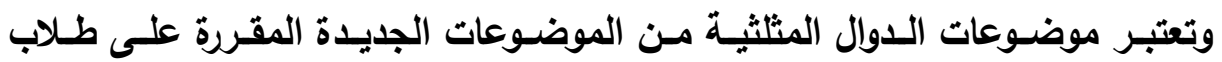
الصف الأول الثانوي حيث لم يسبق لهم في المراحل الدراسية السابقة أن قاموا بدراسـة هذا النوع من الدوال، ومـن خـلال مناقثـة معلمـي ومعلمـات الرياضيات القائمون بتدريس الدوال

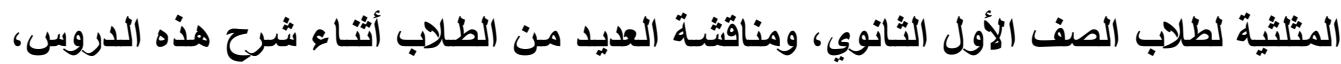
ويفحص نتائج الاختبارات التحصيلية لطلاب الصف الأول الثانوي بموضوعات الدوال المثلثية من مهنة في مقرر الرياضيات، شـعر الباحث بمـا يعانيه طلاب الصف الأول الثانوي من صعويات في دراسة الدوال المثلثية، مما جعل هناك رغبة في إجراء هذه الدراسـة التي تهدف إلى الوقوف هون على صعويات تعلم الدوال المثلثية المقررة بكتاب الرياضيات لطلاب الصف الأول الثانوي، وعلاجها من خلال تصور علاجي مقترح قائم على مهارات التواصل الرياضي.

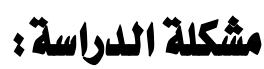
تتحدد مشكلة الدراسة الحالية في السؤال الرئيس التالي: "ما صعويات تعلم موضوعات الدوال المثثية المقررة بكتاب الرياضيات لطلاب الصف الأول الثانوي بالفصل الدراسي الأول والتصور المقترح لعلاجها؟" ويتفرع من السؤال الرئيس الأسئلة الفرعية التالية: ا . مـا مهـارات التواصل الرياضـي الـلازم تضـينها لعـلاج صـويات تعلم موضسوعات الـوال المثلثية المقررة بكتاب الرياضيات لطلاب الصف الأول الثانوي بالفصل الاراسي الأول؟

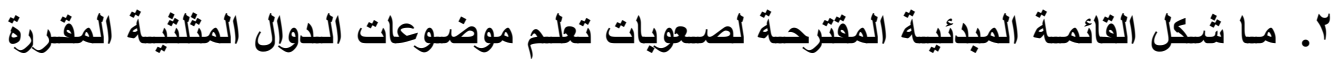

بكتاب الرياضيات لطلاب الصف الأول الثانوي بالفصل الاراسي الأول؟ r. ما الصعويات الفعلية التي يواجهها طلاب الصف الأول الثانوي أثناء دراستهم موضوعات التهات الاوال المثثية المقرة بكتاب الرياضيات بالفصل الدراسي الأول؟

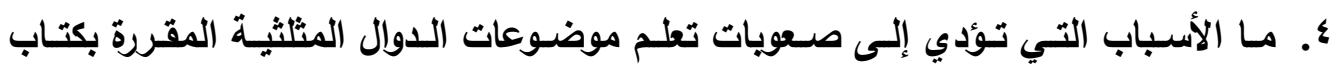
الرياضيات لطلاب الصف الأول الثانوي بالفصل الاراسي الأول ؟ 


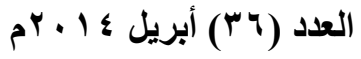

•. ما التصور العلاجي المقترح القائم على مهارات التواصل الرياضي لعلاج صعويات تعلم موضوعات الدوال المثلثية المقرة بكتاب الرياضيات لطلاب الصف الأول الثانوي بالفصل

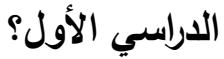

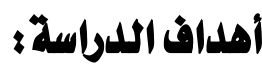

هدفت الدراسة الحالية إلى:

1. التعرف على الصعويات التي تواجه طلاب الصف الأول الثانوي في تعلم موضوعات الدوال المثلثية المقررة بكتاب الرياضيات لطلاب الصف الأول الثانوي بالفصل الدراسي الأول. r. التعرف على أسباب الصعويات التي تواجه طلاب الصف الأول الثانوي في تعلم موضوعات الاوال المثلثية. r. التعرف على مهارات التواصل الرياضي اللازم تضمينها لعلاج صعويات تعلم موضوعات

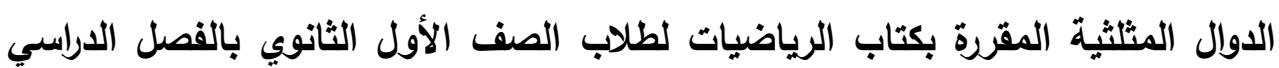
الأول. ؛. وضع تصور مقترح لعلاج صعويات تعلم موضوعات الدوال المثلثية المقررة بكتاب الرياضيات لطلاب الصف الأول الثانوي بالفصل الدراسي الأول من خلال برنامج قائم على مهارات التواصل الرياضي.

\section{حلدود الددابسة}

اقتصرت الدراسة الحالية على:

ا. طلاب الصف الأول الثانوي بمجموعة مـن المـارس الثانويـة بمحافظة أسيوط، وقد تم

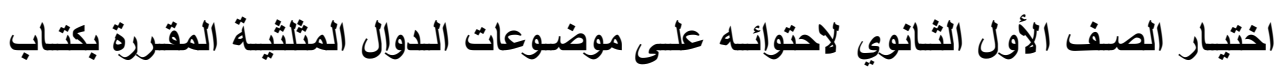

الرياضيات.

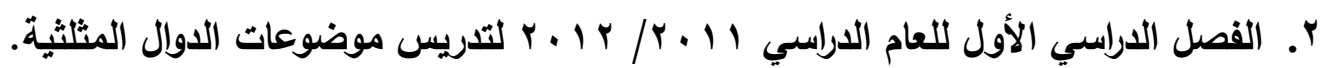
r. الفصل الرابـع (الدوال المثلثيـة) بمقرر الرياضيات لطلاب الصف الأول الثانوي بالفصل الاراسي الأول. 


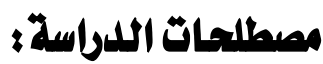

• البرنـامج: يعرف البرنـامج في قـاموس التربيـة بأنـهـ "مجموعـة مـن الأنشـة المنظمـة والمخططة، التي تهدف إلى تطوير معارف المتدربين واتجاهاتهم، وتسـاعدهم على صقل

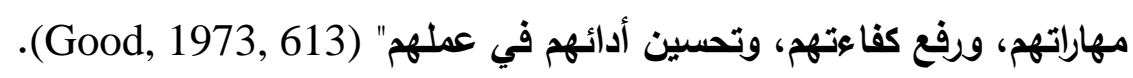

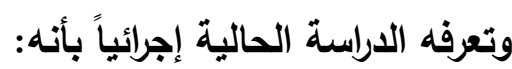

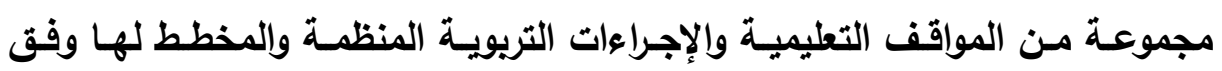
أهـاف محددة في ضـوء مهـارات التواصـل الرياضـي لعـلاج صـويات تعلـم موضـوعاتالدوال المثلثية/المقررة بكتاب الرياضيات لطلاب الصف الأول الثانوي بالفصل الدراسي الأول.

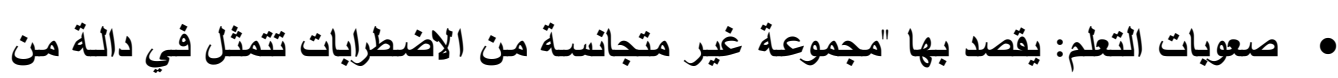

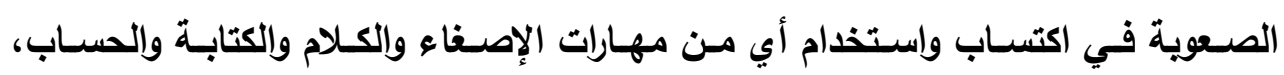

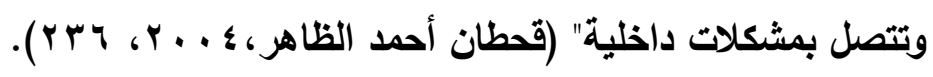
وتعرفها الدراسة الحالية إجرائياً بأنها:

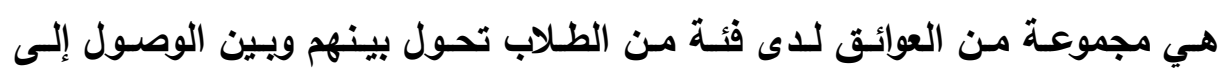
الإجابة الصحيحة ممـا يجعلهم يحصلون على درجات أقل من المتوسط في مـادة الرياضيات

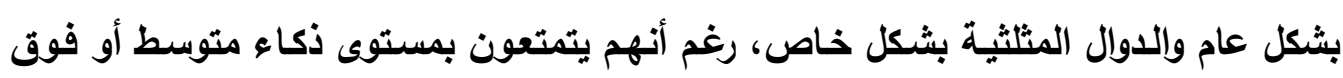
المتوسط، وليس لايهم أي إعاقات عقلية أو جسمية.

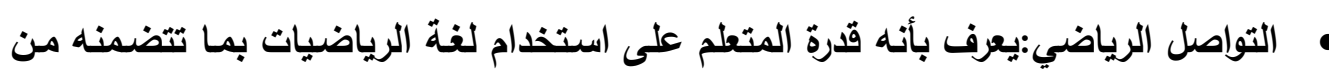

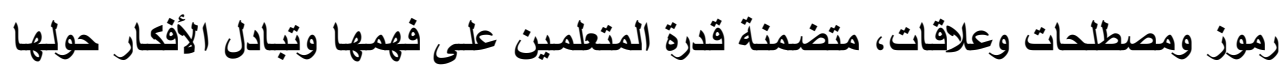

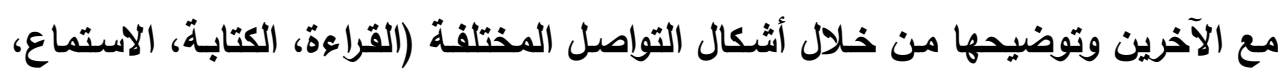
التحدث، التمثيل(Baroody and Cosnick, 1993, 3). وتعرفه الاراسة الحالية إجرائياً بأنه:

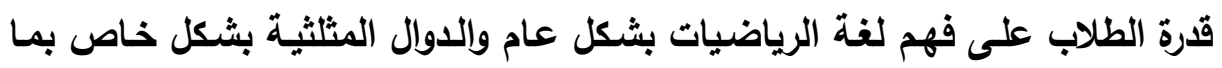

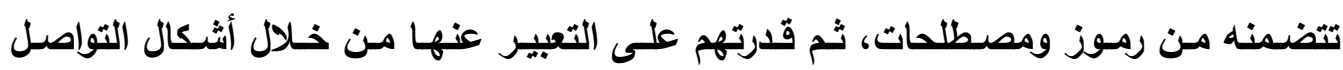
المختلفة (القراءة، الكتابة، الاستماع، التحدث، التمثيل). 


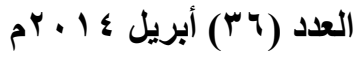

مثرج الدداسة

اعتمدت الدراسة الحالية على المنهجين التاليين:

ا. المنهج الوصفي في إعداد الإطـار النظري للاراسـة وفي إعداد أدوات الدراسـة وتحليل

النتائج وتفسيرها وتقديم التوصيات والمقترحات.

r. المنهج شبه التجريبي في تجربة الدراسة الميدانية.

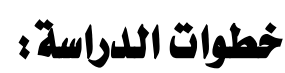

للإجابة عن أسئلة الدراسة، تم إتباع الخطوات التالية:

ا ـ دراسة الأدبيات والدراسات السابقة التي تناولت التواصل الرياضي،وصعويات التعلم بشكل عام وصعويات تعلم الرياضيات بشكل خاص للتعرف على مفهومهمـا وأهميتهما وإجراءات تنفيذهما. r. تحـيــ مهـارات التواصـل الرياضـي الـلازم تضـمينها بموضـوعات الـدوال المثلثيـة المقرر بكتاب الرياضيات لطلاب الصف الأول الثانوي بالفصل الدراسي الأول.

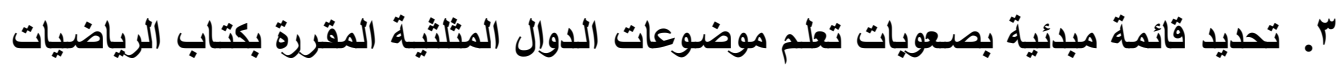

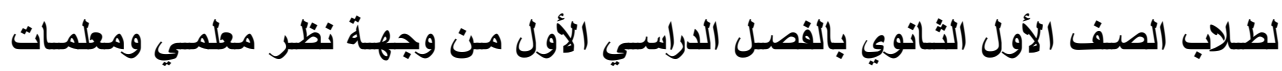
الرياضيات القائمين بتدريسها، وذلك من خلال:

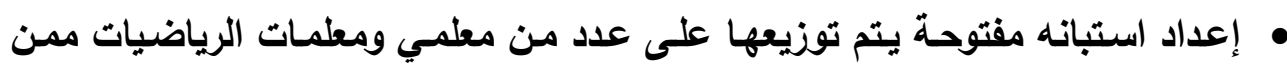

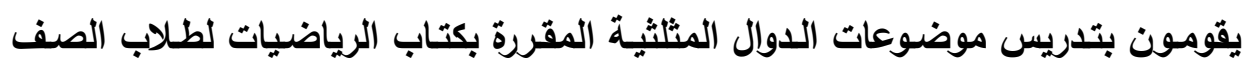
الأول الثانوي بالفصل الدراسي الأول. إجـراء مقـابلات شخصية مـع بعض المعلمين والمعلمـات لإبـاء الـرأي في الاستبانه الاوله المقترحة، حيث يتم مناقثتهم في الصعويات التي يتم تسجيلها بالاستبانه.

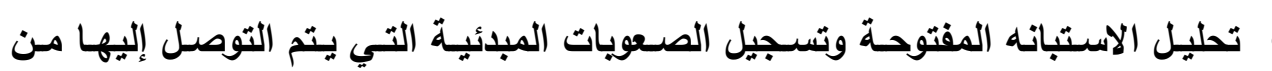
وجهة نظر المعلمين وإلمعلمات وإلتي تم الاتفاق عليها.

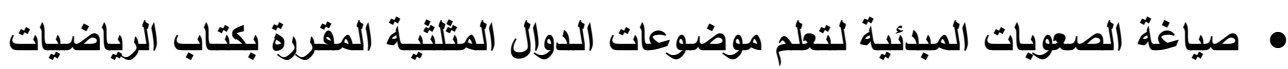
لطلاب الصف الأول الثانوي بالفصل الاراسي الأول.

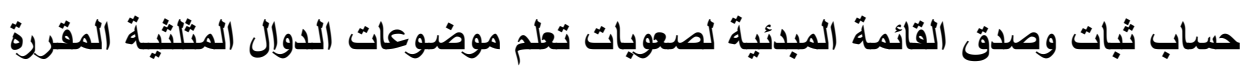
بكتاب الرياضيات لطلاب الصف الأول الثانوي بالفصل الاراسي الأول. 


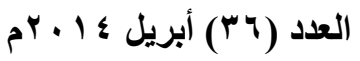

؛. إعداد أدوات الاراسة وقد تضمنت:

• إعداد اختبـار تشخيصـي لصعويات تعلم موضـوعات الـدوال المثلثيـة المقررة بكتاب الرياضيات لطلاب الصف الأول الثانوي بالفصل الدراسي الأول.

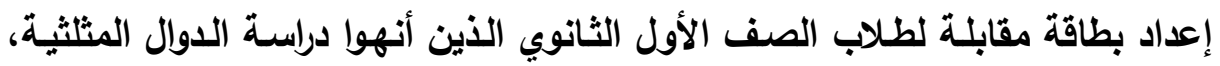

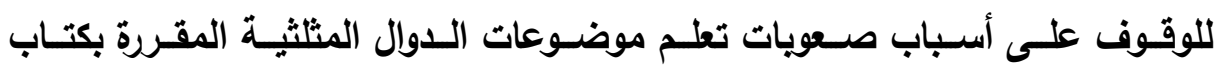
الرياضيات بالفصل الاراسي الأول.

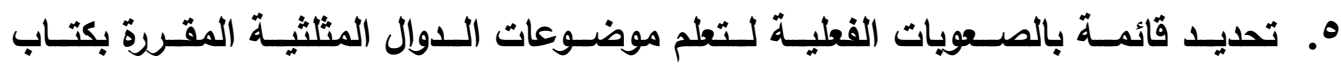
الرياضيات لطلاب الصف الأول الثانوي بالفصل الدراسي الأول.

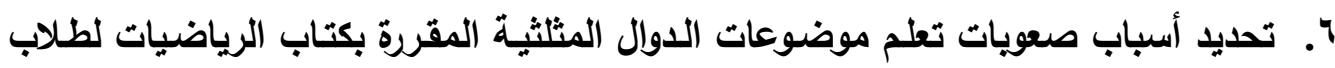
الصف الأول الثانوي بالفصل الدراسي الأول.

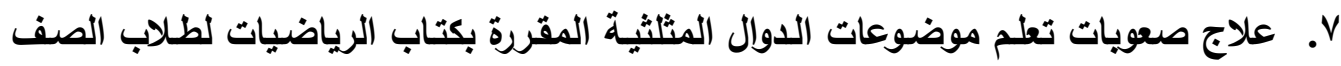

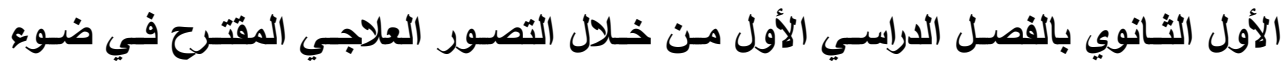

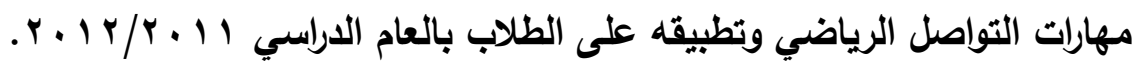

\section{الإطار النظري لللدراسلة}

يتكون الإطار النظري لهذه الاراسة من المحورين التاليين:

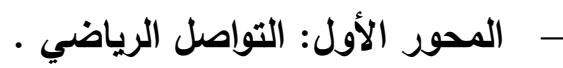
- - المحور الثاني: صعويات تعلم الرياضيات.

\section{المامور الأول : التواصل الرياضي.}

\section{أولاً؛ مفهوم التواصل الرياضي_Mathematic Communication}

تُعد العمليـة التعليميـة عمليـة تواصـل بيلن أطراف الموقف التعليمس، وأداة الاتصـال

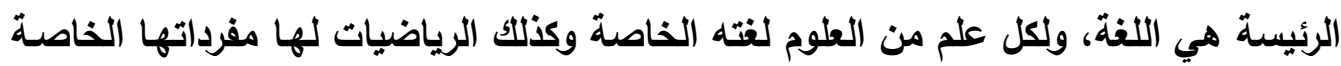

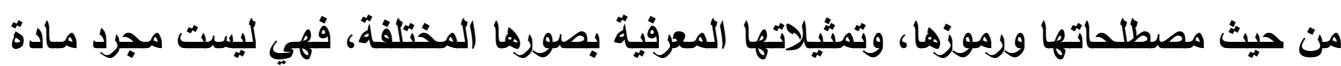

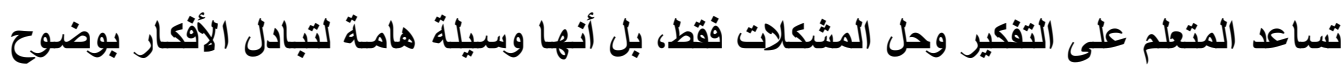
ودقة، فالتواصل الرياضي أحد الأهداف الرئيسـة للمعرفة الرياضية فهو منهج ونظام للتفكير وإدراك العلاقات يتم من خلاله القدرة على التفكير من خلال توظيف مهارات اللغة من قراءة 


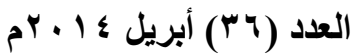

وكتابة وتحدث وإنتماع وتمثيل رياضي مما يساعد الطلاب على فهم الرياضيات وتوظيفها في المواقف الحياتية المختلفة.

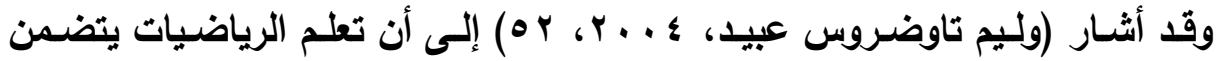

تعلم قراعتها وكتابتها والاستماع إلى مفاهيمها ونظرياتها ومناقشـة موضوعاتها وفهم وإدرالك قواعد التعبير بها أو التعبير عنها، فالطالب عندما يطلب منه حل مشكلة أو يجيب عن سوأل

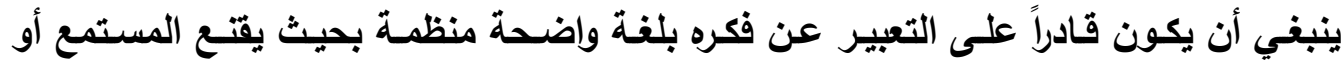

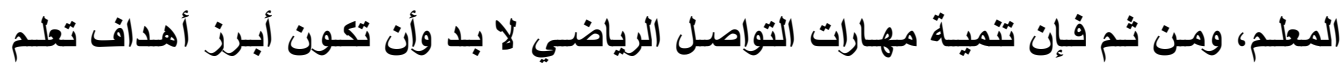
الرياضيات لاى المتعلم والمعلم وصانعي القرار.

ولقد تناولت العديد من الاراسـات مفهوم التواصل الرياضسي بطرق وأسـاليب وتعبيرات

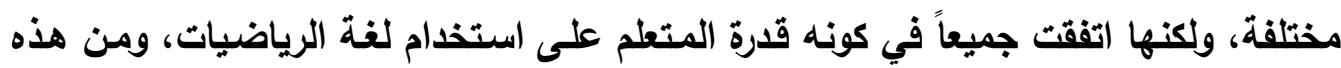
التعريفات:

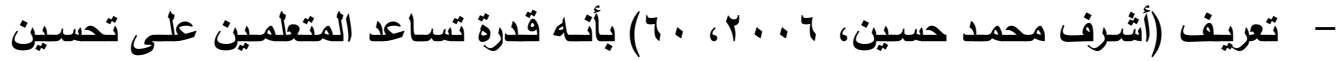
تفكيرهم، وإيجاد دوافع مشتركة بينهم في جو إيجابي، بالإضافة إلى مساعدة المعلم على لـى الاستبصار بمدى تعلم وتمكن طلابه من جوانب التعلم.

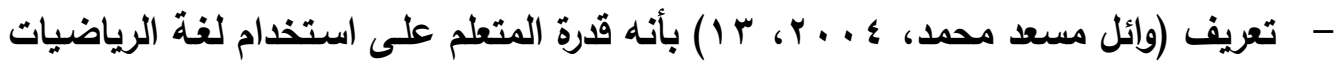

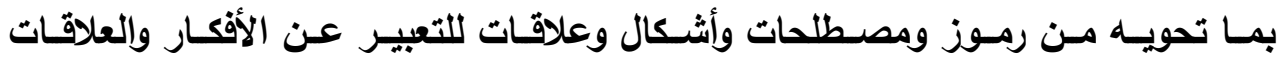
الرياضية، وفهمها وتوضيحها للآخرين.

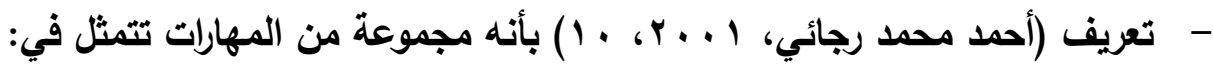

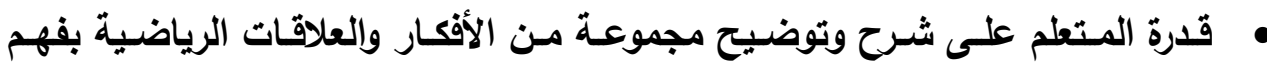
الآخرين.

إعطاء أمثلة صحيحة لمفاهيم أو فكار رياضية. عمل تبرير رياضي للحلول والاستتتاجات الرياضية. • استخدام لغة الرياضيات للوصف. • تمثيل المواقف والعلاقات الرياضية بصورة مختلفة. 


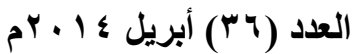

- تعريف شوارز (Schwarz, 1999, 2) بأنه قرة المتعلمين على استخدام لغة الرياضيات

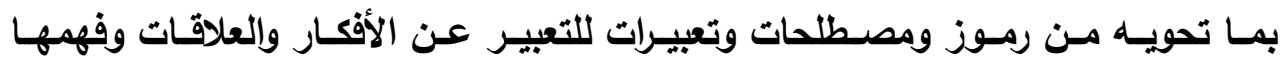
وتوضيحها للآخرين.

- تعريف كوتون (Cotton, 1995, 39) بأنه قدرة المتعلمين على فهم التعبيرات الرياضية

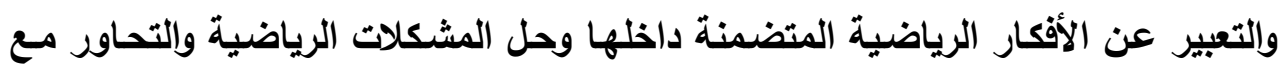
الآخرين من خلال جمل مكتوية بلغة رياضية سليمة.

- - تعريف بارودي (Baroodyand Cosnick, 1993,3) بأنه قدرة المتعلمين على التواصل بلغة الرياضيات قراعة وكتابة وتحدثاً واستماعاً.

ومن تعريفات التواصل الرياضسي السـابقة يمكنتا القول بأن التواصل الرياضسي الجيد

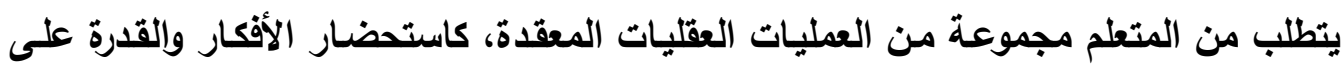
ريطها وتتظيمها وفرزهـا، وهو مـا يتطلب بالضرورة جو تعليمسي خاص يستطيع المعلم من هن خلاله تحفيز طلابه وتدريبهم على التواصل بكافة أشكاله.

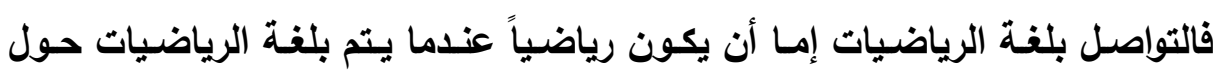

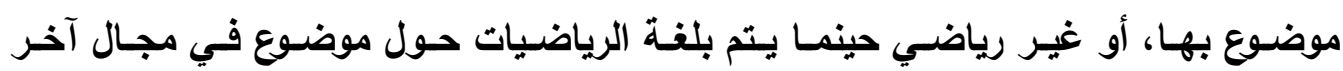

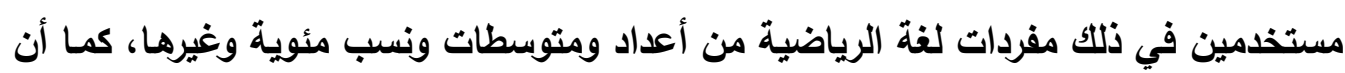

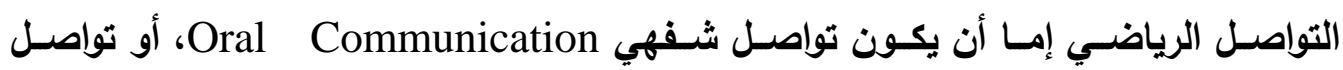
كتابيWritten Communication، وذلك طبقاً لنوع لغة الرياضيات المستخدمة، ويصبح بذلك التواصل الرياضي وسيلة يستطيع بها المعلمون والمتعلمون مشاركة بعضهم البعض في وفي عمليـة تعليم وتعلم الرياضيات، بحيث يصبح المتعلمون قادرين على التعبير عن أفكارهم

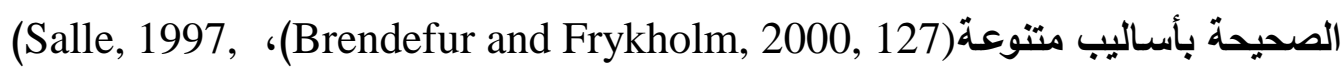

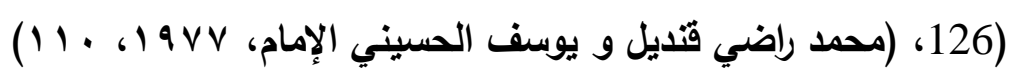

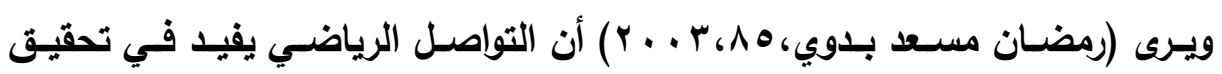
وظـائف كثيرة منهـا مسـاعدة الطـلاب على تحسين وتعزيز فهم الرياضيات، وتوطيد الفهم

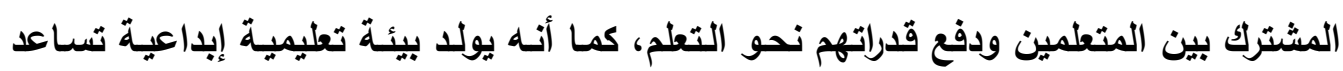

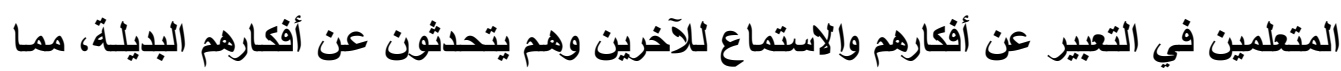
يحول من الرياضيات المجردة إلى معانٍ محسوسة تظهر في المناقشة وإلتفكير والتعليل. 


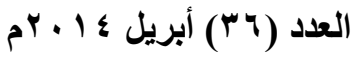

وقد أكدكوزي(Cossey, 1997, 215)على أهمية التواصل الرياضي ليس في كونـه

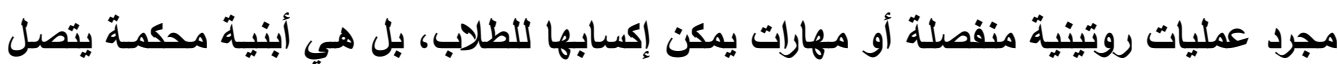

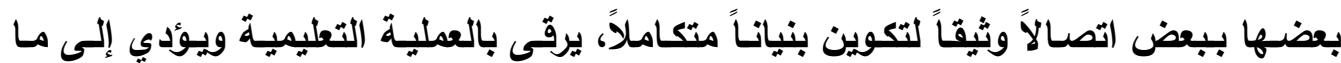

يلي:

ا - يساعد المتعلمين على تحسين وتعزيز فهمهم للرياضيات. r - يساعد على توطيد الفهم المشترك لاى المتعلمين. r- يمكن أن يساعد في دفع قدرة المتعلمين على التعلم. ع - ينمي قرة المتعلم على حل المشكلات والاستدلال. هـ يمكن أن يساعد في توليا بيئة تعليمية مناسبة. צ- يساعد المعلم على اكتساب تقصي طرق تفكير طلابه مما يساعده على توجيههم التوجيه.

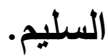

V - ينمي الاتجاه الإيجابي لاى المتعلمين في تعلم الرياضيات.

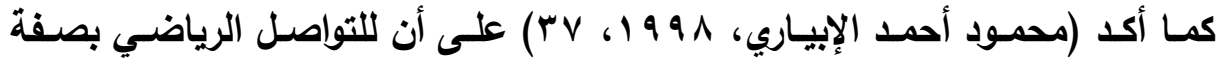

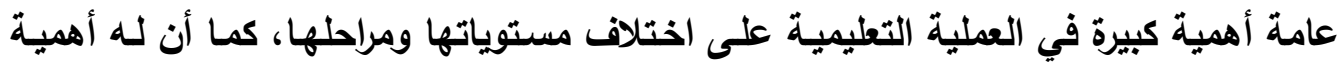
بالغة في تدريس الرياضيات وتفعيل عملية تعليمها وتعلمها، ويمكن عرض أهمية التواصل الرياضي وما يمكن أن يقدمه أثثاء التفاعل الصفي في النقاط التالية: ا ـ معرفة مفردات لغة الرياضيات من رموز وألفاظ وأثكال وتوظيفها في الحوار بشكل جيد.

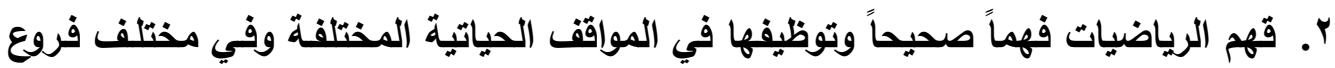

r. تنمية المقدرة الرياضية المتمثلة في حل المشكلات والاستدلال. ؛. تنمية المواقف والعلاقات الرياضية بصور متنوعة ومختلفة. ه. تنمية قرة المتعلم على التأمل لما يدور في ذهنه من أفكار رياضية. 7. استخدام لغة الرياضيات لوصف الأثنكال الهندية والمجسمات التمثيلات البيانية. وقــ أكدت التقـارير المختلفـة الصـادرة عـن المجلس القـومي لمعلمـي الرياضـيات

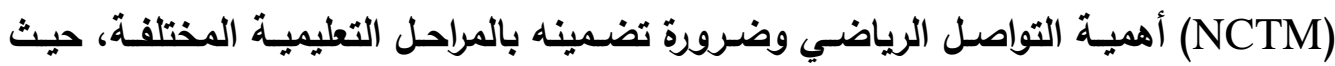
أوصى بما يلي(NCTM, 1989,26-228), (NCTM, 2000,140-143): 


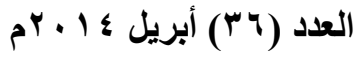

ا ــ ضرورة تتمية ثقة المتعلمين بأنفسهم ويمقدرتهم الرياضية.

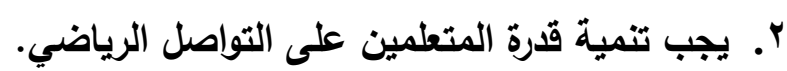
r. يجب أن يكون المتعلم قادراً على تحليل وتقييم التفكير الرياضي والاستراتيجيات الرياضية لاى الآخرين.

؛. ضرورة استخدام المتعلم للغة الرياضيات من خلال التعبير عن الأفكار الرياضية بدقة.

\section{ألثكال التواصل الرباضيخ:}

تعددت أثـكال التواصل الرياضـي داخل حجرة الاراسـة، والتـي يتم من خلالها تبادل

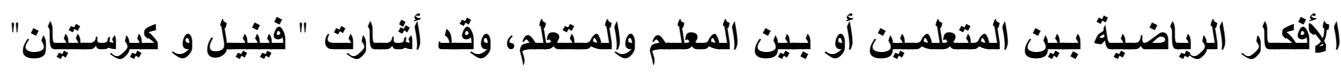
(Fennell and Christian, 1995, 37-39)

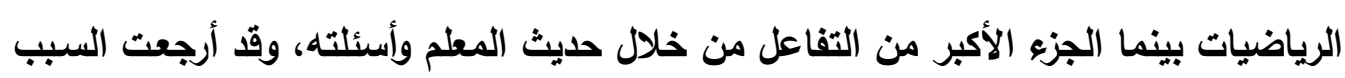
في ذلك إلى محدودية قدرات الطلاب ونقص دافعيتهم للاتصال في حصص الرياضيات.

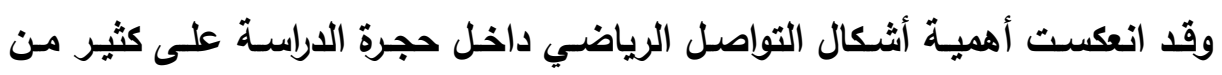

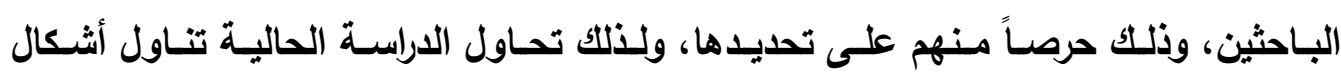
التواصل الرياضي داخل حجرة الدراسة بشئ ودهئ من التفصيل كما يلي:

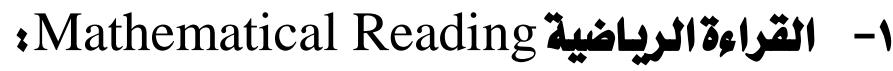

تعني تحديد وتفسير الأفكار والعلاقات والمشكلات الرياضية المقدمة للمتعم في شكل

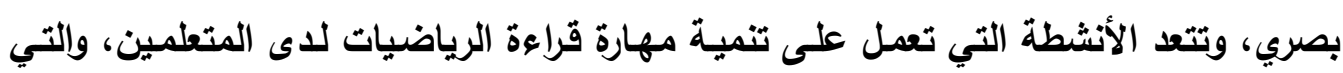

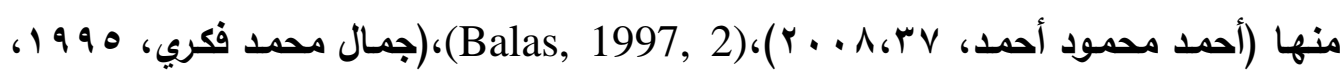
$:(Y V$ - ق قراءة الكتاب المدرسي بروية وتأني. - توجيه المتعلمين ومساعدتهم على فهم المفردات الرياضية الواردة بالكتاب. - مساعدة المتعلمين على مواصلة القراءة إذا توقفوا أثنائها. - توجيه أسئلة تفسيرية للمتعلمين لإثراء فهمهم بمفردات اللغة الرياضية. - مساعدة المتعلمين على تقصي الأفكار العامة والرئيسة بعد قراءة النص الرياضي.

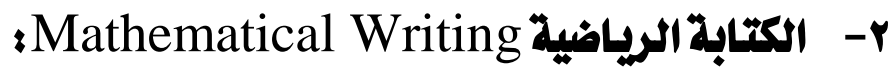




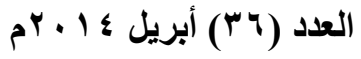

تعنـي قدرة المـتعلم على تنظيم ووصـف المواقف والعلاقـات الرياضية كتابـةً، وتعد

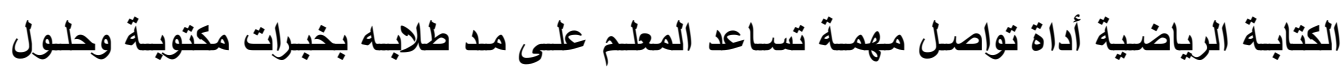

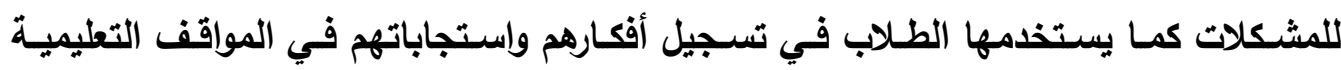
(المختلفة)(Mal and Peter, 1998, 29)(Miller, (Mallips and Crespo, 1995, 3)(5) .1991, 516)

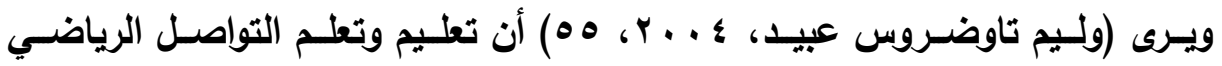

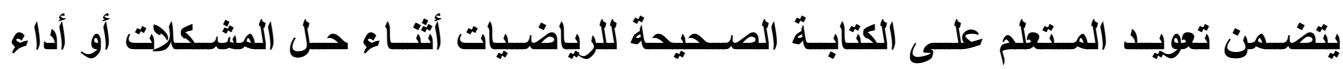

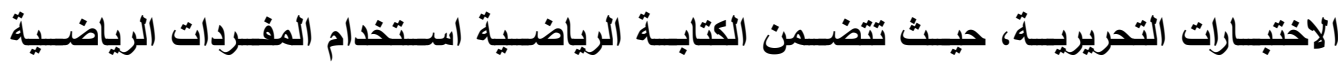
والمصطلحات والتراكيب للتعبير عن الأفكار بصورة مكتوبة أو مصورة. \$- Mathematical Listening الاستماع الرياضي يعني تحديد وتفسير الأفكار والعلاقات والمشكلات الرياضية المقدمة للمتعم في شكل شفهي، فهو ألفاظ الرياضيات المنطوقة بصورة صحيحة والتي يمكن تثجيع الطلاب عليها

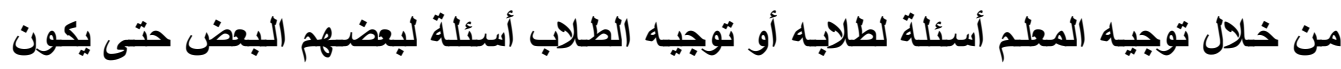

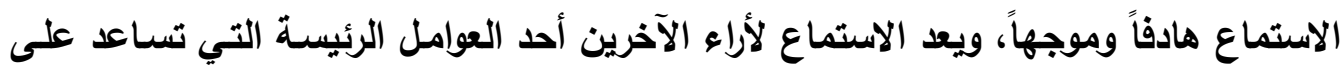

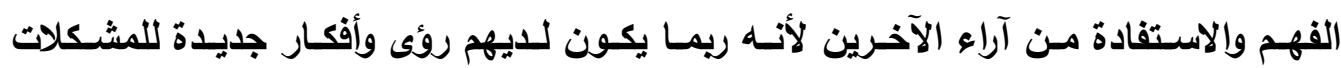
الرياضية المطروحة تغيب عن المستمع (Nical, 1999,57).

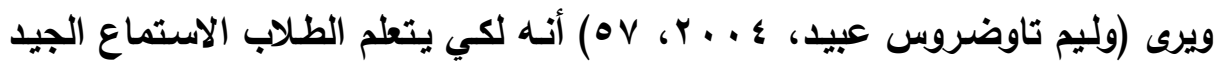

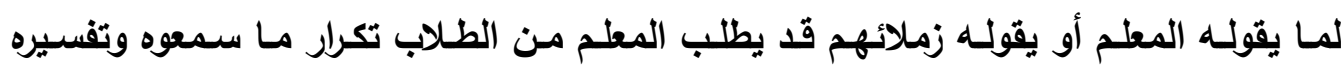
ومناقشته مع بعضهم البعض ليتحقق من أنهم سمعوه بصورة صحيحة.

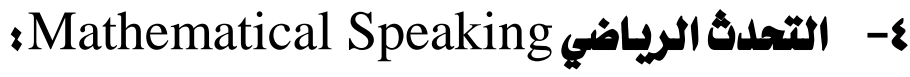
يعني مناقشة وتقويم الأفكار والحلول وطرق التفكير في حل المشكلات الرياضية، مـع المعلمة والأقران باستخدام المفردات اللغوية الرياضية، فيمكن من خلالها استخدام المفردات الرياضية والمصطلحات والتراكيب للتعبير عن الأفكار بصورة شفوية أو مكتوية أو مصورة. ويعتبر التحدث بلفة الرياضيات أحد أهم أثكال التواصل الرياضسي التي يمارس فيها الطلاب مهارات التواصل الثفهي والمناقشة الرياضية التي تسمح لهم بشرح أفكارهم، والتعبير عن تفكيرهم الرياضي(Leikin and Zaslavsky, 1997, 332). 


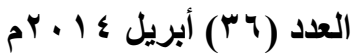

\section{0- Mathematical Representation التشيل الرياضي}

يعني إعادة تقديم أو ترجمة الأفكار والعلاقات والمشكلات الرياضية في صورة أخرى

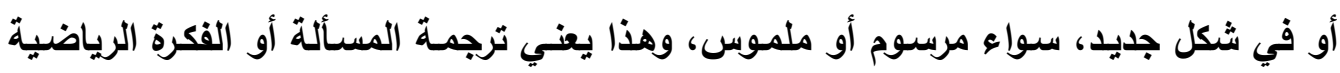

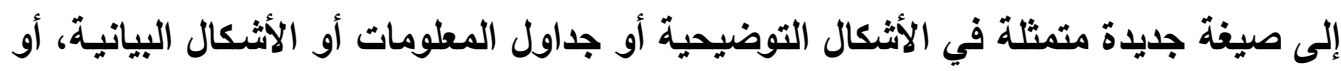

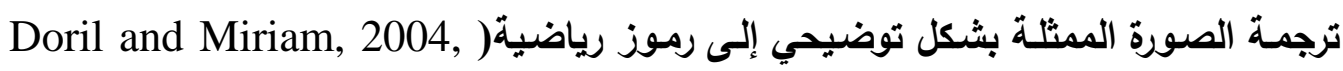

وقد تناولت العديد مـن الدراسـات أثـكال التواصل الرياضس، وكيفيـة توظيفها داخل

حجرة الدراسة في تعليم وتعلم الرياضيات، ومن هذه الدراسات:

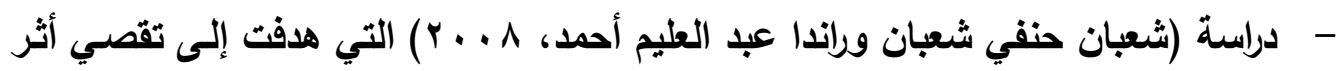
برنـامج قائم على التعلم التأملي للتظلب على قصور المهارات الرياضية وتنميـة مهارات

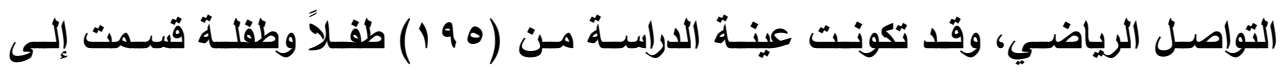
مجموعتين ضابطة وتجريبية، وقد توصلت نتائج الدراسـة إلى أن للبرنامج المقترح تأثيراً كبيراً في التظلب على قصور المهارات الرياضية لدى الأطفال ذوي القصور بالمجموعة التجريبية.

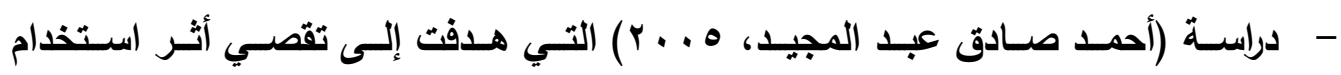
الاستراتيجيات المعرفيـة ومـا وراء المعرفيـة في تـريس الرياضيات على تنميـة مهارات

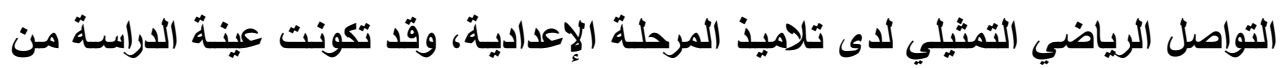
( ) ( الب من طلاب المرحلة الإعدادية بمحافظة سوهاج تم تقسيمهم إلى مجموعتين:

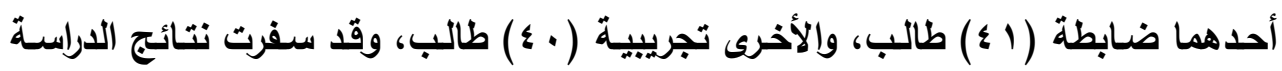
عن أن قدرة طلاب المجموعة التجريبيـة على التواصل الرياضـي التمثيلـي أعلى وذات دلالة إحصائية من قدرة تلاميذ المجموعة الضابطة في هذه الوحدة. - - دراسة كوكي ويتشولز (Cooke and Buchholz, 2005) التي هدفت إلى التعرف فعالية التواصل الرياضي في تعلم الأطفال للرياضيات والتأثير على طريقة تفكيرهم، وقد أجريت

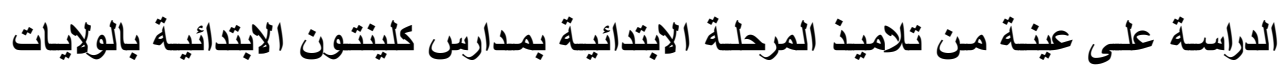
المتحدة الأمريكية في جنوب ولاية كارولينا، وقد أثنارت نتائج الدراسة إلى أهمية التواصل 


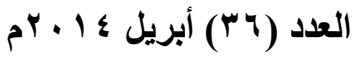

الرياضي في التأثير على تفكير تلاميذ المرحلة الابتدائية بشكل عام، وأن المعلم صاحب

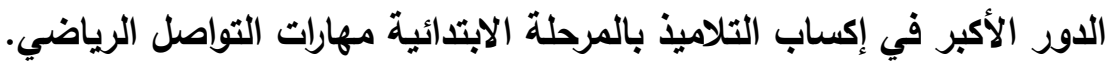
- دراسـة جونجيزي ويريس وسـاندرا(Jingzi, Bruce and Sandra, 2005) : التي هدفت إلى التعرف على التواصل الرياضي من خـلال مقارنـة بين التراكيب المعرفية لمحادثة كل من المعلم والطالب في درس الرياضيات للمرحلة الثانويـة. تم اختيار عينة من المعلمين

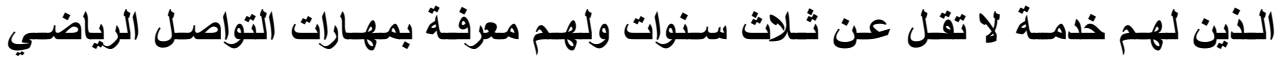

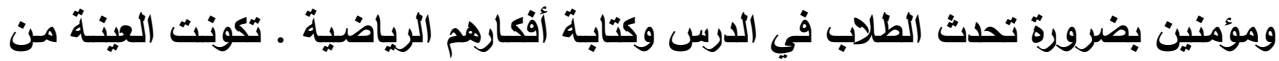

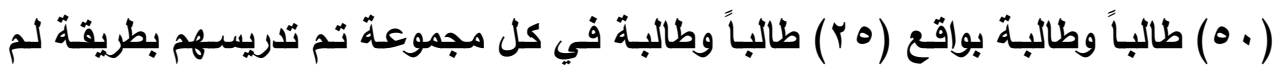
تختلف كثيرا عن الدروس التقليدية حيث يتم عرض المفهوم او الموضوع الرئيسي من المدرس ويقوم الطلاب بحل الأسئلة الرياضية التي حوله ومن ثم الواجب البيتي. وعند الدرس يتواصل الطلاب لحل المسالة وعلى الأغلب فان المجاميع عند التواصل الرياضي تحدث ضوضاء نتيجة المحادثات المتبادلة. ولقياس الأبنية المعرفية الحاصلة في دروس الإس التواصل الرياضي تم عن طريق تسجيل (10) درساً بواقع (ه ؟) سـاعة، أظهرت النتائج أن كل الأبنية المعرفية ظهرت في حديث المدرس في الرياضيات.وعندما يكون المدرس واعيا وفعال يدفع إلى أبنية معرفية عالية المستوى لتكون لاى الطلاب.

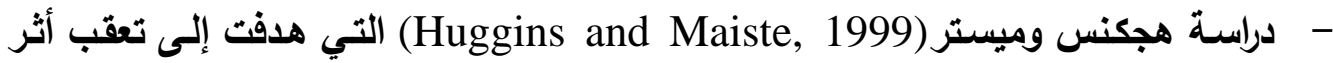
برنـامج مقتـرح لتطـوير مهارات التواصـل الريـاض في اسـتخدام التعلم التعـاوني، وحـل المسائل الواقعية، وإلتركيز على المفردات الرياضية لدى عينة من تلاميذ الصفين الثالث والرابع الابتدائي في الولايات المتحدة الأمريكية، والذين أظهروا ضعفاً في مهارات التواصل الرياضي من خلال نتائج الاختبارات التي طبقت لذلك الغرض، وقد أسفرث نتائج الاراسـة إلى تحسين مهارات التواصل الرياضي لدى أفراد العينة. - - دراسة إيرفن (Irvin, 1993) التي هدفت إلى تحديد المسائل المعدة في كتب الرياضيات المقررة على تلاميذ الصف السادس والسابع في مدراس تكساس لعام • 99 1، لتقييم قدرة

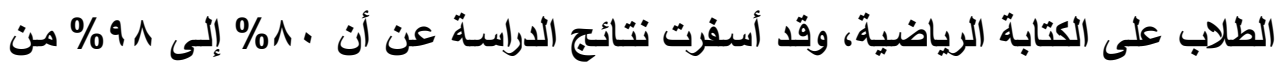
الواجبـات الكتابيـة فـي كتـاب التلميـذ تحقـق الهـدف المرجـو منهـا، وأن نسـبة تحقيـق

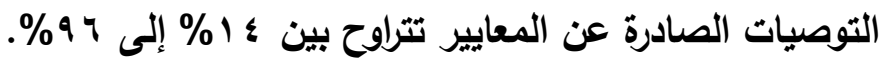




\section{مهارات التواصل الرياضي)}

تناولت العديد من الأدبيات والاراسات التريوية مهارات التواصل الرياضي معتمدين في ذلك على معايير المجلس القومي الأمريكي لمعلمي الرياضيات (62-NCTM, 2000, 59)، ومن هذه الاراسات:

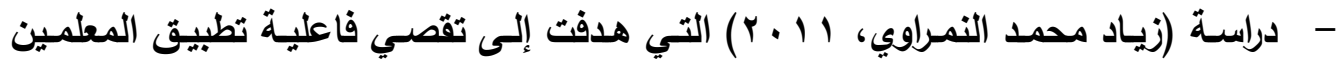
لتوجـه منظور المدرسـة البنائيسة الاجتماعيـة في تـريس الرياضـيات ودوره في تطوير

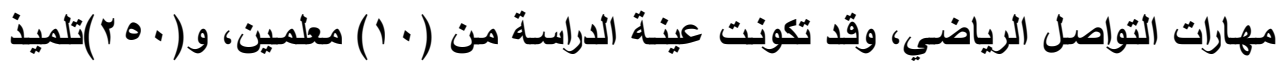
من شعب الصف السادس الأساسي، وقد أسفرت نتائج الدراسة عن وجود حوار وتفاوض اجتمـاعي بنـاء حول الأفكار الرياضية، وتعدد مصـادر المعرفة وقلة سبطرة المعلم، كمـا دلت النتائج على تطور في استخدام التلاميذ مهارات التواصل الرياضسي والمتمثلة في القراءة والكتابة وأنشطة الترجمة. - دراسـة لوكسي وكيرنـي (Lexi and Kearney, 2009)التي هدفت إلى التعرف على

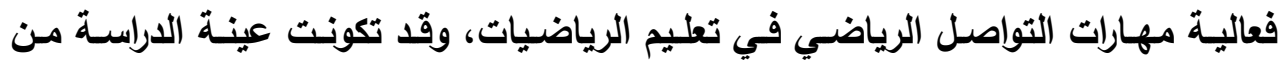
مجموعة من طلاب الصف السابع بلـغ عددهم ( • (ب) طالباً بمدينة لنكون الأمريكية، وقد أسفرت نتائج الدراسة عن تمكن المعلمين من مهارات التواصل الرياضسي إلى حد مـا، وأن المعلم المتمكن بلرجة أفضل كانت نتائج طلابه في اختبار التواصل الرياضسي أفضل، كما وجد أن تمكن الطلاب من مهارات التواصل الرياضسي قد انعكس على تعلمهم مفردات الرياضيات وفهمها، مما يذل على انجاز الطلاب في مادة الرياضيات.

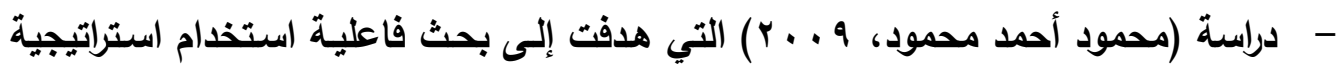

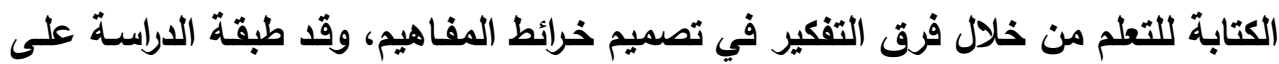
عينة من طلاب الفرقة الرابعة رياضيات بكلية التربية بنيني سويف- جامعة بنـي سويف،

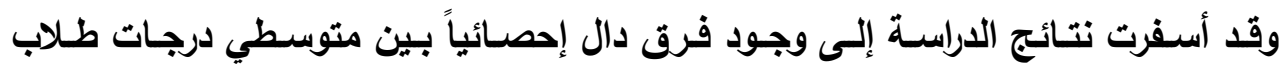

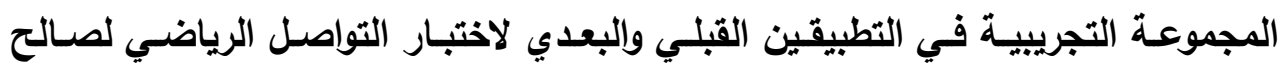
التطبيق البعدي، ممـا يـل على فعالية الكتابـة للتعلم من خـلال فرق التفكير في تصميم خرائط المفاهيم وأثرها الفعال على تتمية التواصل الرياضي. 


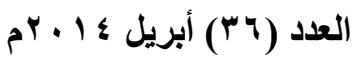

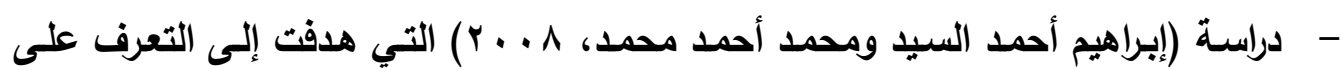

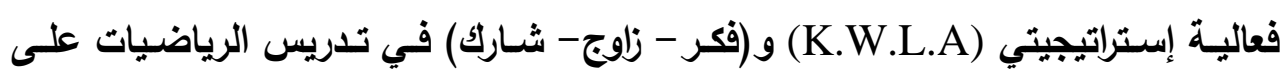

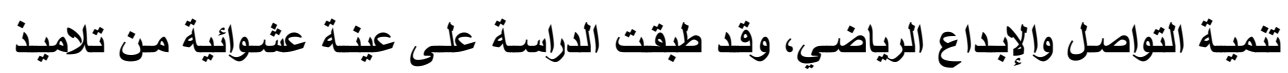

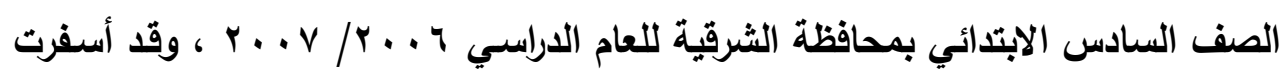
نتائج الدراسـة عن فعاليـة إستراتيجيتي (K.W.L.A) و(فكر - زاوج- شـارك) في تنميـة مهـارات التواصـل الرياضــي لـدي تلاميـذ المجموعـة التجريبيـة الـذين درسـوإ باسـتخدام

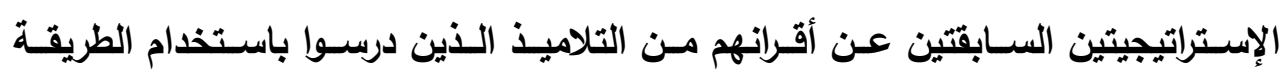
التقليدية.

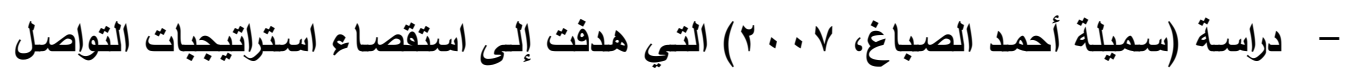

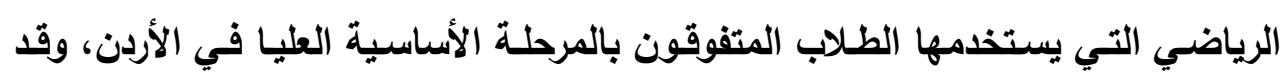

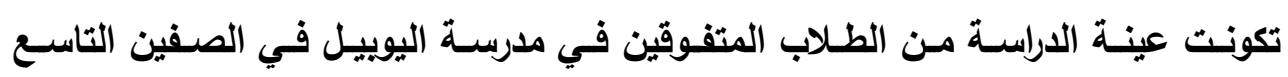

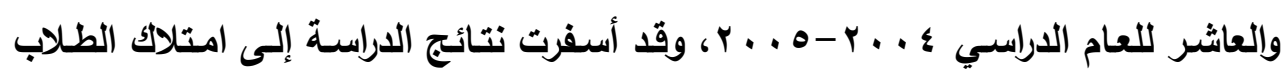
المتفوقين للعديد من استراتيجيات التواصل الرياضسي لاسيما استراتيجيات تنظيم تفكير

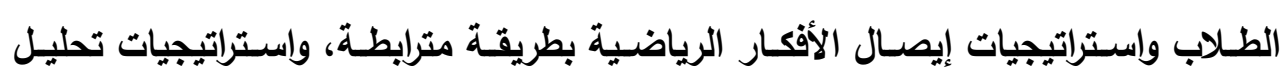
وتقييم تفكير الآخرين.

ومن تحليل الدراسات السابقة يمكنتا تحديد مهارات التواصل الرياضي الرئيسـة، ولكل

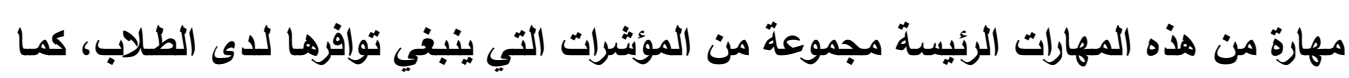

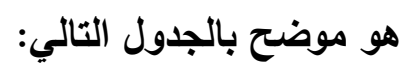




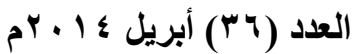

جدول (1)

مهارات التواصل الرياضي الرئيسة ومهاراتها الفرعية

\begin{tabular}{|c|c|c|c|c|}
\hline المؤثرات التي ينبغي توافرها لاى الطلاب & & 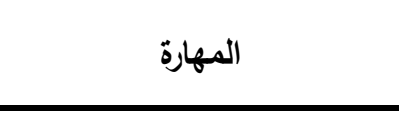 & شكل التواصل & ? \\
\hline 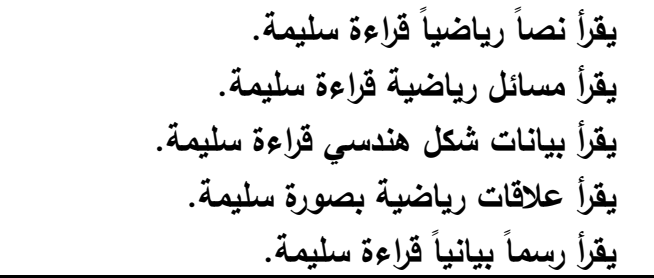 & $\begin{array}{l}\bullet \\
\bullet \\
\bullet \\
\bullet \\
\bullet\end{array}$ & 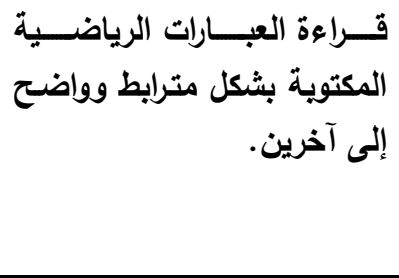 & القراءة الرياضية & 1 \\
\hline 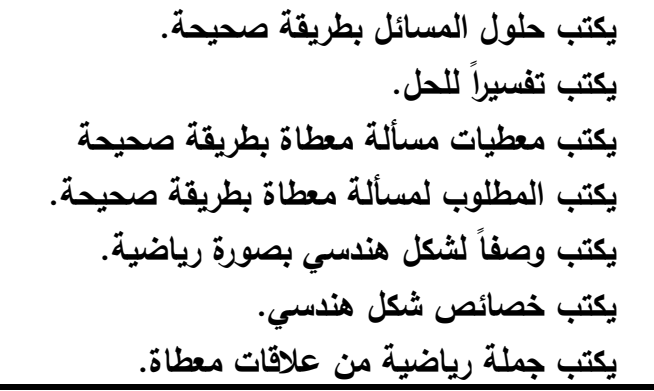 & $\begin{array}{l}\bullet \\
\bullet \\
\bullet \\
\bullet \\
\bullet \\
\bullet \\
\bullet\end{array}$ & 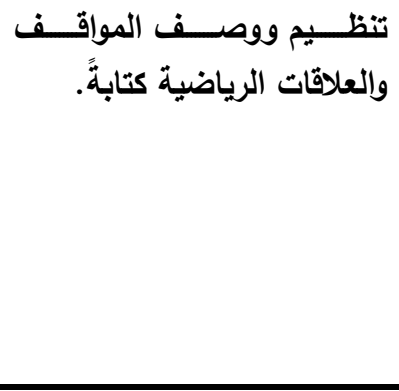 & الكتابة الرياضية & r \\
\hline يسمتسار الإجابة الصحيحة لسؤال من عدة إجابات & $\begin{array}{l}\bullet \\
\bullet \\
\bullet \\
\bullet\end{array}$ & 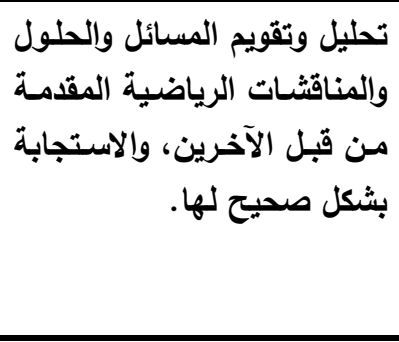 & الاستماع الرياضي & $r$ \\
\hline 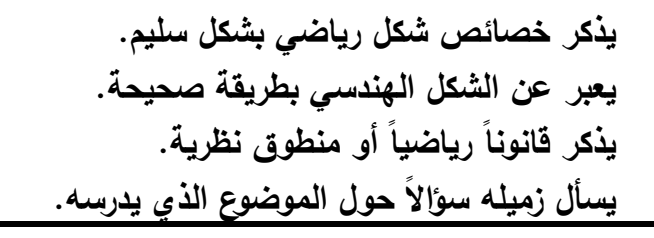 & $\begin{array}{l}\bullet \\
\bullet \\
\bullet \\
\bullet\end{array}$ & 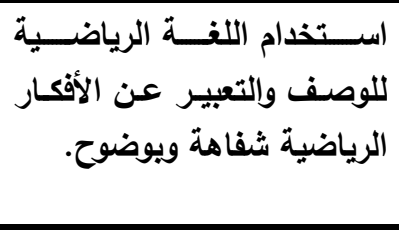 & التحدث الرياضي & $\varepsilon$ \\
\hline 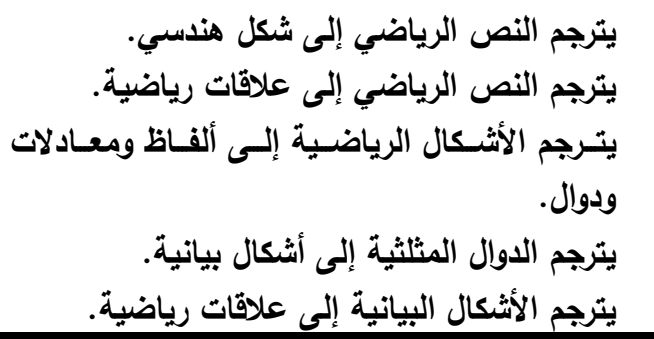 & $\begin{array}{l}\bullet \\
\bullet \\
\bullet\end{array}$ & 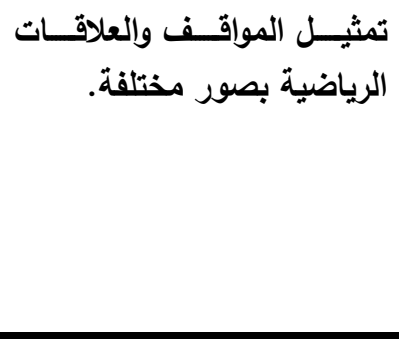 & التمثيل الرياضي & 0 \\
\hline
\end{tabular}




\section{دور الماملم في التواصل الرباضي)}

يعد المعلم محور العملية التعليمية والأداة الفعالة لتحقيق أهداف التربية، لذلك فهو

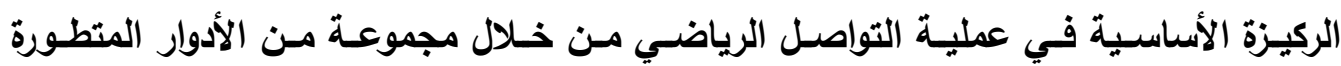
والمتجددة وفقاً للمواقف التعليمية المختلفة التي يقوم بها داخل حجرة الدراسـة لتفعيل التواصل

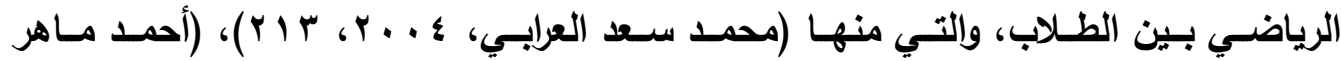

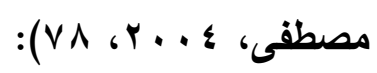

ا ـ الاستماع باهتمام إلى أفكار الطلاب، ومراقبة مشاركاتهم. r. تشجيع الطلاب على طرح الأسئلة، وصياغة التخمينات المناسبة. r. مساعدة الطلاب على توضيح أفكارهم وتبريرها شفهياً وكتابةً. ؛. تعزيز الحوار الصفي بين الطلاب، بحيث ينمي قدرة الطلاب على الإصغاء والاستجابة

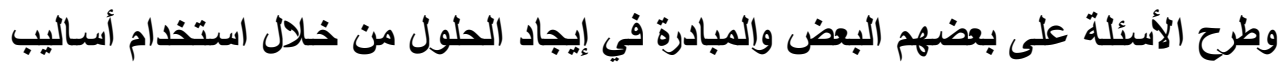

$$
\text { متنوعة في التفكير. }
$$

•. اختيار الوقت الملائم للتعقيب على اللغة والرموز الرياضية التي يستخدمها الطلاب أثناء

$$
\text { عرض أفكارهم. }
$$

ج. تحديد الأفكار التي يجب على الطلاب الاستمرار في مناقشتها بعمق. V. القبل طرق الحل المتعددة من الطلاب. ^. السماح للطلاب بتمثيل المشكلة بصور متعددة. 9 . تلدعيم الثقة المتبادلة بين الطلاب، وحثهم على الاحترام المتبادل بينهم. • 1 ـ دعم حرية التفكير والمناقشة، وإعطاء جميع الطلاب فرص متساوية. 11. ' طرح الأسئلة التي تساعد الطلاب على تنمية مهارات التواصل المختلفة لديهر. r 1 ا. حث الطلاب على تكرار ما سمعوه ليتأكد من أنهم سمعوه بصورة صحيحة.

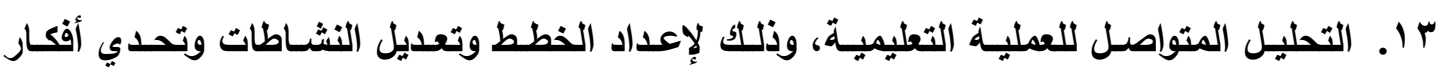
الطلاب وتوسيعها.

لذلك يجب أن يكون المعلـم مدركاً لـدور التواصل الرياضـي في مجـال تعليم وتعلم

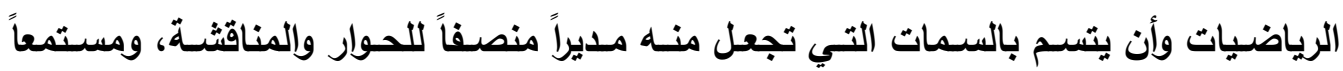
ماهراً، ومتحدثاً قادراً على استتتاج نوع المهارة التي يمكن تنميتها في موقف معين. 


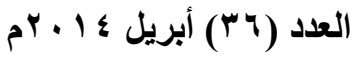

\section{المعور الأثاذي ؛ صعوبات التهلم.}

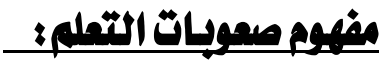

يُعد مجال صعويات التعلم من المجالات الهامة، التي تتضح فيها الفروق بين الطلاب

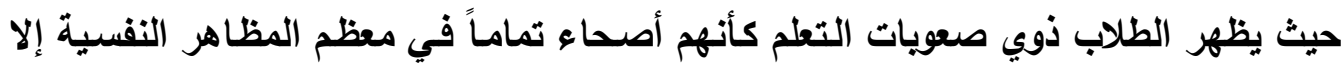
أنهم يعانون من عجز واضِح في مجال أو آخر من مجالات التعلم.

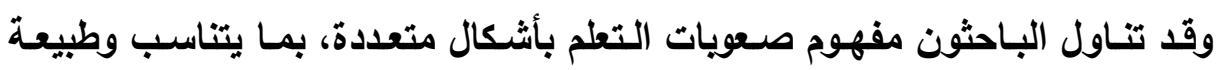

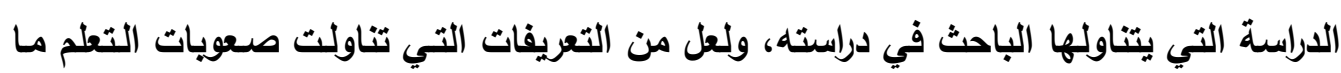
يلي:

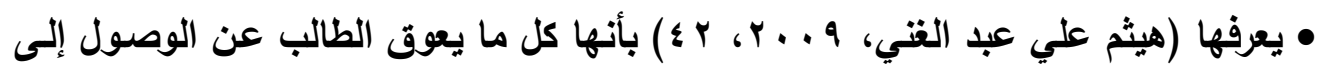

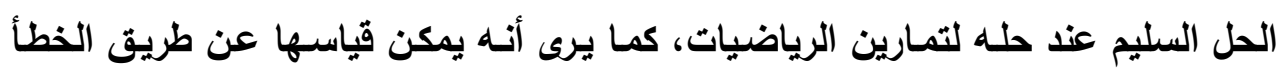
الثائع وهو الذي يتكرر الوقوع فيه بنسبة ه r\% فأكثر من الطلاب.

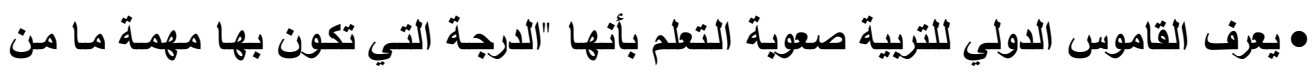

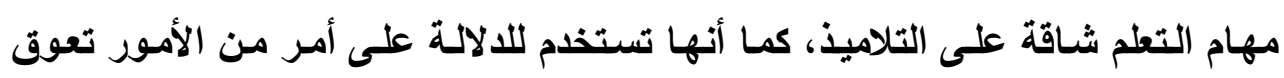

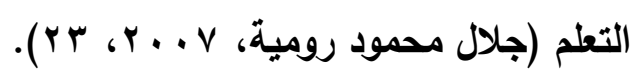

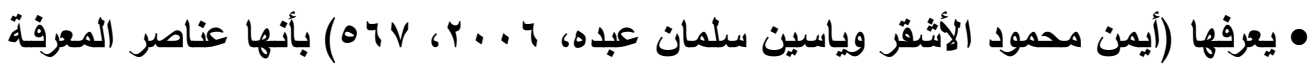

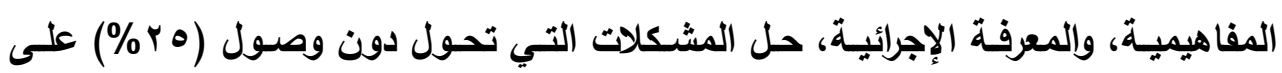

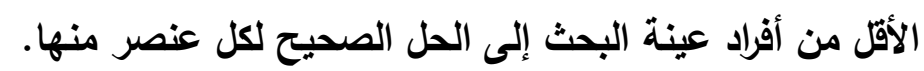

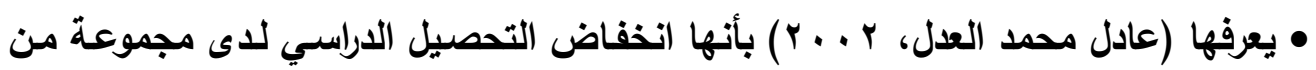
المتعلمين عن بقية زملائهم، مع أنهم يتمتعون بذكاء متوسط أو فوق المتوسط كما أنهم

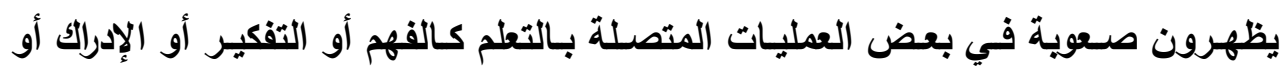
الاتتباه أو القراءة أو الكتابة أو التحدث أو إجراء بعض العضات العمليات الحسابية. • يعرفها سيجيل(Siegel, 1999, 305) بأنها اضطراب في واحدة أو أكثر من العمليات النفسية الأساسية التي تثنمل على الفهم أو استخدام اللغة المنطوقة أو المكتوية والتي

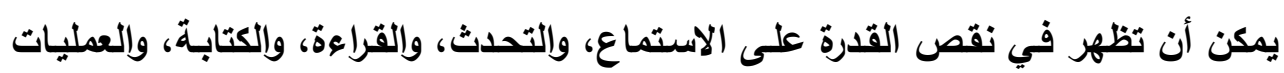
الحسابية. 


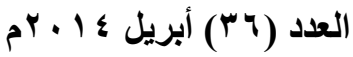

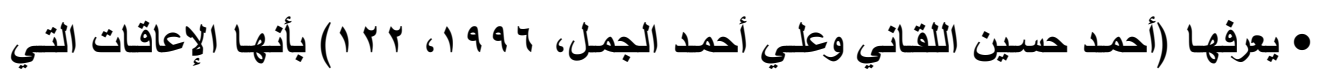

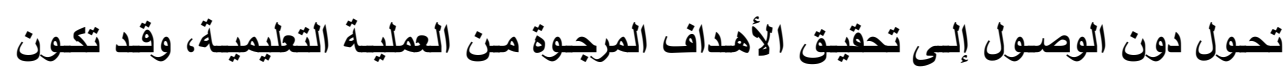

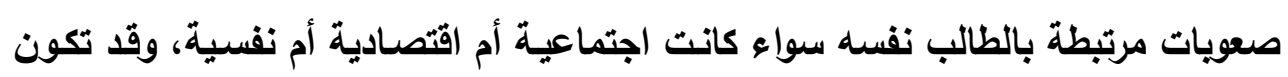

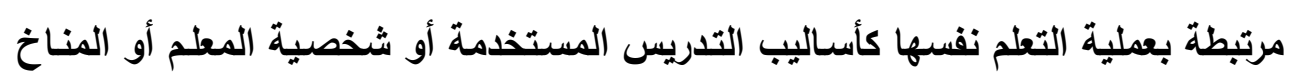
السائد داخل المدرسة.

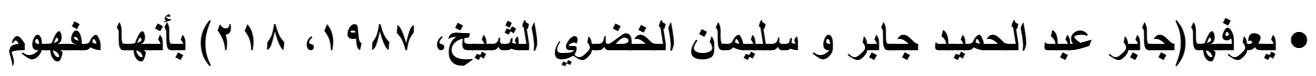
يستخدم لوصف مجموعة من الطلاب يظهرون انخفاضاً في التحصيل الاراسي الفعلي عن

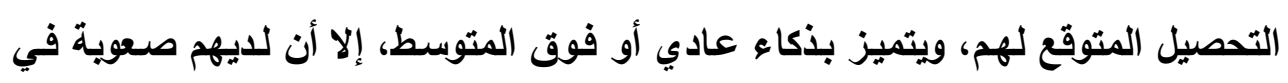

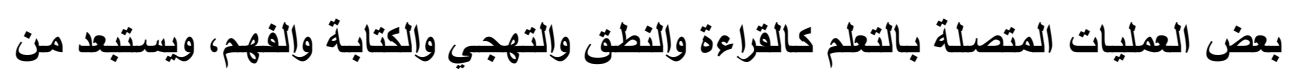
هؤلاء المعوقون والمتخلقون عقلياً.

ويتحليل التعريفات التي تتاولت صعويات التعلم يمكن القول بأنها اتفقت فيما بينها

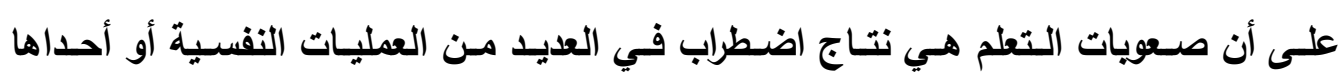

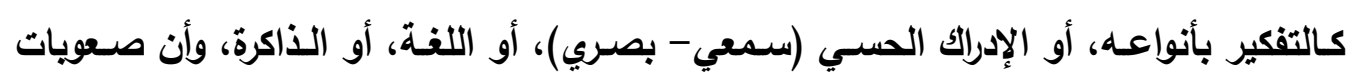

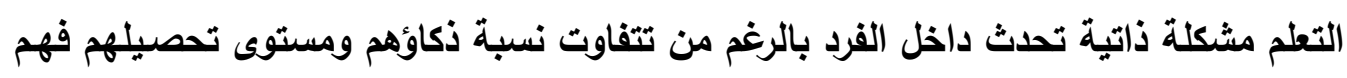
متوسطي الأكاء أو فوق المتوسط. وقد أوضـح إيفانس(Evans, 2007)أن هنـاك أدلـة متزايدة على أن صعويات التعلم

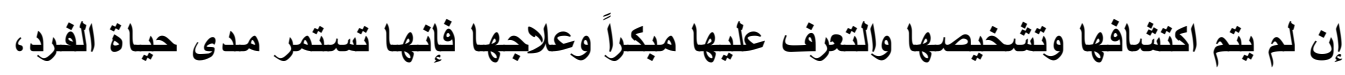

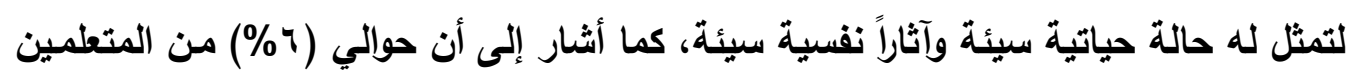
بالمدارس لديهم قصور دال في الحسـاب، والقراءة، ولكن ليس معنى هذا أن كل من لايـه صعويات في القراءة لايه صعويات في الحساب.

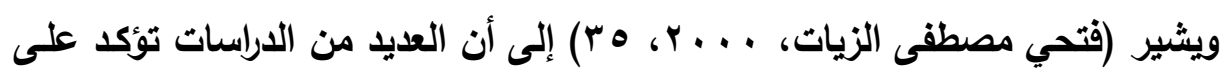

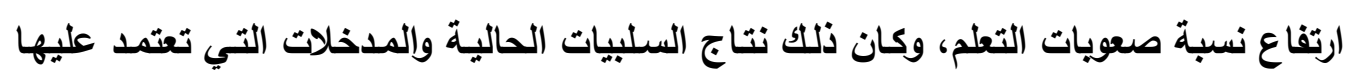

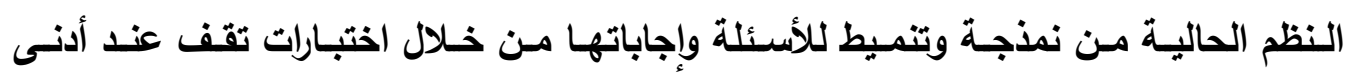

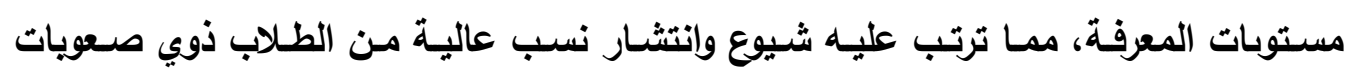
التعلم داخل الفصول الدراسية. 


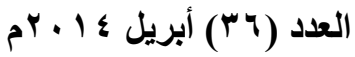

لذلك فقد توجهت أنظار الباحثين لموضوع صعويات التعلم لمـا له من أهمية بالغة تؤثثر بشكل مباشر على عملية التعليم والتعلم وذلك لأنها تؤدي إلى ضعف مستوى الإنجاز

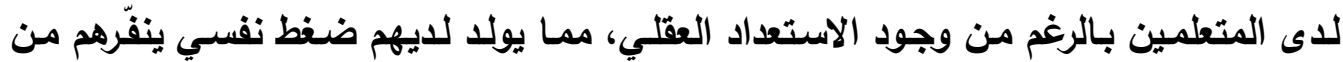

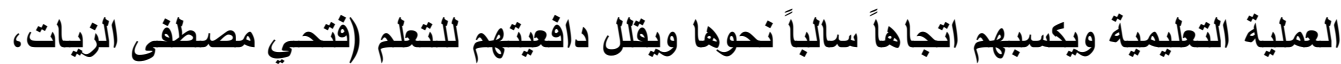
.$(\leqslant 10.1990$

وقد تناولت العديد من الدراسات مجال صعويات التعلم لما له من أهمية وقدرة بالغة

في التأثير على مستوى الطلاب بالمراحل التعليمية المختلفة، ومن هذه الدراسات:

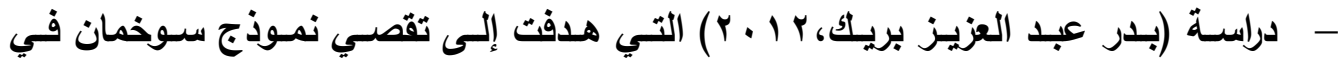
تصويب التصورات الخطأ في مـادة العلوم للدي التلاميذ ذوي صعويات التعلم، وقد تكونت

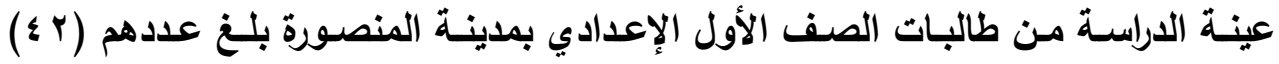

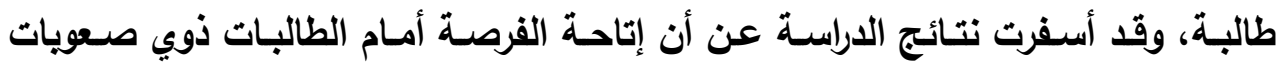
التعلم لطرح تساولاتهن أدى إلى تصويب ما لايهن من تصورات متعلقة بالمفاهيم العلمية المتضمنة بوحدة الدراسة.

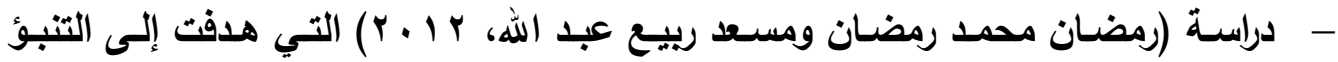
بأداء التلاميذ ذوي صعويات التعلم في اختبار المكون اللفظي للذاكرة العاملة من خلال درجاتهم على اختبار الفهم القرائسي، وتكونت عينـة الدراسـة من (19 1 ) تلميذ من تلاميذ الصف الخـامس والسـادس الابتدائي، وقد أسفرت نتائج الدراسـة عن أن الدرجـة الكليـة لاختبارات المكون اللفظي للأكرة العاملة، وإختبار الكلمات المتشابهة لفظياً قد ساهما في التنبؤ بالفهم القرائي مما يؤكد على أنه يمكن التنبؤ بالفهم القرائي للتلاميذ ذوي صعويات التعلم من خلال اختبار الكلمات المتثابهة لفظياً والدرجة الكلية للاختبار.

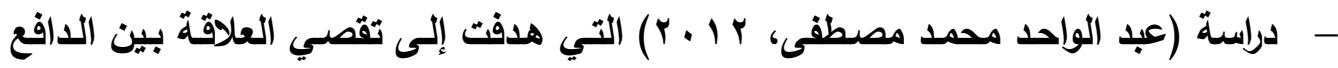
للإنجاز وفعالية الذات الأكاديمية لدى الطلاب ذوي صعويات التعلم الأكاديمية، وتكونت

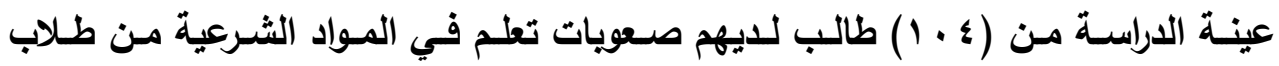
الثانوية الأزهريـة بمحافظة بور سعيد، وقد أسفرت نتائج الدراسـة عن وجود علاقة بين

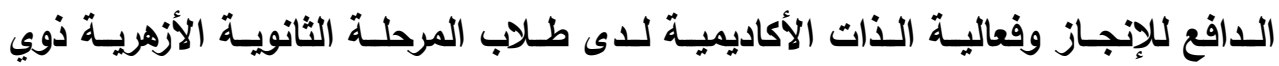




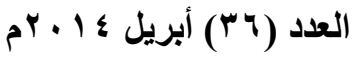

صعويات التعلم الأكاديميـة، كما يمكن التتبؤ بالدافع للإنجاز من درجـات فعاليـة الذات الأكاديمية لاى طلاب المرحلة الثانوية الأزهرية ذوي صعويات التعلم الأكاديمية.

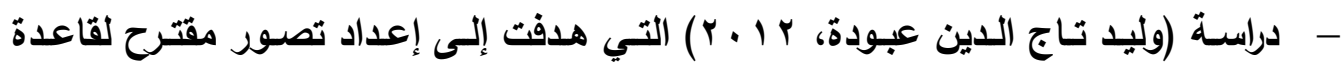
بيانات برنامج المحاكاة بالكمبيوتر الخاص بتنمية التحصيل لذوي صعويات تعلم الفيزياء، وتكونـت عينـة الدراســة مـن طـلاب الصف الأول الثـانوي العـام مـن ذوي صـويات تعلـم

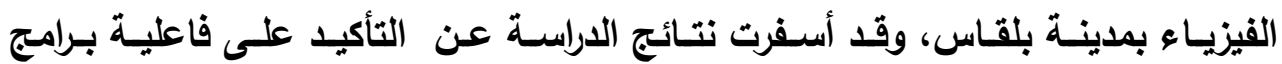
المحاكاة الكمبيوترية بالنسبة للتحصيل بوجه عام لفئة ذوي صعويات التعلم.

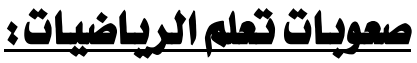

يُعد تـريس الرياضيات مـن المهام الصـعبة، وذلك لمـا تتصف بـه هذه المـادة مـن

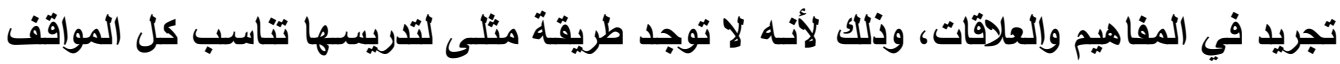
والدروس كما أن هناك بعض الصعويات المرتبطة بطبيعتها ويأسلوب تدريسها وطريقة عرض لماته محتواها في الكتاب المدرسي، مما يعرقل تقدم الطلابويؤثثر على مستواهم التعليمي في جميع بـاني المواد الدراسبة.

وتوصف صعوية تعلم الرياضيات بأنها مشكلة غير متوقعة يتم اكتشافها بعد أن يزود

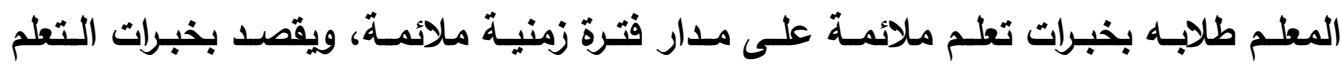
الملائمة تلك الممارسات التي تبذل لمساعدة الطلاب على تعلم المهارات والمفاهيم التي تمثل تحدياً لهم في تعلمها، لذلك فالمتعلم من ذوي صعويات تعلم الرياضيات يعاني من صعوية في تصني التقام الاراسي لمادة الرياضيات مقارنة بأقرانه في المجموعة على الرغم من من تطبيق ممارسات تعليمية فعالة خلال فترة زمنية ملائمة (Bryant, 2005, 342).

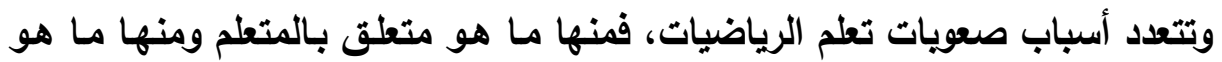

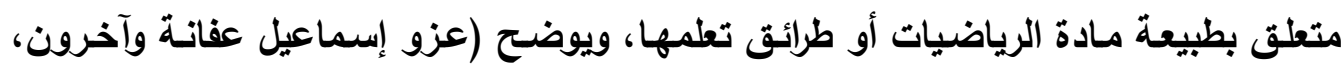

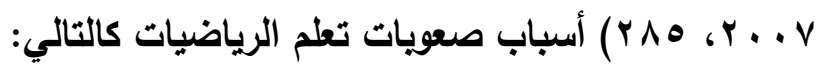
1. الضعف في امتلاك بعض الطلاب المتطلبات اللازمة للتعلم. r. ضعف الطلاب في مهارات القراءة الرياضية. r. عدم شعور الطلاب بفائدة الرياضيات في الحياة العملية. ؛. عدم قدرة الطلاب على ربط الرياضيات بالحياة. 
•. قلة تركيز المعلم على الأساسيات اللازمة لتعلم الموضوعات الجديدة. 7. استخدام الطريقة التقليدية في عرض الموضوعات وحل التمارين. V. عدم اهتمام المعلم بمراعاة الفروق الفردية بين الطلاب. ^. قُلة متابعة المعلم للواجبات المنزلية المعطاة للطلاب. 9. عدم إدارة الفصل بصورة فعالة.

أما ريشمان وكوفمان (Reisman and Kauffman, 1980, 20) يقسمان أسباب

$$
\begin{aligned}
& \text { صعويات تعلم الرياضيات إلى أربعة مجالات هي: } \\
& \text { ا ـ المجال المعرفي. } \\
& \text { r. المجال النفس حركي. } \\
& \text { r. المجال الحسي والفيزيقي. } \\
& \text { ع. المجال الانفعالي والاجتماعي. }
\end{aligned}
$$

وقد أثار إلى أن المجال المعرفي والمجال النفس حركي كلاهما ينطبق مباشرة على الطلاب ذوي صعويات تعلم الرياضيات، وأن المختصين في مجال صعويات تعلم الرياضيات يميلون إلى التركيز على المجال المعرفي وإهمال المتغيرات المتعلقة بالدافعية والمتغيرات غير العقلية.

وقد اهتمت العديد من الاراسات بمجال صعويات تعلم الرياضيات، للوقوف على هذه الظاهرة ومعرفة ماهيتها وأسباب حدوثها في مـادة الرياضيات بشكل خاص وكيفية علاجها لاى كثير من الطلاب الذين يعانون منها، ومن هذه الدراسات التي تناولت صعويات التعلم في مادة الرياضيات ما يلي: - دراسة أثنا وآخرون(Asha et al., 2013) -لتي هدفت إلى التعرف على فعالية التدريس في مجموعات صغيرة على تعلم الرياضيات والحد من خطر صعويات تعلمها في المرحلة الإبتدائية، وقد تكونت عينة الدراسة من (Y Y ) مدرسة إبتدائية في الغرب الأوسط للولايات

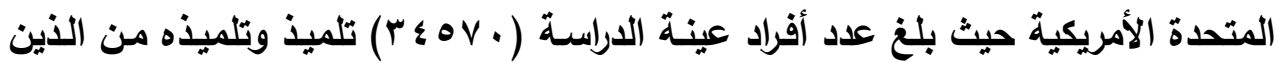
حصلوا على درجات منخفضة في مادة الرياضيات، وقد أسفرت نتائج الدراسـة عن فعالية تدريس موضوعات الرياضيات في مجموعات صغيرة في الحد من خطر إصابة التلاميذ بصعويات تعلم الرياضيات. 


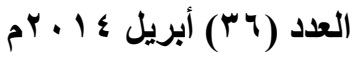

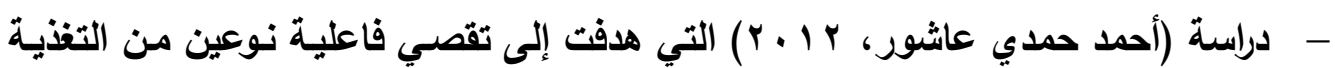

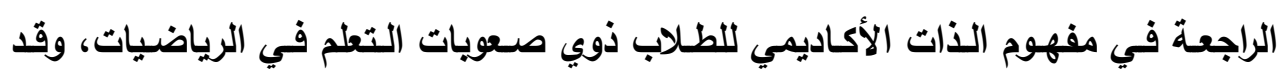

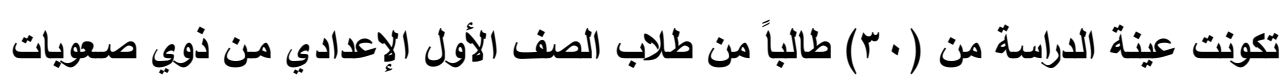

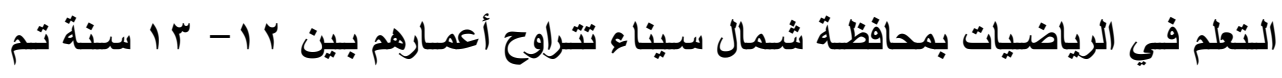
تقسيمهم إلى ثنلاث مجموعات: الأولى تجريبية وتتلقى التظذيـة الراجعة الحسية، والثثاتيـة

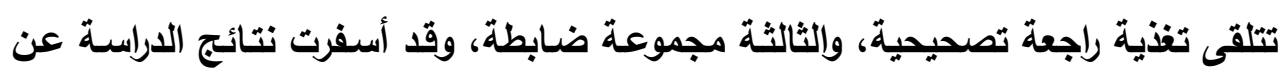

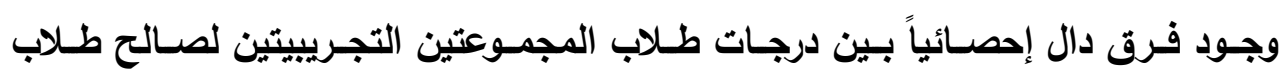
المجموعـة التجريبيـة التي تتلقى تفذيـة راجعة حسية، كمـا توصلت إلى فاعليـة التغذيـة الراجعة الحسية في علاج صعويات تعلم الرياضيات لدى المجموعة التجريبية التي تتلقى تغذية راجعة حسية.

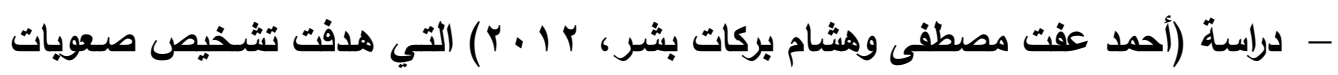

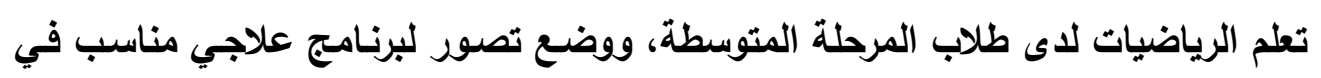

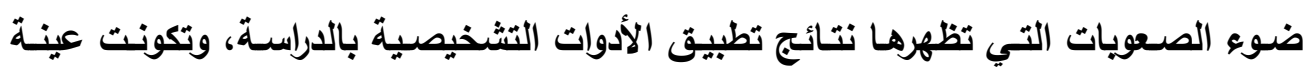

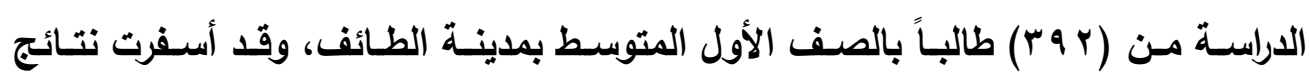

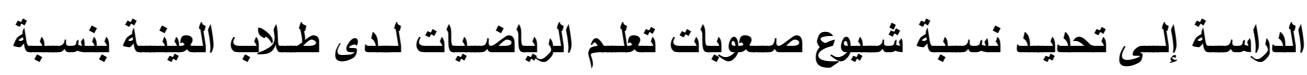
.$(\% \backslash \vee$ ،

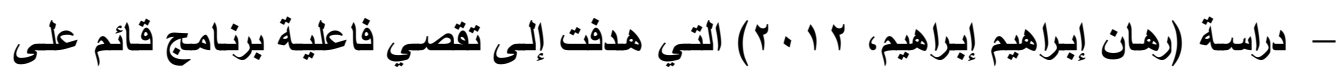

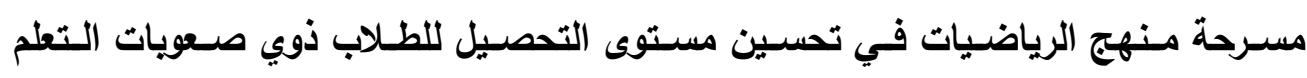

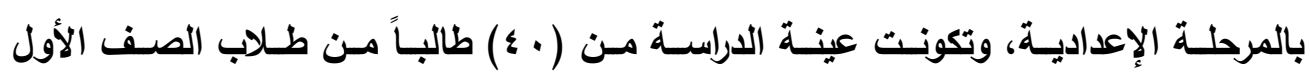

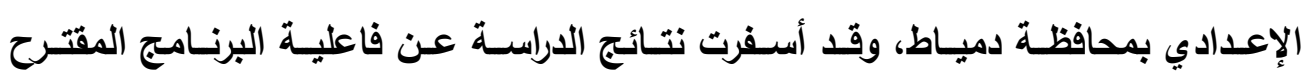
باستخدام مدخل مسرحة المناهج في تلدريس الرياضيات لذوي صعويات تعلم الرياضيات كما كان له الأثر الإيجابي على تنمية الأكاء الوجداني لاى أفراد المجموعة التجريبية.

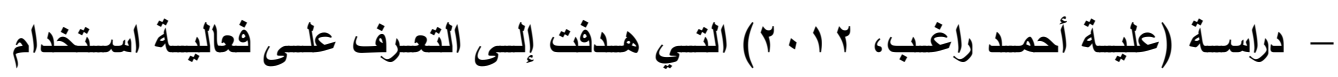

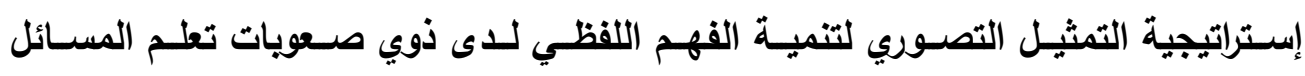

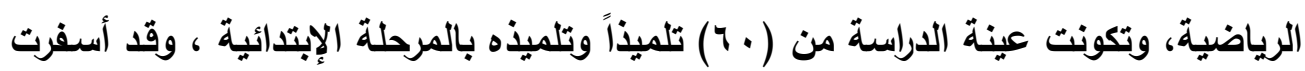




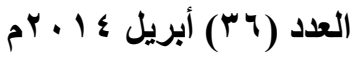

الاراسة عن على فعالية استخدام إستراتيجية التمثيل التصوري لتنمية الفهم اللفظي للى ذوي صعويات تعلم المسائل الرياضية.

- دراسـة آنـي (Anne, 2012) التـي هدفت إلى التعرف على فعاليـة استراتيجيات التدخل لعلاج صعويات تعلم الرياضيات في المدارس الابتدائية الأيرلندية، وقد تكونت عينة الدراسـة

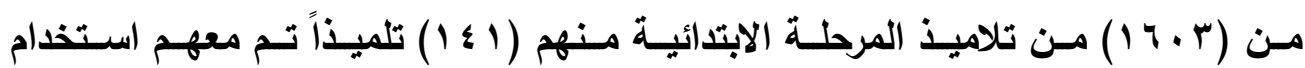
استراتيجيات التذخل لعلاج صعويات تعلم الرياضيات، وقد أسفرت نتائج الدراسـة عن فعالية استخدام استراتيجيات التذخل لعلاج صعويات التعلم لاى تلاميذ هذه المرحلة. - دراسة (Ali, 2011) التي هدفت إلى استكشاف صعويات تعلم الرياضيات لطلاب المرحلة الثانويـة في باكستان وكيفية التغلب على هذه الصعويات، وقد تكونت عينة الدراسـة من أربعة مدارس ثانويـة أثنين منهم مـن مدارس التعليم الخـاص وأثنين مـن مدارس التعليم

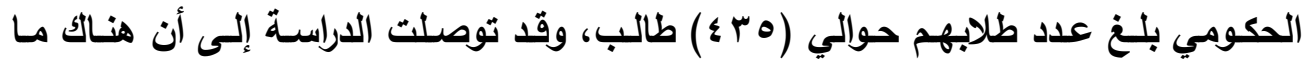

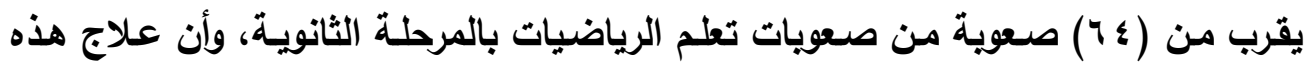

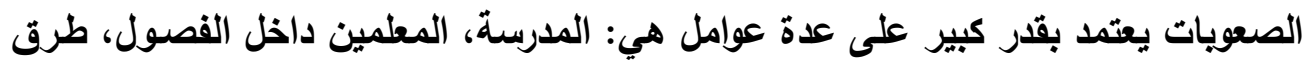
تأهيل وإعداد المعلمين، المقررات الدراسية وطريقة تنظيمها.

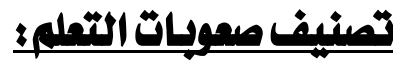

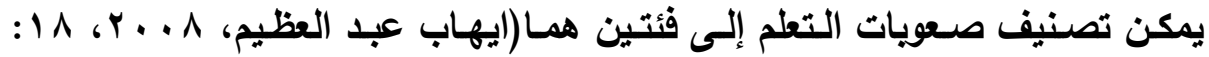

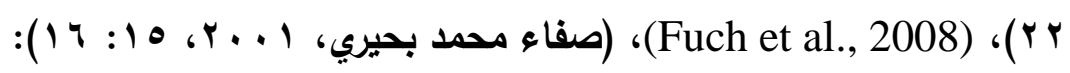
1 - صعويات التعلم الأكاديمية: وهي التي تهتم بدراسة المشكلات الأكاديمية التي ترجع إلى بلى وجود صعويات التعلم، وهي تتمثل في ثلاثة مجالات رئيسة هي: أ- صعويات التعلم النوعية في القراءة: وهي تحدث عندما تكون مهارات الفرد في القراءة مهات

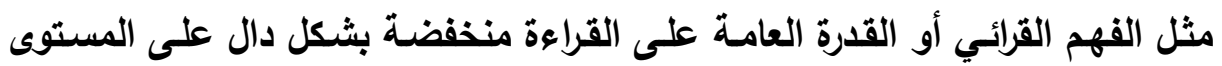
المتوقع وفقاً لمستوى الأكاء. ب- صعويات التعلم النوعيـة في الكتابة: وتحدث عندما تكون مهارات الفرد في الكتابـة

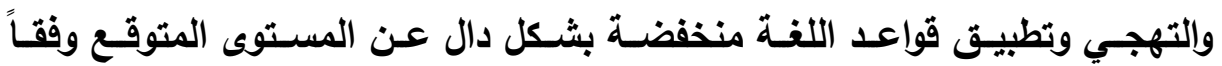
لمستوى الأكاء ولا تثمل صعوية الكتابة تحسين الخط. 


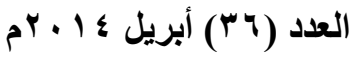

ج- صعوية التعلم النوعية في الحسـاب:تحدث عندما تكون مهارات الحساب المتمثلة في

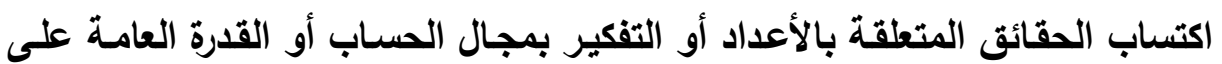
التفكير فيما يتعلق بالرياضيات منخفضة بشكل دال عن المستوى المتوقع للأكاء. r - صعويات التعلم النمائيسة: وهي تتعلق بالوظـائف الدماغيـة، والعمليـات العقلية والمعرفيـة التي يحتاجها المتعلم في تحصيله الأكاديمي مثل الإدراك الحسي، والانتباه والتفكير واللغة والذاكرة وهذه الصـويات ترجـع أصـلاً إلى اضطرابات وظيفيـة في الجهاز العصبي المركزي، ويمكن تقسيمها إلى:

أ- صعويات نمائية أولية: وهي التي تتعلق بعمليات الانتباه والإدراك والذاكرة. ب- صعويات نمائية ثانوية: مثل التفكير، الكلام، الفهم أو اللغة الثفئية بعهية. وسـوف تتــاول الدراسـة الحاليـة صـويات التعلم الأكاديميـة، والتـي تبعد تمامـاً عن

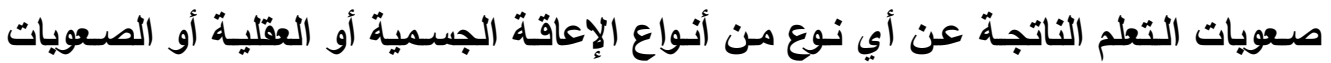
النمائية.

وتتشـم خصـائص الطـلاب ذوي صسويات تعلـم الرياضـيات بمـا يلـي(عزو إســاعيل

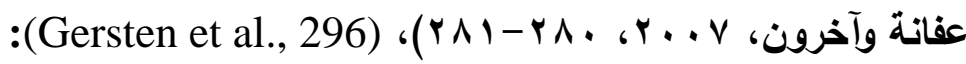
ا .قصور في التعبير عن ذاتهم والتعامل مع الآخرين. r بتشتت فى الانتباه وعدم القدرة على التركيز. ץ.النشاط وإلحركة الزائدة. ؛ .علدم الانتهاء من الأعمال المكلف بها. •.عدم القدرة على اكتشاف أخطائه بنفسه، ويالتالي عدم القدرة على التقويم الذاتي. 7.قصور في التمييز والذاكرة السمعية أو البصرية.

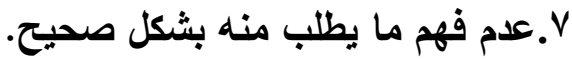
^.عدم القدرة على فهم المسائل الرياضية شفهياً. 9 .صعوية إجراء العمليات الأساسية في الرياضيات بشكل صحيح. • ا.عدم القدرة على قراءة الرموز الرياضية بشكل صحيح. 11 (صعوية كتابة الأرقام الحسابية والرموز الرياضية بشكل صحيح. r ا .عدم القدرة على فهم وإنتاج الأشكال الهندسية والتمييز بينها. 


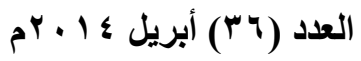

r ا.عدم القدرة على تنظيم الأفكار أو التعبيرعنها بسهولة.

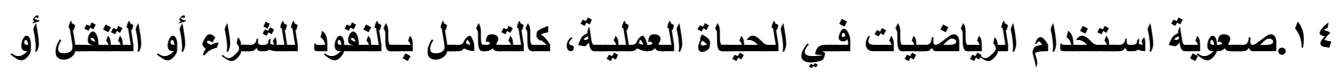
التعرف على الاتجاهات. ه 1 .صعوية تطبيق القوانين والنظريات.

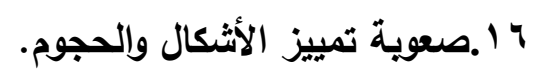
V ا.عدم القدرة على إجراء المهارات الحسابية. 1 ا.تقلب حاد في المزاج.

\section{اجمراعات اثلداسلةو}

أولاً: تَايل محتوى موضومات الددوال المثلثية المقررةبكتاب الرياضيات على طلاب الصف الأول

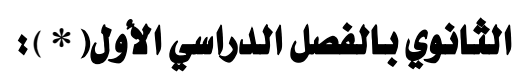

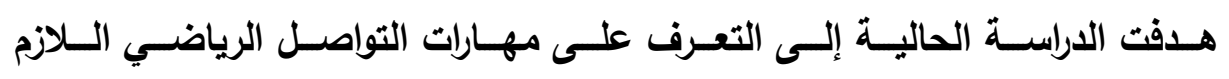

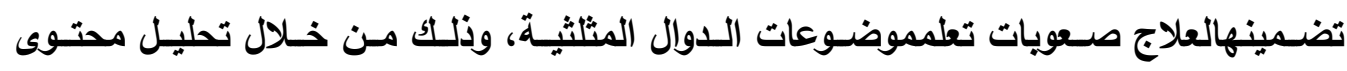
موضوعات الدوال المثلثية المقررة بكتاب الرياضيات على طلاب الصف الأول الثانوي بالفصل الاراسيالأول لتحديد تلك المهارات المتضمنة وقد اشتملت أداة التحليل على: هدف التحليل: هدفت عمليـة التحليل إلى تحيد مهارات التواصل الرياضسي الـلازم تضمينهابموضوعات

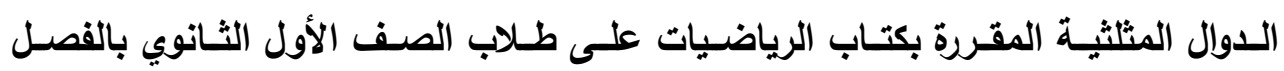

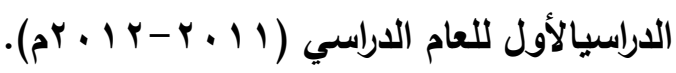

$$
\begin{aligned}
& \text { فئة التحليل: }
\end{aligned}
$$

ويقصد بها " العناصر الرئيسة أو الثانوية التي يتم وضع وحدات التحليل فيها سواء كانت كلمـة أو موضـوع أو قيم أو غيرهـا ويمكن وضــع كل صـفة مـن صـفات المحتـوى فيهـا

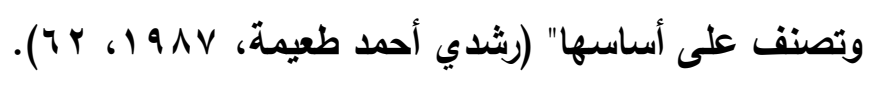

(*)ملق (1): تحليل محتوى موضوعات الدوال المثلثية المقررة بكتاب الرياضيات على طلاب الصف الأول الثانوي بالفصل الدراسي الأول. 


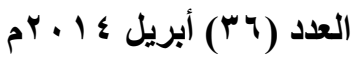

ضوابط التحليل:

لكي يكون تحليل موضوعات الدوال المثلثية المقررة بكتاب الرياضيات على طلاب الصف

الأول الثانوي بالفصل الاراسيالأول دقيقاً تم وضع الضوابط التالية: - - تم التحليل في إطار المحتوى العلمي والتعريف الإجرائي لمهارات التواصل الرياضي. - - تم التحليل في إطار المحتوى والأشكال الهندية والأمثلة والتدريبات. صدق التحليل:

أعتمد الباحث في صدق التحليل على صدق المحكمين (*) حيث تم عرض نتائج التحليل المتضمنة بموضوعات الدوال المثثيـة بكتاب الرياضيات المقرر على طلاب الصف

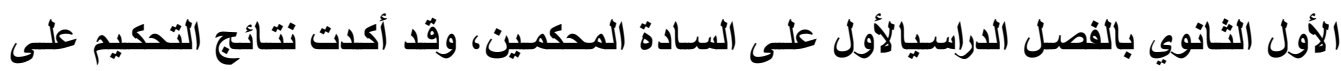
شمولية التحليل. • ثمبات التحليل

يقصد بثبات التحليل إعطاء التتائج نفسـها تقريباً إذا تم التحليل عدة مرات بإتباع

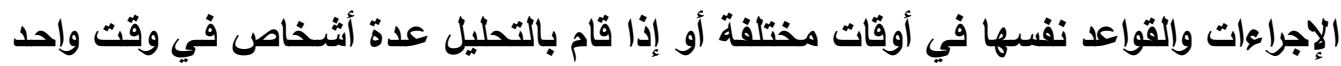

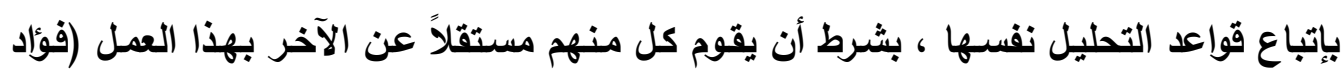
أبو حطب، أمال صادق، 199 (1)، ؛ 19 (0).

وقد تم حساب ثبات التحليل بإتباع الخطوات التالية:

- ق قام الباحث بإجراء تحليل موضوعات الدوال المثلثية المقرة بكتاب الرياضيات على طلاب

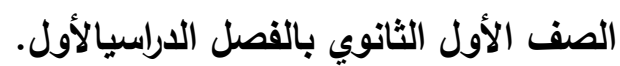
- قام أحد الزملاء بتحليل نفس الموضوعات مرة ثانيـة ملتزمـاً بالتعريفـات الإجرائية التي حدها له الباحث. - أمكن حساب معامل الثبات لتحليل موضوعات الدوال المثثيـة المقررة بكتاب الرياضيات

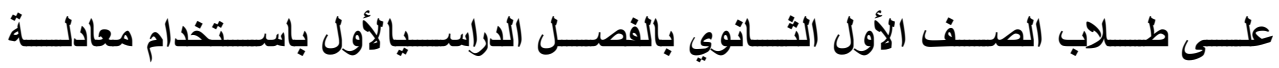
هولستي) (Holsti, 1969, 68): معات معامل الثبات = (ץ × عدد نقاط الاتفاق للتحليلين) ٪ (عدد نقاط التحليل الأول + عدد نقاط التحليل الثاني) 


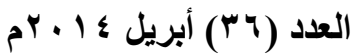

وقد وجـد أن معامـل الثبـات = ج 9، ، ، وهـو معامـل ثبـات مرتفع، ممـا يـدل على أن

التحليل يعطي النتائج نفسها تقريباً إذا تم التحليل مرة أخرى.

ومـن نتيجـة التحليل السـابق أمكن تحديـ قائمـة مهـارات التواصـل الرياضـي الـلازم

تضمينها في موضوعات الدوال المثلثية المقررة بكتاب الرياضيات على طلاب الصف الأول الثانوي بالفصل الاراسيالأول(*)، ويالتالي يكون قد تم الإجابة على السؤال الأول من أسئلة الاراسة والأي ينص على: بالئ

"ما مهارات التواصل الرياضي اللازم تضمينها لعلاج صعويات تعلم موضوعات الدوال المثلثية المقررة بكتاب الرياضيات لطلاب الصف الأول الثانوي بالفصل الدراسي الأول؟".

ثانيـاً : إعداد قائمة مبلدئية بصعوبـات تعلم موضوعات الـلدوال المثلثية المقررة بكتـاب الريـاضيات لطلاب الصف الأول الثانوي بـالفصل الدراسي الأول : - - تم إعداد استبانه مفتوحة لعدد من معلمي ومعلمات الرياضيات الذين يقومسون بتدريس

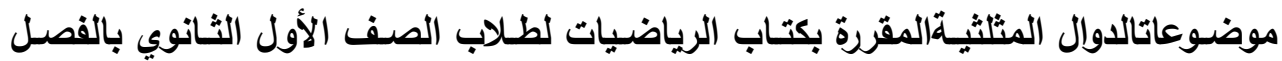

الاراسي الأول، وقد تم توضيح الهُف منها (*).

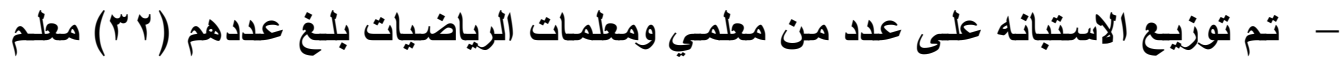
ومعلمة، وطلب منهم إبداء آرائهم في الصعويات التي تواجه طلاب الصف الأول الثانوي عند دراسة موضوعاتالدوال المثلثية المقرة بكتاب الرياضيات بالفصل الدراسي الأول.

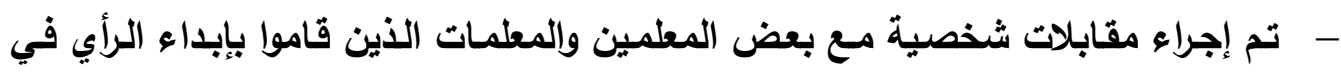
الاستبانه المقترحة، حيث تم مناقشتهم في الصعويات التي تم تسجيلها بالاستبانه.

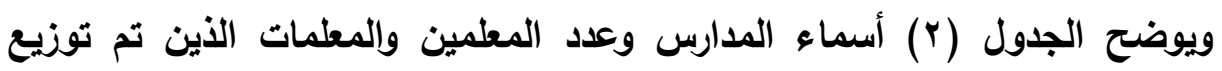
الاستبانه عليهم لاستطلاع رأيهم حول صعويات تعلم موضوعات الدوال المثلثية المقررة بكتاب الرياضيات لطلاب الصف الأول الثانوي بالفصل الدراسي الأول.

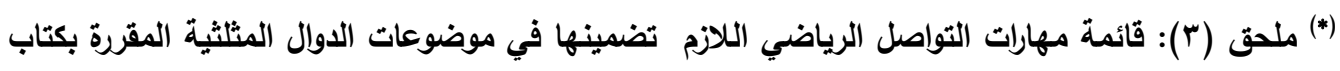
الرياضيات على طلاب الصف الأول الثانوي بالفصل الدراسي الأول.

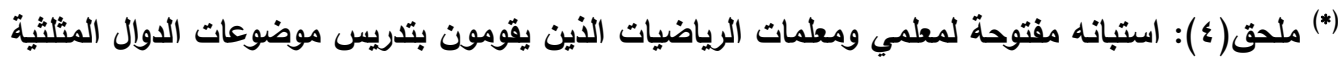
المقررة بكتاب الرياضيات لطلاب الصف الأول الثانوي بالفصل الدراسي الأول. 


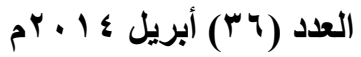

$$
\text { جدول(r) }
$$

بيان بأسماء المدارس وعدد المعلمين والمعلمات الذين تم توزيع الاستبانه عليهم لاستطلاع رأيهخ حول صعويات تعلم موضوعات الدوال المثلثية المقررة بكتاب الرياضيات لطلاب الصف الأول الثانوي بالفصل الاراسي الأول.

\begin{tabular}{|c|c|c|}
\hline المعلمات & المعلمين & اسم المدرسة \\
\hline$\varepsilon$ & ○ & الجامعة الموحدة الثانوية \\
\hline$r$ & $\varepsilon$ & الخياط الثانوية بنات \\
\hline$r$ & 7 & المشير أحمد إسماعيل الثانوية بنين \\
\hline r & $\bullet$ & جمال فرغلي سلطان الثانوية بنين \\
\hline ir & r. & الإجمالي \\
\hline
\end{tabular}

- - تم تحليل الاستبانه المفتوحة وتسـيل الصـويات المبلئية التي تم التوصل إليها من وجهة نظر المعلمين والمعلمات والتي تم الاتفاق عليها. - - تم الاستفادة من تحليل موضوعاتالدوال المثلثية المقررة بكتاب الرياضيات لطلاب الصف

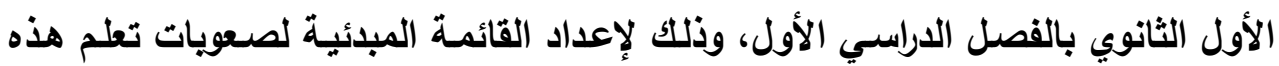
الموضوعات.

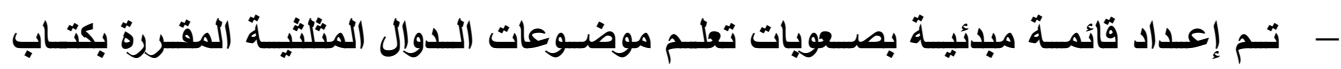
الرياضيات لطلاب الصف الأول الثانوي بالفصل الدراسي الأول.

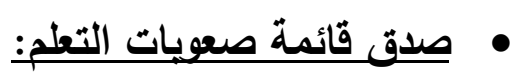
تم عرض قائمسة صعويات تعلم موضوعات الدوال المثلثية المقررة بكتاب الرياضيات لطلاب الصف الأول الثانوي بالفصل الدراسي الأول في صورتها الأولية على مجموعة من من السادة المحكمين وذلك للتأكد من صدقها وإبداء الرأي عليها (لاول. 


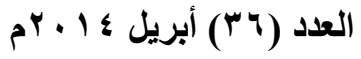

\section{• • • ثبات قائمة صعويات التعلم:}

وقد تم حساب ثبات التحليل بإتباع الخطوات التالية:

- قام الباحث بإجراء تحليل الاستبانه المفتوحة بعد تطبيقها مباشـرة لتحديد القائمـة المبائية

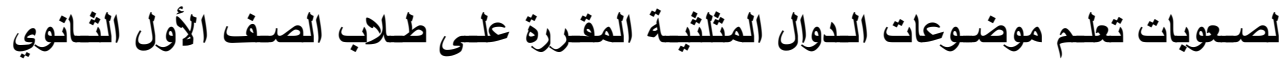

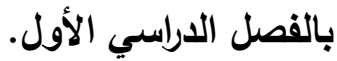

- قام أحد الزملاء بتحليل نفس الاستبانه المفتوحةملتزماً بنفس الخطوات الإجرائية التي اتبعها الباحث أثناء التحليل. والجدول رقم (r) يوضح نتائج التحليل:

جدول (r)

نتائج تحليل الاستبانه المفتوحة

\begin{tabular}{|c|c|c|c|}
\hline الاتفاق & الثانيلي & الأوليل & الصعويات الناتجة من التحليل \\
\hline r & $r \wedge$ & $\leqslant$. & \\
\hline
\end{tabular}

- وقد تم حساب معامل الثبات باستخدام معادلة هولستي لحساب معامل الاتفاق.

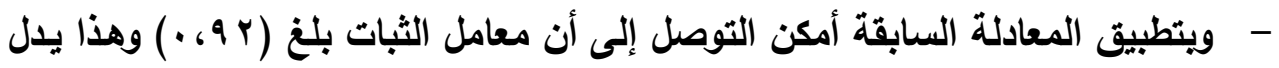
على ثبات مرتفع للتحليل. بعد التأكد من صدق وثبات قائمـة صعويات التعلم المبائية، فقد أمكن تحديد قائمـة صعويات التعلم المبائية من وجهة نظر المعلمين (*).

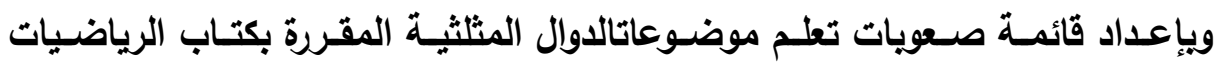
لطلاب الصف الأول الثانوي بالفصل الدراسي الأولفي صورتها النهائية، والتتأكد من

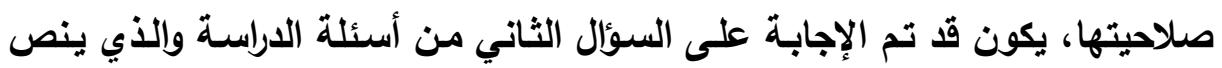
على: "ما شكل القائمـة المبائية المقترحة لصعويات تعلم موضوعات الدوال المثلثية المقررة بكتاب

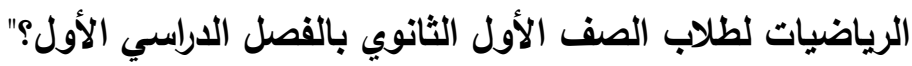
ثالثاً: إعداد أدوات الدراسة:

(*) ملحق (•): قائمة صعويات التعلم المبئية. 


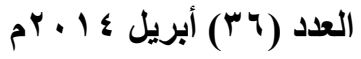

اــ إعلداد الاختبار التشخيصي لصعوبـات تعلم موضوعات اللدوال المثلثية :

تم إعداد الاختبار التشخيصي وفقاً للخطوات التالية:

$$
\text { أ- تحديل الهدف من الاختبار التشخيصي: }
$$

تشخيص صعويات تعلم موضوعات الدوال المثلثية المقررة بكتاب الرياضيات لطلاب

الصف الأول الثانوي بالفصل الاراسي الأول.

وقد اعتمدت الدراسة الحالية على تحديد الأهداف التي سيقيسها الاختبار التثخيصي الاول

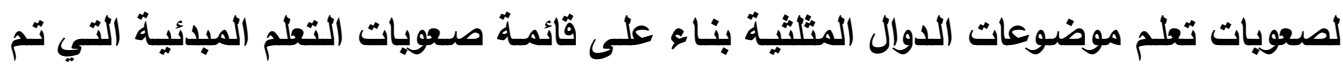
إعدادها مسبقاً، حيث تم بناء الاختبار التشخيصي بحيث يغطي قائمة صعويات التعلم. ب- ت تحليد أبعاد الاختبارونوع مفرداته : تـم إعداد الاختبـار التشخيصـي في ضـوء المسـتويات المعرفيـة التي حددها ولبيم

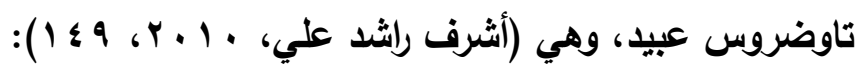
- المستوى الأدنحيف ويتضمن التذكر والاسترجاع وإجراء عمليات حسابية مباشرة. - المستوى الوسـيط: ويتضـمن فهم وإدرالك واستيعاب المفـاهيم والعلاقـات بينهمـا، والقدرة على الترميز وتطبيق القوانين واختيار العمليات المناسبة لكل مشكلة.

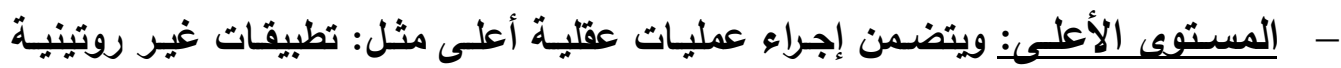
للمفاهيم، وتحليل المشكلة إلى مكوناتها والتوصل إلى تعميمات واشتتقاق علاقات جديدة، والتدليل على صحة مواقف جديدة وحل مشكلات لم يسبق للطلاب المرور بها. وقد راعى الباحث ما يلي في صياغة مفردات الاختبار: - - أن تكون الفقرات من نوع الاختيار من متعدد، حيث تتكون كل فقرة من مقدمـة تتبعها أربعة بدائل إحداها فقط صحيحة. - أن تكون مقدمة كل فقرة واضحة وتعبر عن مشكلة محددة.

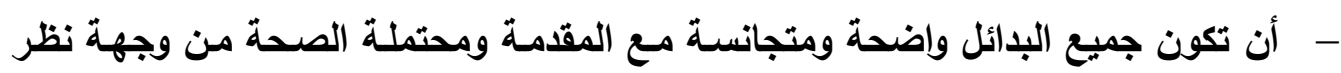
الطالب. - - أن يتم توزيع الإجابات الصحيحة بطريقة عشوائية في المواضيع المختلفة للبدائل. 


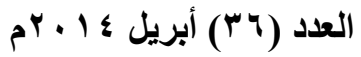

ويوضح جدول ( ع) مواصفات الاختبار التشخيصي لموضوعات الدوال المثلثية موزعة

بين المستويات المعرفية وأرقام المفردات التي يقيسها.

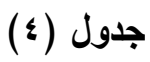

مواصفات الاختبار التشخيصي لموضوعات الدوال المثلثية موزعة بين المستويات المعرفية وأرقام المفردات التي يقيسها

\begin{tabular}{|c|c|c|c|}
\hline المئوية & 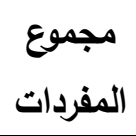 & أرقام المفردات التي تقيس المستوى المعرفي & \\
\hline$\%$ \%ч ४ & $\wedge$ & $r 0,1 \Lambda, 1 r, 11, \Lambda, v, r, 1$ & المستوى الأدنى \\
\hline$\% \leq 4, \vee$ & $1 \varepsilon$ & 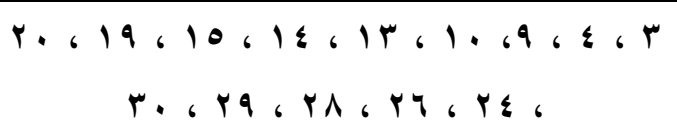 & المستوى الوسبط \\
\hline$\%$ \%४ เV & $\wedge$ & 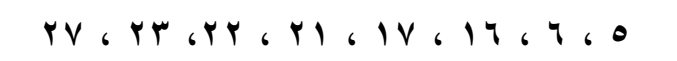 & المستوى الأعلى \\
\hline$\% 1 \ldots$ & $r$. & 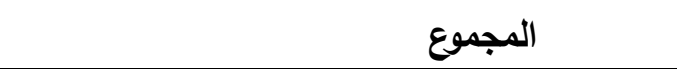 & \\
\hline
\end{tabular}

ج- صباغة تعلبمات الاختبار:

تـم إعداد تعليمـات الاختبار التشخيصـي كي تسـاعد الطـلاب على أداء استجاباتهم بيسر وسهولة ودقة ونظام، كما تم مراعاة ما يلي: • • أن تكون التعليمات قصيرة ومباشرة. سهولة اللغة ووضوحها ومناسبتها لمستوى طلاب الصف الأول الثانوي. • توجيه الطلاب إلى ضرورة قراءة السؤال بدقة قبل الإجابة عنه. • عديد طريقة الإجابة على أسئلة الاختبار تحديداً واضحاً. • أن تتضمن التعليمات الهذف من الاختبار . توضيع زمن الاختبار

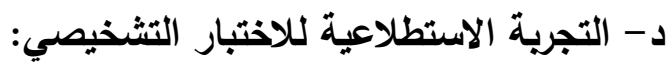
طبق الاختبار التشخيصي في صورته الأولية على مجموعة من طلاب الصف الأول الثانوي بلغ عددها ( • ؛ ) طالباً وطالبة بمدرسة الجامعة الموحدة الثانوية بمحافظة أسيوط في هي

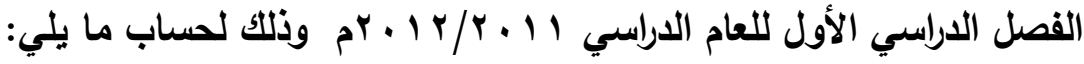




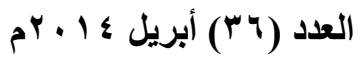

$$
\text { حساب زمن الاختبار: }
$$

تم حسـاب الزمن اللازم للإجابة على أسئلة الاختبار وذلك برصد زمن الاختبار لكل فرد من أفراد العينة، وفي نهايـة هذه التجريـة، تم حسـاب متوسط زمـن الاختبـار من خـلال

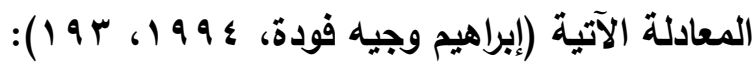
الزمن الذي استغرقه أول طالب + الزمن الذي استغرقه آخر طالب الزمن المناسب للاختبار r

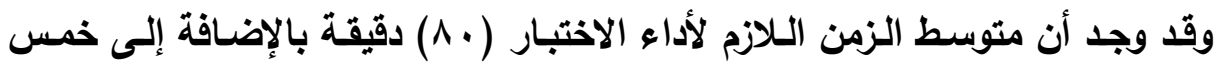

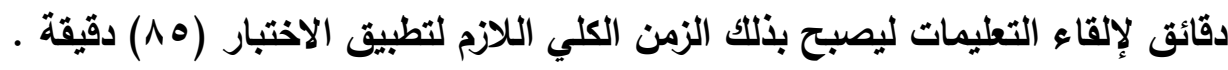
• • حساب معامل صدق الاختبار: أ- صدق المحكمين: تم عرض الاختبار على مجموعة من السـادة المحكمين (*)لتحقق من انتماء فقرات

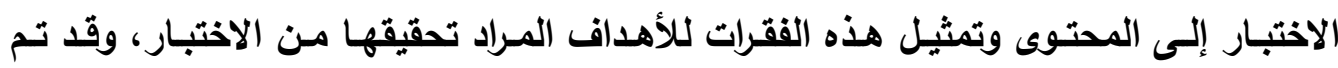
الاتفاق على شمولية الاختبار للأهداف المرجوة وفق آراء السادة المحكمين. بـ- صدق الاتساق الإخلي:

ويقصد بـه مدى اتسـاق كل فقرة من فقرات الاختبار مـع المجـال الذي تنتمـي إليها الفقرة، حيث تم تقسيم الاختبار إلى ثلاثة مجالات، بحيث يقيس كل مجال مستوى معرفي من

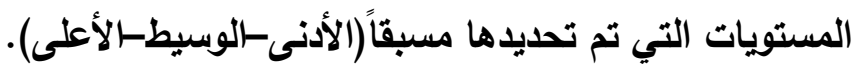
وقد تم حساب صدق الاتساق الداخلي للاختبار من خـلال حساب معاملات الارتباط بين كل

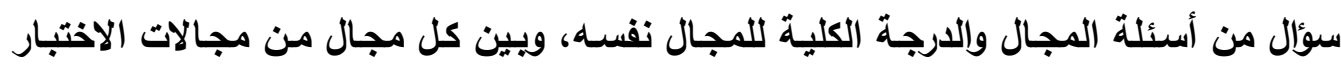

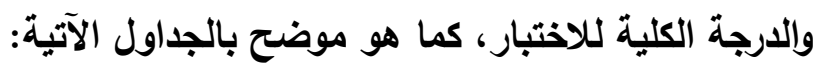




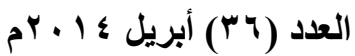

جدول (0)

معاملات الارتباط بين كل مفردة من مفردات المستوى الأدنى

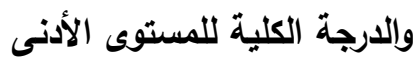

\begin{tabular}{|c|c|c|c|c|c|}
\hline الدلالة & الارتباط & رقمر & مستوى الدلالة & الارتباط & المفردة \\
\hline$\ldots .0$ & $.6 \leqslant 1$ & Ir & $\ldots 0$ & . & 1 \\
\hline .60 & 1.67 & $1 \pi$ & $\ldots 0$ & . $6 \leqslant 0$ & r \\
\hline$\ldots 0$ & 94.69 & 19 &.$\ldots 0$ & אדים. & 9 \\
\hline .60 & $.0 \%$ & Y & . . & . 0 & V \\
\hline
\end{tabular}

جدول (7)

معاملات الارتباط بين كل مفردة من مفردات المستوى الوسيط

والدرجة الكلية للمستوى الوسيط معرد معردات

\begin{tabular}{|c|c|c|c|c|c|}
\hline مستوى الدلالة & معامل الارتباط & المفردة & مستوى الدلالة & معامل الارتباط & المفردة \\
\hline .6 .0 & .679 & $r$. & .6 .0 & .67 & $r$ \\
\hline .60 & ודים & $r_{1}$ & .6 .0 & $.6 V Y$ & $\varepsilon$ \\
\hline. .0 & .601 & ro &. .00 & . ( $\leqslant 1$ & $\Lambda$ \\
\hline .60 & rד. & rV & .60 & .699 & 9 \\
\hline .60 & . & rq & .60 & . ، & $1 \varepsilon$ \\
\hline .60 &.$\vee V r$ & $r$. & .60 & .609 & 10 \\
\hline .6 .0 & r & r &. .00 & ס שr. & 17 \\
\hline
\end{tabular}




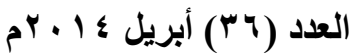

جدول (v)

معاملات الارتباط بين كل مفردة من مفردات المستوى الأعلى

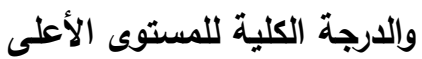

\begin{tabular}{|c|c|c|c|c|c|}
\hline مستوى الدلالة & الارتباط معامل & المفردة رقم & الدلالة & معامل الارتباط & المفردة رقم \\
\hline .60 & .671 & rr & .60 & . ، $\{1$ & 0 \\
\hline .60 & צ'. & $r r$ & .60 & .009 & 1. \\
\hline .60 & . & $r \leq$ & .60 & r r.6. & 11 \\
\hline . . . 0 & .01 & $r \wedge$ & .60 & . $V Y r$ & IV \\
\hline
\end{tabular}

جدول (^)

معاملات الارتباط بين كل مستوى من مستويات الاختبار التشخيصي

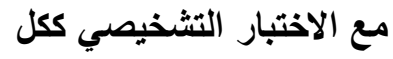

\begin{tabular}{|c|c|c|}
\hline مستوى الدلالة & معامل الارتباط & المجال \\
\hline .6 .0 & .679 & المستوى الأدنى \\
\hline .6 .0 & . $6 \leqslant$ & المستوى الوسيط \\
\hline .6 .0 & .67 & المستوى الأعلى \\
\hline
\end{tabular}

حساب معامل ثبات الاختبار:

تم حساب معامل ثبات الاختبار باستخدام طريقة التجزئة النصفية من خلال معادلة

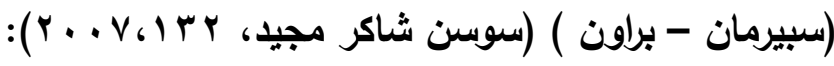

$$
\begin{aligned}
& \frac{j+1}{j+2}
\end{aligned}
$$

م: معامل ثبات الاختبار ككل.

ر : معامل الارتباط بين نصفي الاختبار.

وقد بلغ معامل الثبات وفق المعادلة السابقة ( I Y A، • ) وهو معامل ثبات مرتفع يفي 


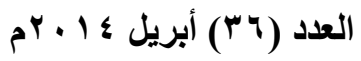

هـ - الصورة النهائية للاختبار التشخيصي(*)(***):

بعد التأكد من صدق وثبـات الاختبار، أصبح الاختبار في صورته النهائيـة، مكونـاً

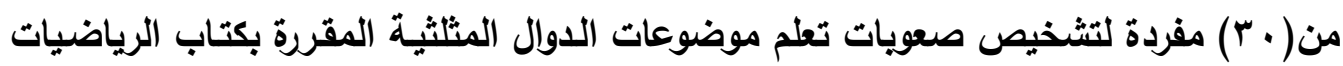
لطلاب الصف الأول الثانوي بالقصل الدراسي الأول. و - طريقة تصحيح الاختبار: تم تحديد درجة واحدة لكل مفردة من مفردات الاختبار، ويالتالي تصبح الدرجة الكلية كلاختبار ( • ب) د برجة.

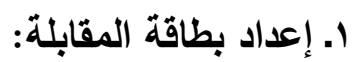
تم إعداد بطاقة المقابلة وفقاً للخطوات التالية: أ- تحديد الهرف من بطاقة المقابلة: هدفت بطاقة المقابلة إلى إجراء مقابلات شخصية مـع عينـة من طلاب الصف الأول

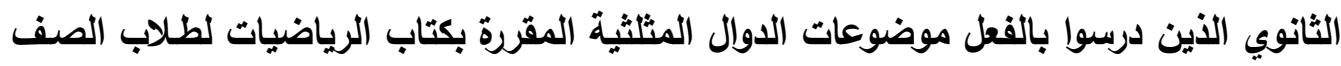

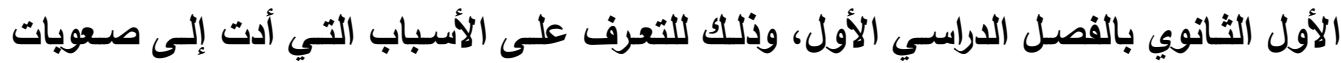
دراستهم لهذه الوحدة. ب - تحديد مفردات بطاقة المقابلة: تم تصنيف الأسباب التي تؤدي إلى صعويات تعلم الرياضيات في موضوعات الدوال المثلثية المقررة بكتاب الرياضيات على طلاب الصف الأول الثانوي بالفصل الاراسي الأول

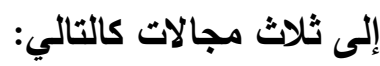

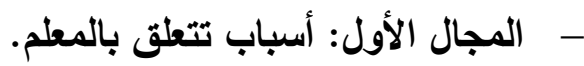
المجال الثاني: أسباب تتعلق بالطلاب.

- - المجال الثالث: أسباب تتعلق بالكتاب المدرسي وطبيعة موضوعات الدوال المثلثية. وقد اشتملت البطاقة في صورتها الأولية على ( • ب) سبياً. ج- تقتين بطاقة المقابلة: • حساب معامل صدق بطاقة المقابلة:

(*) ملحق (†): الصورة النهائية للاختبار التثخيصي. ملحق (V): مفتاح تصحيح الاختبار التثخيصي. 


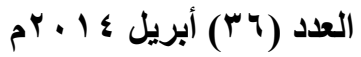

تم عرض البطاقة في صورتها المبدئية على مجموعة من السادة المحكمين(*)، وذلك

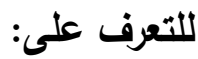

- مدى مناسبة الأسباب للأهداف المطلوب تحقيقها.

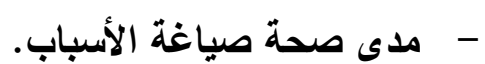

وينـاء على آراء السـادة المحكمين تم تعديل بعض الأسباب، وحذف بعض الأسباب

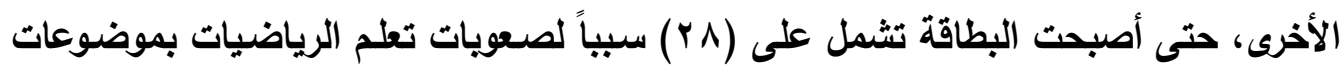

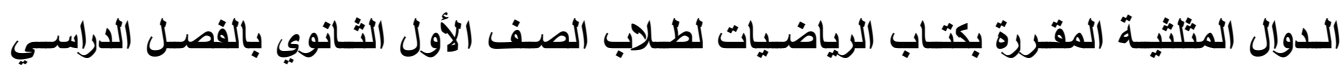
الأول.حساب معامل ثبات بطاقة المقابلة: تم حسـاب ثبات بطاقة المقابلة من خلال قيام الباحث بتحليل نتائج تطبيق بطاقة المقابلة على العينة الاستطلاعية التي تم مقابلتها، ثم قام الباحث أخر بتحليل نتائج تطبيق

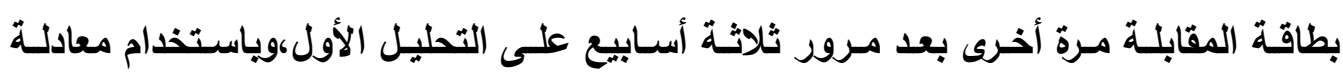

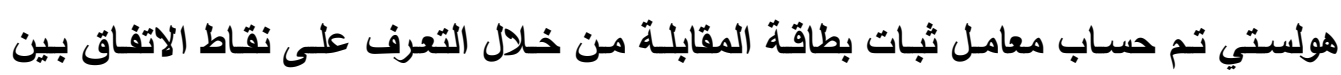

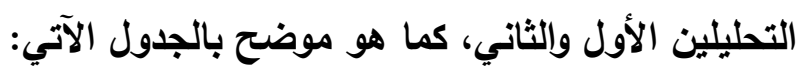

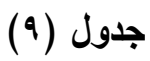

نتائج تحليل بطاقة المقابلة

\begin{tabular}{|c|c|c|c|}
\hline الاتفاق & التانيليل & الأحليل & أسباب الصعويات الناتجة من التحليل \\
\hline$r \leqslant$ & ro & Y & \\
\hline
\end{tabular}

وقد بلفت نسبة الاتفاق (؛ 9، .)، وهو معامل ثبات مرتفع ممـا يدل على صـلاحية

البطاقة للاستخدام.

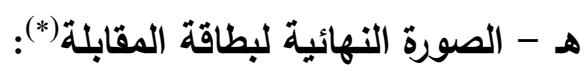

بعد التأكد من صدق وثبات الاختبار، أصبحت بطاقة المقابلة في صورتها النهائية

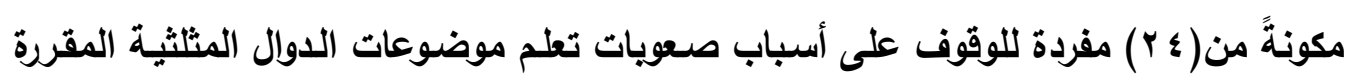

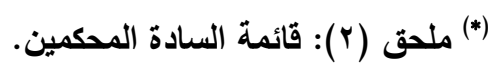
(*) ملحق (^): الصورة النهائية لبطاقة المقابلة. 


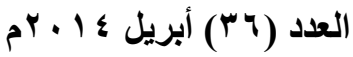

بكتـاب الرياضـيات لطـلاب الصـف الأول الثانوي بالفصـل الدراسـي الأول مقســة إلى ثـلاث

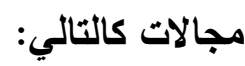

- - المجال الأول: ويحتوي على (V) أسباب تتعلق بالمعلم.

- المجال الثاني: ويحتوي على (r l ) سبب تنتعلق بالطلاب.

- - المجال الثالث: ويحتوي على (•) أسباب تتعلق بالكتاب المدرسي وطبيعة موضسوعات

الدوال المثلثية.

رابعاً : تنفيذ تجربة الدراسة :

( ) مينة الدراسة:

تم اختيار عينة عشوائية ممثلة لطلاب وطالبات الصف الأول الثانوي، وذلك من أريعة مدارس من مدارس محافظة أسيوط، وقد شملت العينة ( . . 1) طالباً وطالبة، تم اختيارهم كما هو موضت بالجدول الآتي:

$$
\text { جدول (1.) }
$$

أسماء المدارس وعدد الطلاب والطالبات التي تم

الاستعانة بهم كعينة للارراسة وعلة ولطاب

\begin{tabular}{|c|c|c|}
\hline الطالبات & الطلاب & اسم المدرسة \\
\hline - & r. & ناصر الثانوية بنين \\
\hline$r$. & - & الخياط الثانوية بنات \\
\hline - & $r \cdot$ & المشير أحمد إسماعيل الثانوية بنين \\
\hline r. & - & خديجة يوسف الثانوية بنات \\
\hline ○. & ○. & الإجمالي \\
\hline
\end{tabular}

أ- تم تطبيق الاختبار التشخيصس لصعويات التعلم على عينة الاراسـة والمكونـة من ( . 1 )

طالب وطالبـة مـن طلاب الصف الأول الثانوي، وذلك لتشـيص صـويات التعلم وتحديد

القائمة النهائية لصعويات التعلم من واقع دراسة الطلابلموضوعات الدوال المثثية. 


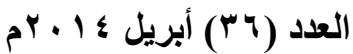

ب- تم تطبيق بطاقة المقابلة على أفراد العينة العثوائية التي تم اختيارها مسبقاً والمكونـة من ( . . 1) طالب وطالبة من طلاب الصف الأول الثانوي، وذلك للوقوف على أسباب صعويات

تعلم موضوعات الدوال المثلثية.

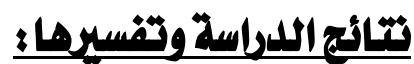

أولاً: النتائج المتعلقة بالسـؤال الثالث مـن أسئلة الاراسـة واللذي ينص على " مـا الصعويات الفعلية التي يواجهها طلاب الصف الأول الثانوي أثناء دراستهم موضوعات الدوال المثثثية

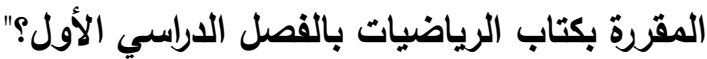
تمت الإجابة عن هذا السؤال من خلال تطبيق الاختبار التشخيصي لصعويات تعلم موضوعات الدوال المثلثية المقرة بكتاب الرياضيات على طلاب الصف الأول الثانوي بالفصل الدراسي الأول، ثم تم تصحيح الاختبار التشخيصسي وتجميع البيانات وحسـاب النسبة المئويـة لتكرار الخطأ لكل مفردة من مفردات الاختبار وذلك من خلال المعادلة التالية (سوسن شـاكر

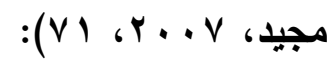

عدد تكر ار الخطأ$$
\text { النسبة المئوية لتكرار الخطأ= }
$$

ويوضح جدول (11) النسبة المئوية لتكرار الخطا في الاختبار التتخيصي لموضوعات الدوال المثلثية لجميع أفراد العينة:

جلول (11) - (11) - (1)

النسبة المئوية لتكرار الخطأ في الاختبار التثخيصي لموضوعات الدوال المثلثية لجميع أفراد العينة:

\begin{tabular}{|c|c|c|c|c|c|}
\hline المئسونية & التُكران & رقم المفرددة & المئنسية & التيكّان. & المقرَّردة \\
\hline$\% 11$ & 11 & 17 & $\% 0$ & 0 & 1 \\
\hline \%रr & YY & TV & $\%$ \%r. & r. & $\bar{Y}$ \\
\hline$\%$ \%ःव & ६9 & $\pi$ & $\% 10$ & 10 & $\Gamma$ \\
\hline$\% 11$ & $\pi$ & 19 & $\% 1 \lambda$ & $\pi$ & $\xi$ \\
\hline \%rr & $F T$ & F. & $\% 00$ & 00 & $\overline{0}$ \\
\hline$\% \backslash V$ & IV & Tा & $\% 17$ & 17 & 7 \\
\hline$\% 19$ & 19 & YY & $\%$ \% & $\Gamma \xi$ & $\bar{v}$ \\
\hline$\% \leqslant 0$ & $\leqslant 0$ & $\overline{T T}$ & $\% 1 \xi$ & T\& & $\pi$ \\
\hline$\% 01$ & $\Delta \lambda$ & Tई & \%०र & OT & 9 \\
\hline \%रा & Tा & TO & $\% \circ\{$ & $0 \xi$ & 1. \\
\hline \%र. & T. & 79 & $\% 07$ & 07 & $\pi$ \\
\hline$\% 01$ & 01 & TV & $\% 11$ & $\pi$ & TY \\
\hline$\% \circ 9$ & 09 & Tर & $\% 10$ & 10 & $T$ \\
\hline$\% 0$. & 0. & rq & $\% 1$. & T. & Tई \\
\hline \%रद & TE & r. & \%र. & T. & 10 \\
\hline
\end{tabular}


ويتضح من الجدول ما يلي:

أنه بحسـاب التكرارات وإلنسب المئويـة لإجابـات الطلاب على كل مفردة من مفردات

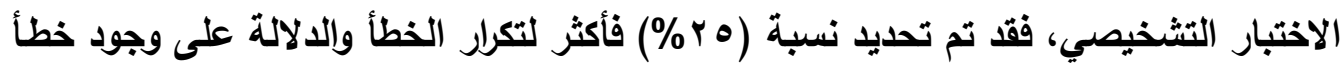
شـائع لاى الطلاب وهذه النسبة تتفق مـع النسبة التي حددتها دراسـة كل مـن (أحمد أحمد

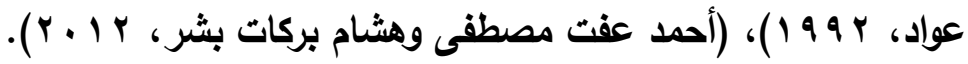

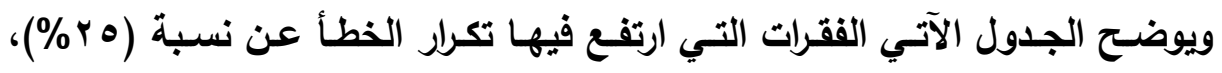
وكنلك الققرات التي قل فيها تكرار الخطأ عن نسبة (ه ب\%):

$$
\text { جدول (r) }
$$

الفقرات التي ارتفع فيها تكرار الخطأ عن نسبة (ه ج\%)، وكنلك الفقرات

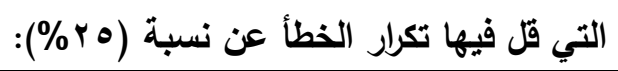

\begin{tabular}{|c|c|}
\hline الفقرات التي قل فيها تكرار الخطأ عن نسبة & (الفقرات التي ارتفع فيها تكرار الخطأ عن نسبة \\
\hline 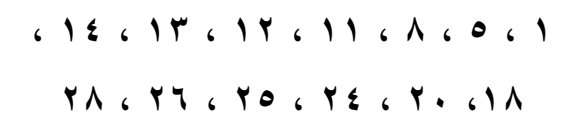 & $\begin{array}{l}61961061,696 V 696 \varepsilon 6 r 6 r \\
r \cdot 6 r q 6 r V 6 r r 6 r r 6 r 161961 V\end{array}$ \\
\hline
\end{tabular}

ويالتالي يمكن تحديد القائمـة الفعليةلصـويات تعلم الرياضيات في موضوعات الدوال المثلثية المقررة بكتاب الرياضيات لطلاب الصف الأول الثانوي بالفصل الدراسي الأول كما يلي: ا ا ـ تحديد إثارة الاوال المثلثية الأساسية. r. إيجاد قيمة نقطة على دائرة الوحدة لزاوية (ه) في وضعها القياسي ثم حسـاب الدوال المثلثية الأساسية للزاوية (ه). r. تحليد إثارة مقلويات الدوال المثلثية. ؛. الريط بين الدوال المثلثية ومقلوياتها. ه. إيجاد قيمة نقطة على دائرة الوحدة لزاوية (ه) في وضعها القياسي ثم إيجاد مقلويات الاوال المثلثية. 7. حل معادلات الدوال المثلثية لبعض الزوايا الخاصة. V. الريط بين الدوال المثثثية ومقلوياتها بنظرية فيثاغورس. ^. حل معادلات الدوال المثلثية بمعلومية زاوية حادة في مثلث قائم الزاوية. 


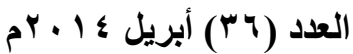

9

• أ قياس زاوية معلوم إحدى قيم الدوال المثلثية لها.

ويالتالي أمكن تحديد قائمة الصعويات الفعلية التي تواجه طلاب الصف الأول الثانوي

في تعلم الرياضيات بموضوعات الدوال المثلثية المقررة بالفصل الدراسي الأول.

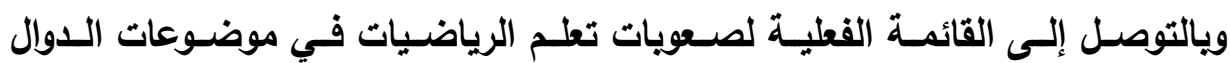

المثلثية المقررة بكتاب الرياضيات لطلاب الصف الأول الثانوي بالفصل الاراسي الأول، يكون

قد تم الإجابة على السؤال الثالث من أسئلة الدراسة.

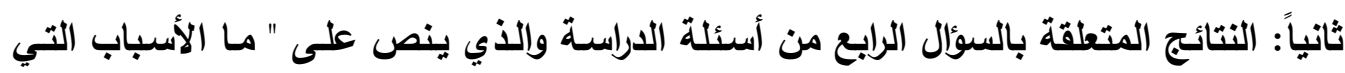

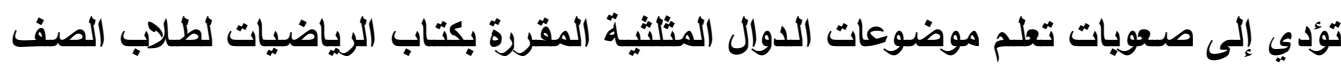

الأول الثانوي بالفصل الاراسي الأول ؟":

تمث الإجابة عن هذا السؤال من خلال:

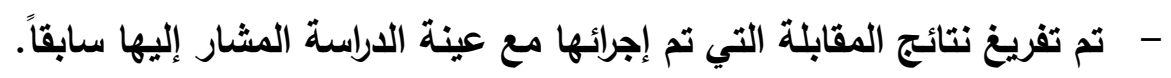

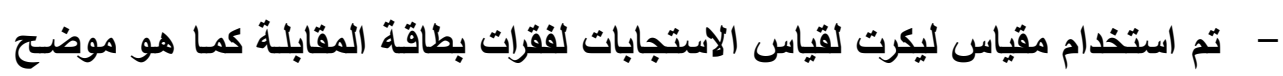

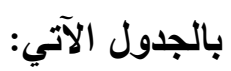

جلول (T)

درجات مقياس ليكرت

\begin{tabular}{|c|c|c|c|c|}
\hline لا تمثل صعوية & قليلة & متوسطة & كبيرة & الاستجابة \\
\hline$\cdot$ & 1 & $r$ & $r$ & الارجة \\
\hline
\end{tabular}

تم حساب المتوسط الحسابي والوزن النسبي لكل فقرة من فقرات بطاقة المقابلة، كما

هو موضح بالجدول الآتي:

جدول ( 1 ( )

المتوسط الحسابي والأهمية النسبية والرتبة لكل فقرة من فقرات المجال الأول:

\begin{tabular}{|c|c|c|c|}
\hline الرتبة & الأهمية النسبية & المتوسط الحسابي & الفقرة \\
\hline 1 & $91 . \wedge \wedge$ & $r_{6} \wedge 1$ & 1 \\
\hline 0 & $\Lambda 9.9 \Lambda$ & r.79 & $r$ \\
\hline $\bar{r}$ & $91 \ldots$ & 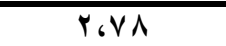 & $r$ \\
\hline 7 & $\overline{\lambda Y_{6} \cdot V}$ & $r, 01$ & $\xi$ \\
\hline$\xi$ & $9.60 \mathrm{~V}$ & Y.VV & 0 \\
\hline $\mathrm{V}$ & 87.19 & YGrT & 7 \\
\hline $\bar{Y}$ & $91, \mathrm{YT}$ & Y.Vq & $\bar{v}$ \\
\hline
\end{tabular}




$$
\text { ويتضح من جدول ( ؛ ا ) ما يلي: }
$$

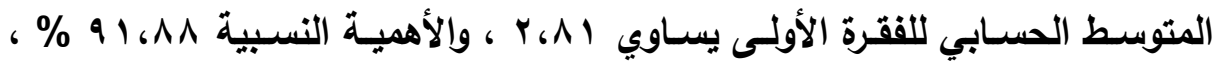

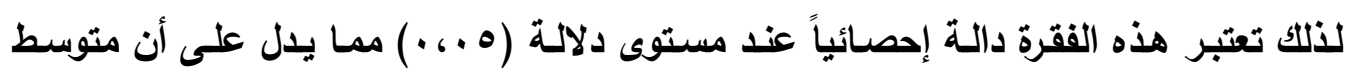

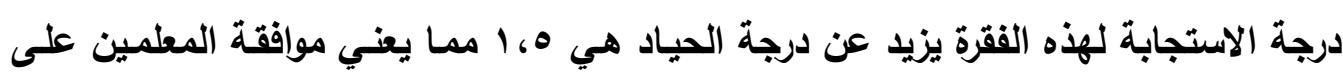
أن استخدام الطريقة التقليدية في التدريس من أحد أسباب صعويات تعلم موضوعات الدوال الدال

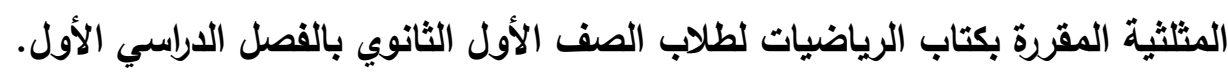

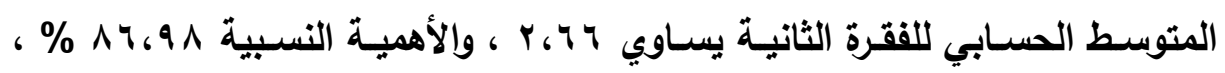

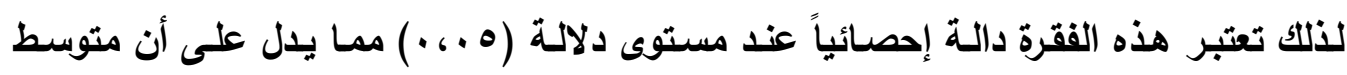

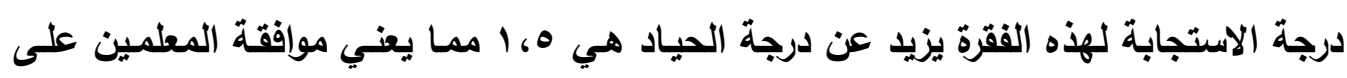

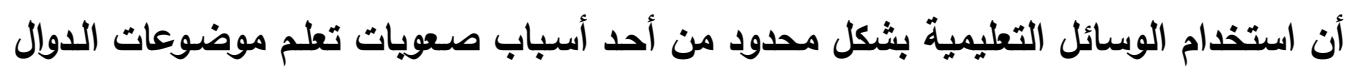
المثلثية المقررة بكتاب الرياضيات لطلاب الصف الأول الثانوي بالفصل الدراسي الدئي الأول.

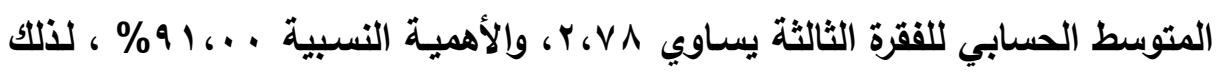

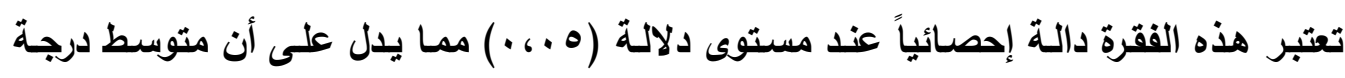

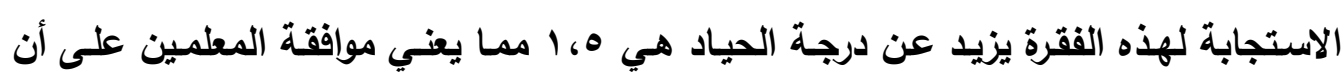

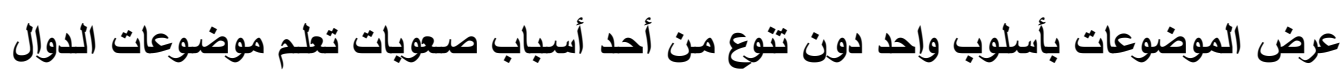

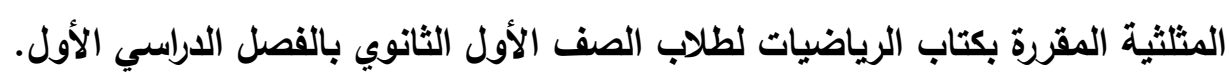

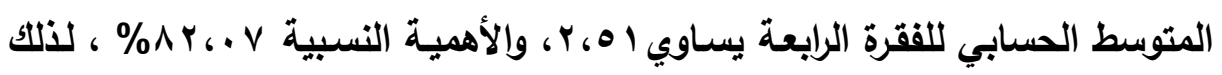

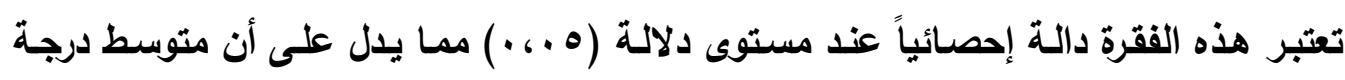

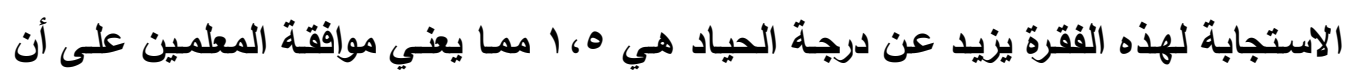

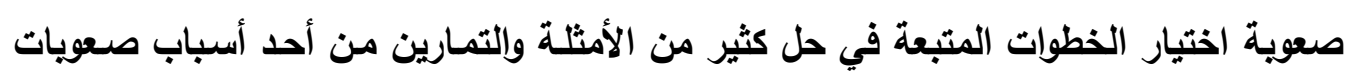

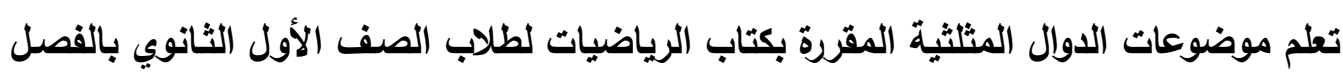

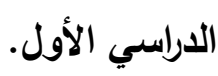

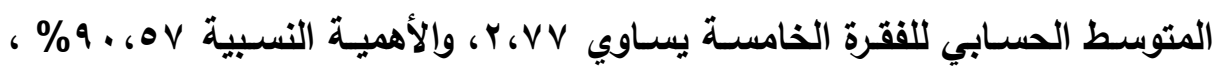

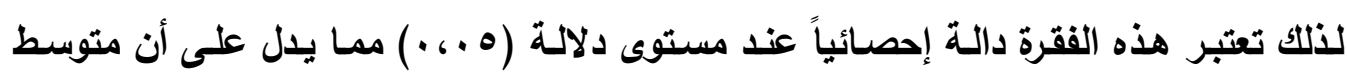

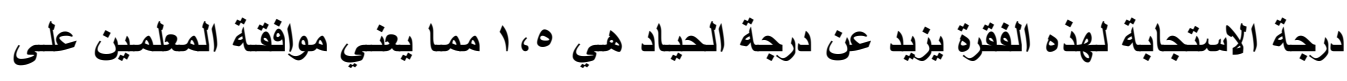

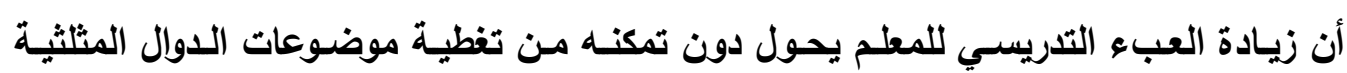




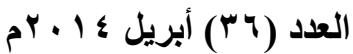

بشــل أفضـل مـن أحسـ أسـباب صـعويات تعــم موضـوعات الـــوال المثلثــة المقـررة بكتـاب الرياضيات لطلاب الصف الأول الثانوي بالفصل الاراسي الأول.

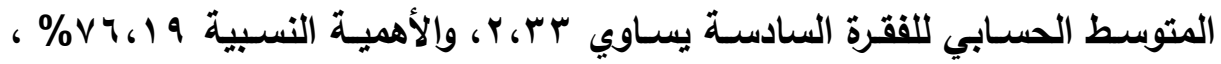

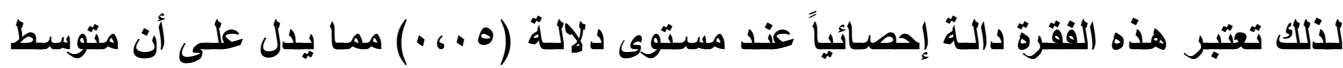

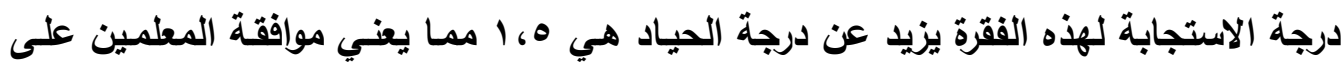

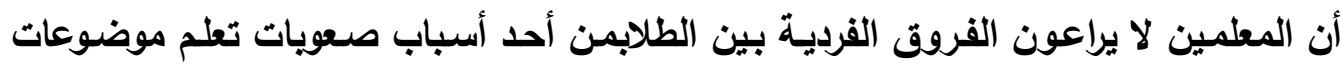
الدوال المثلثية المقررة بكتاب الرياضيات لطلاب الصف الأول الثانوي بالفصل الاراسي الأول.

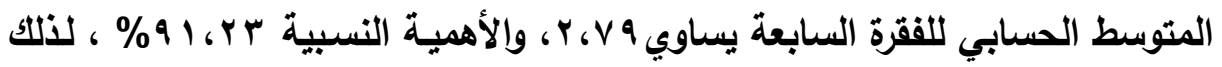

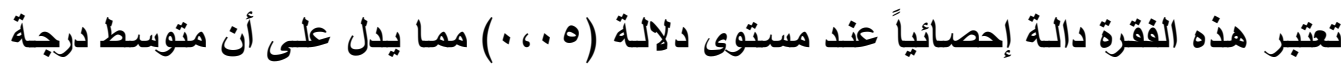

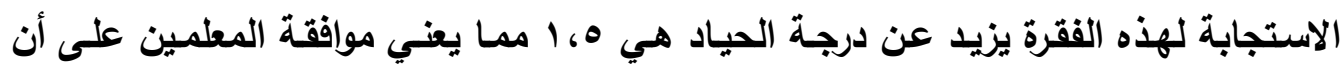
قصور أساليب التقويمالتي يتبعها المعلمون على قياس المعرفة فقطهو أحد أسباب صعويات تعلم موضوعات الدوال المثلثية المقررة بكتاب الرياضيات لطلاب الصف الأول الثانوي بالفصل

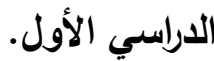

جدول (10)

المتوسط الحسابي والأهمية النسبية والرتبة لكل فقرة من فقرات المجال الثاني:

\begin{tabular}{|c|c|c|c|c|c|c|c|}
\hline الرتبة & الأهمية & المتوبط الحسبي & الفقرة & الرتبة & الأهمبية & الحتوسطب & الفقرة \\
\hline 0 & $\Lambda v_{G}, \mu$. & Y.7V & V & $r$ & $\wedge \wedge, 7)$ & Y.VI & 1 \\
\hline$\Lambda$ & $\wedge 0,99$ & r.7 & $\Lambda$ & $r$ & 19,94 & Y $6 V_{0}$ & $r$ \\
\hline 1. & ג0, & Y.7I & 9 & 1 & q., ro & $r_{6} V 7$ & $r$ \\
\hline V & A & Y.7 & 1. & $\varepsilon$ & גV. & Y.7^ & $\varepsilon$ \\
\hline 11 & A & $Y_{6} \diamond \wedge$ & 11 & 7 & $\wedge \neg, ৭ \wedge$ & Y.77 & 0 \\
\hline 9 & 10,7V & Y.TY & Ir & Ir & $\Lambda r_{\text {GV }}$ & $Y_{6} 07$ & 7 \\
\hline
\end{tabular}

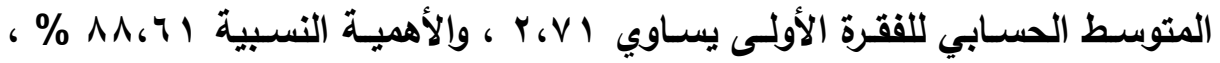

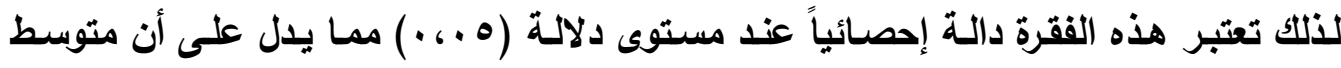

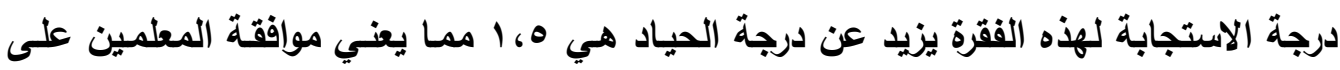

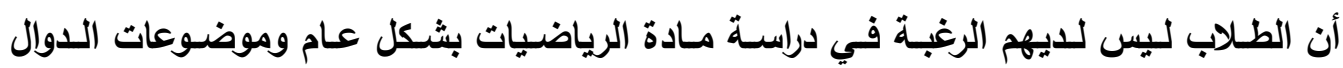




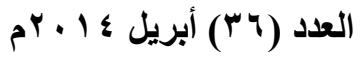

المثلثية بشكل خاص من أحد أسباب صعويات تعلم موضوعات الدوال المثلثية المقررة بكتاب الرياضيات لطلاب الصف الأول الثانوي بالفصل الاراسي الأول.

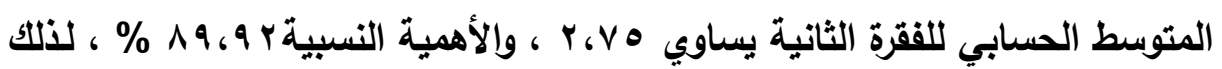

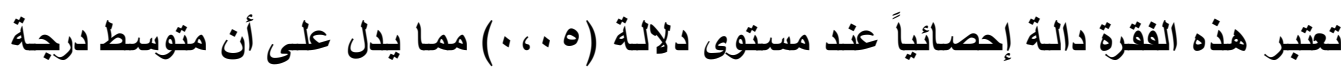

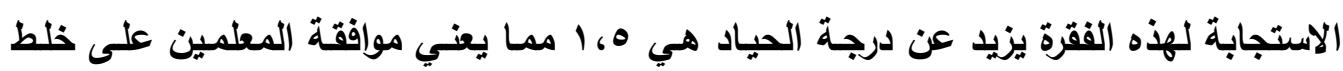

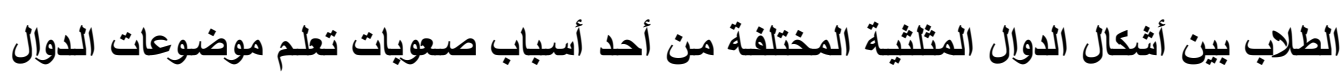
المثلثية المقررة بكتاب الرياضيات لطلاب الصف الأول الثانوي بالفصل الدراسي الأول.

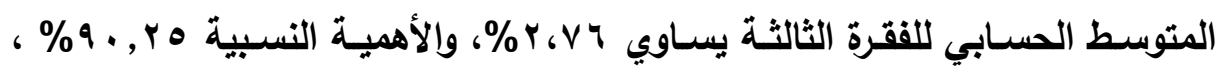

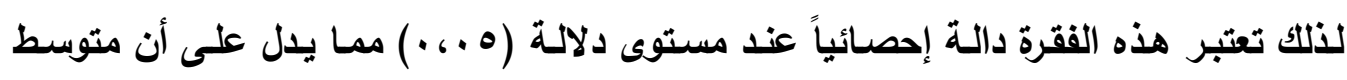

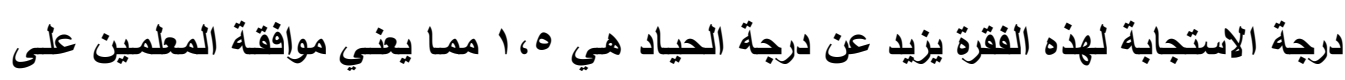

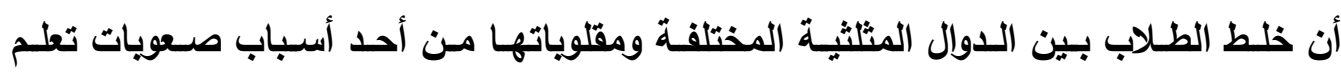
موضـوعات الدوال المثلثيـة المقررة بكتاب الرياضيات لطلاب الصف الأول الثانوي بالفصل

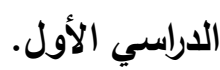

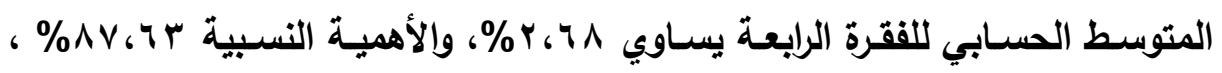

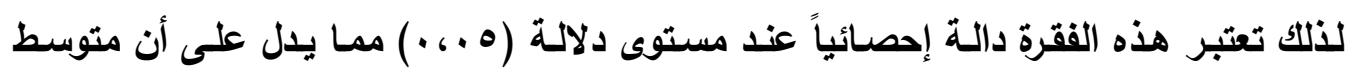

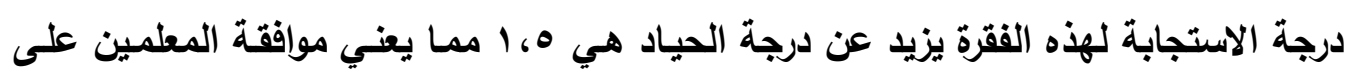
أن ضعف الطلاب في تطبيق مهارة الترميز من أحد أسباب صعويات تعلم موضوعات الدوال المثلثية المقررة بكتاب الرياضيات لطلاب الصف الأول الثانوي بالفصل الاراسي الأول.

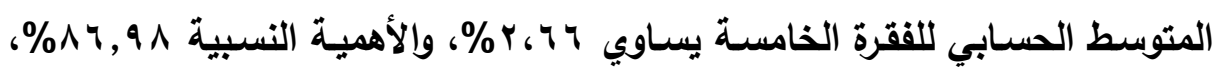

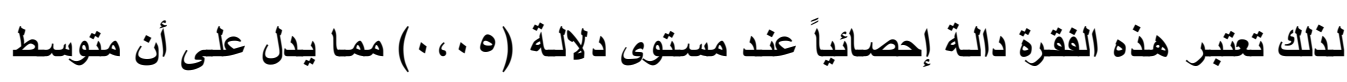

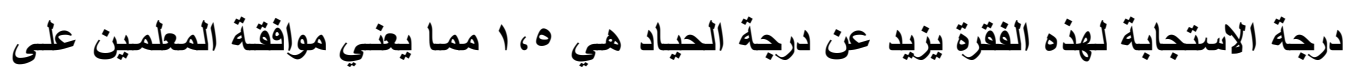

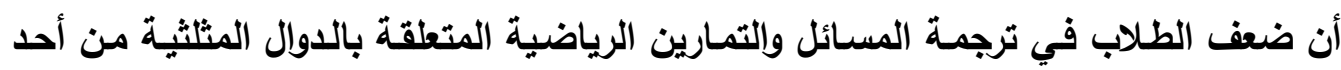

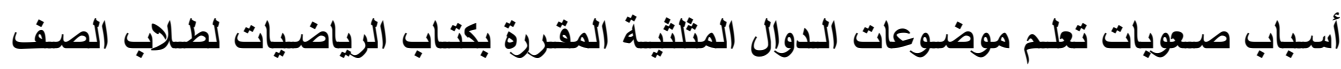
الأول الثانوي بالفصل الدراسي الأول.

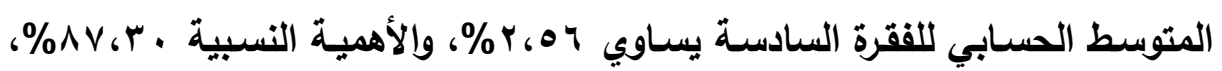

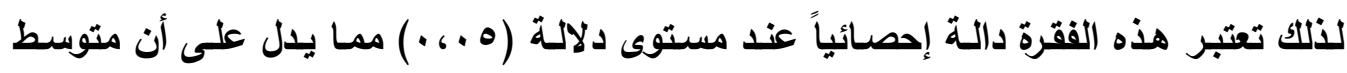




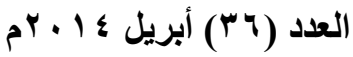

درجة الاستجابة لهذه الفقرة يزيد عن درجة الحياد هي ه، 1 ممـا يعني موافقة المعلمين على

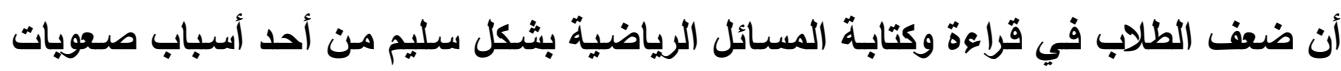
تعلم موضوعات الدوال المثلثية المقررة بكتاب الرياضيات لطلاب الصف الأول الثانوي بالفصل فئل فلئل

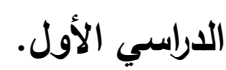

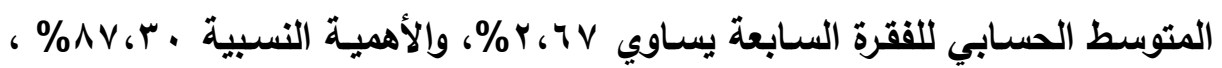

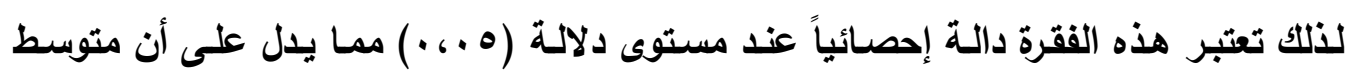

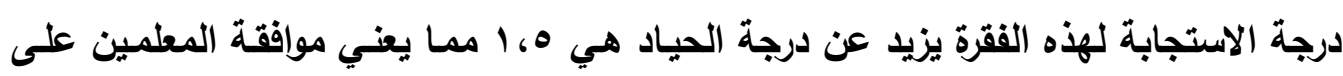

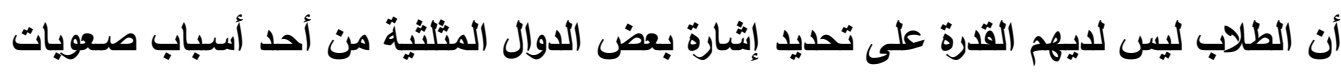

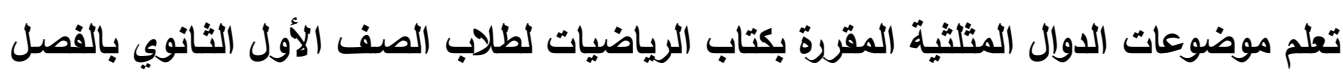

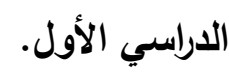

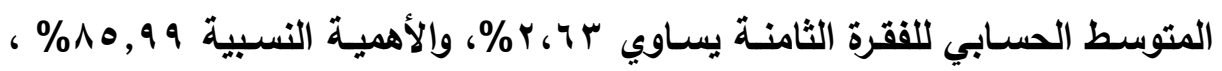

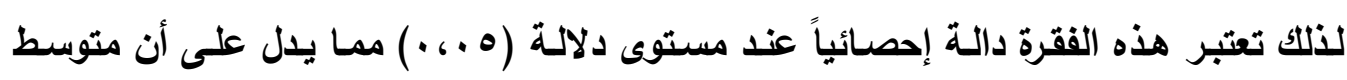

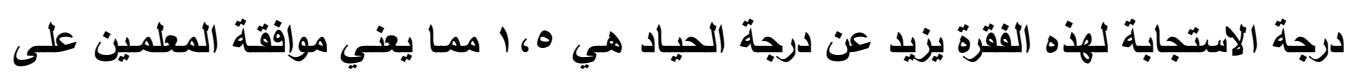

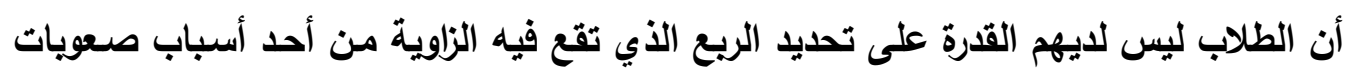

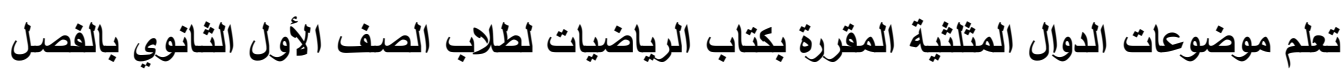

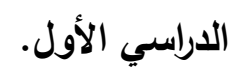

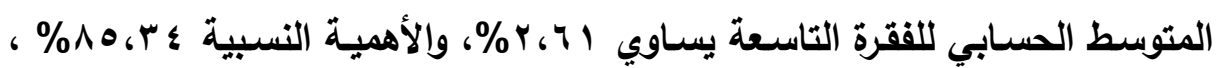

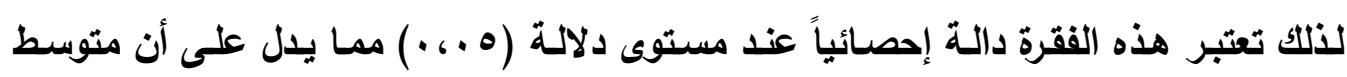

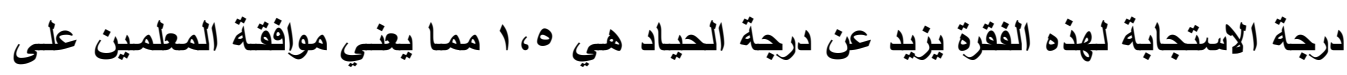

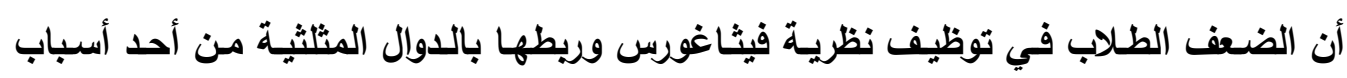

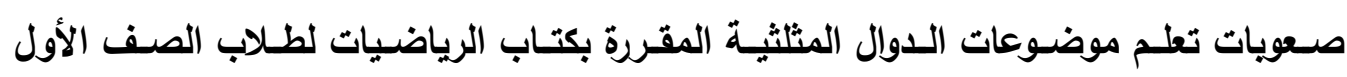
الثانوي بالفصل الاراسي الأول.

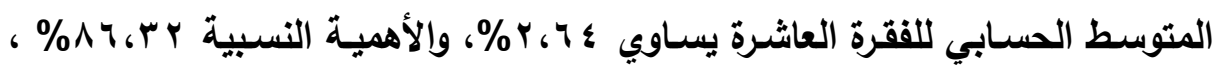

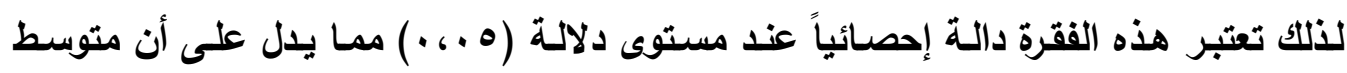

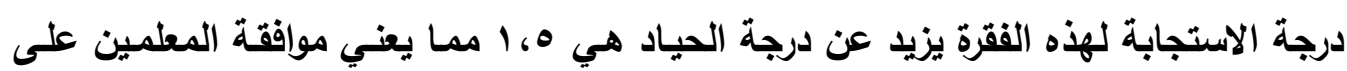
أن الطلاب غير قادرين على التفريق بين الضلع المقابل والمجاور للزاويـة الحادة في المثلث 


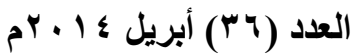

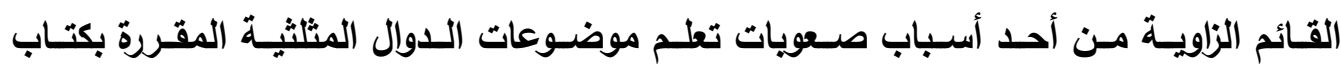
الرياضيات لطلاب الصف الأول الثانوي بالفصل الاراسي الأول.

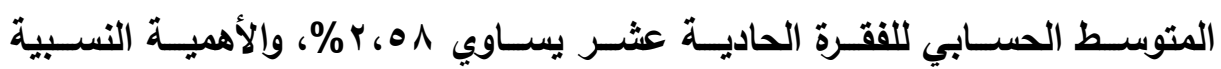

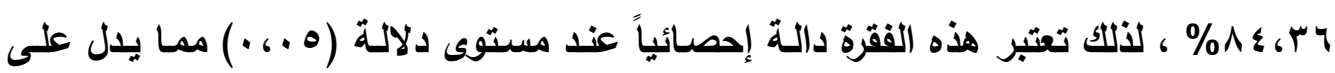

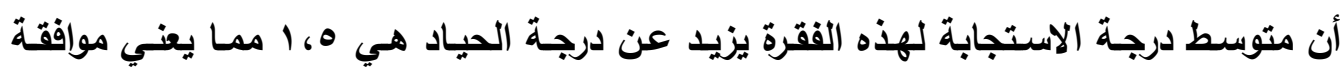

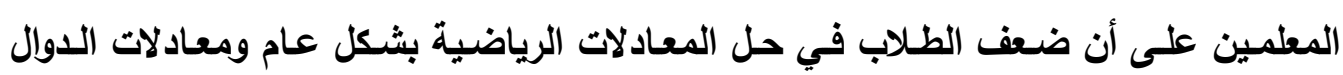

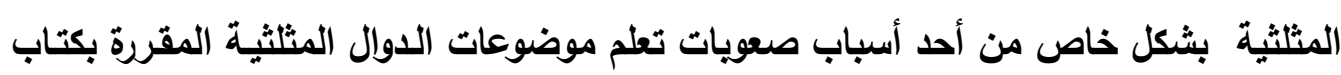

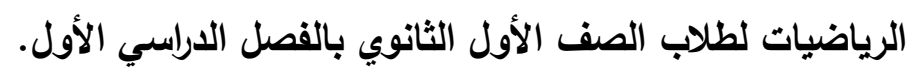

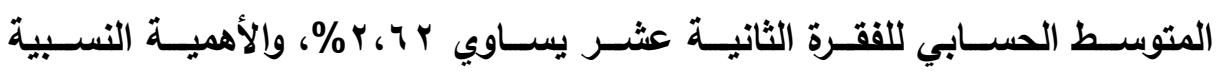

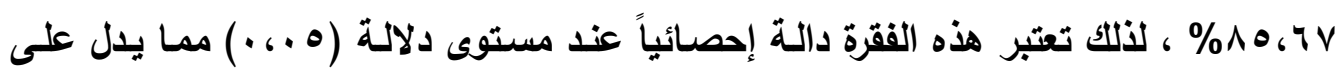

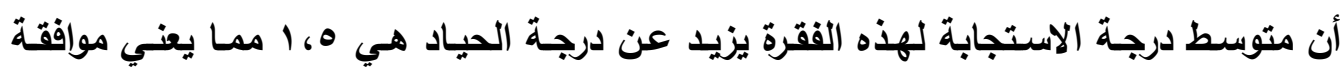

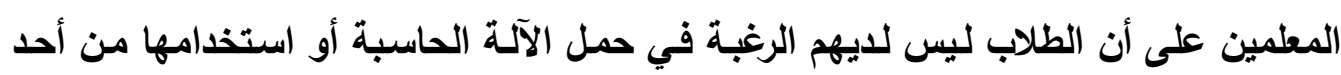

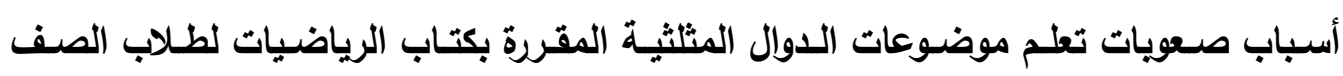
الأول الثانوي بالفصل الدراسي الأول.

جدول (17)

المتوسط الحسابي والأهمية النسبية والرتبة لكل فقرة من فقرات المجال الثالث:

\begin{tabular}{|c|c|c|c|}
\hline الرتبة & الأهمبة النسبة & المتوسط & الفقرة \\
\hline 1 & 91600 & $r_{6} \Lambda$. & 1 \\
\hline$r$ & גV. & Y.7 & $r$ \\
\hline$r$ & $\Lambda r_{6} v^{\prime}$ & $Y, 07$ & $r$ \\
\hline$\varepsilon$ & $\Lambda r_{6} V Y$ & $r, \Delta r$ & $\varepsilon$ \\
\hline 0 & $\Lambda I_{6} \leqslant Y$ & $r_{6} \leqslant q$ & 0 \\
\hline
\end{tabular}

ويتضح من جدول (7 ا ) ما يلي:

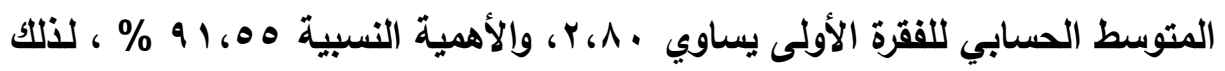

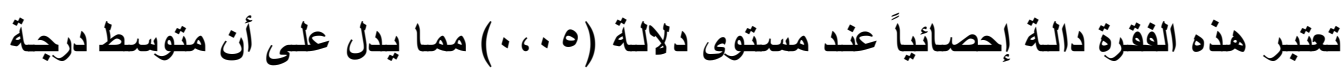

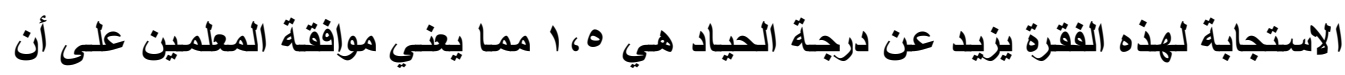

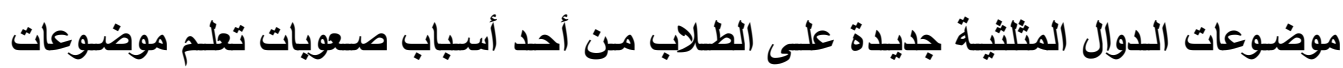

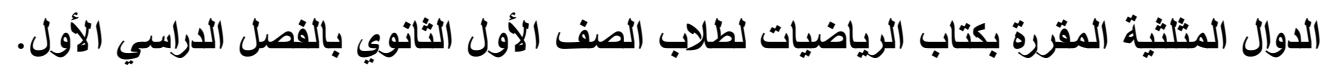




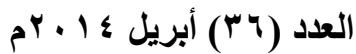

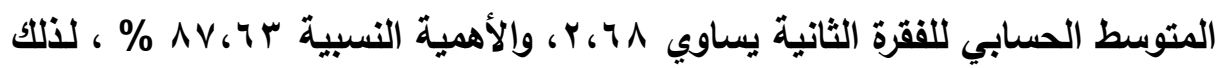

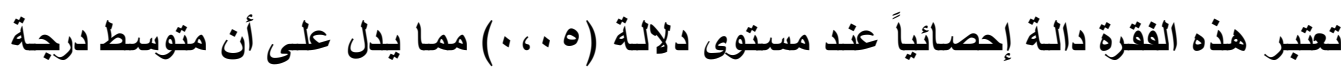

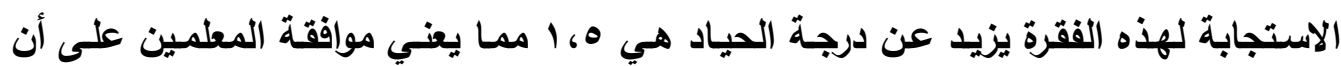

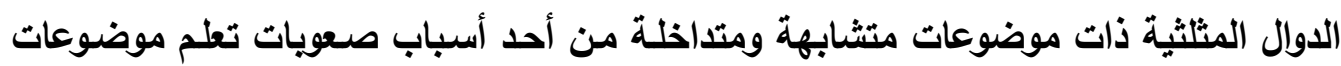
الدوال المثلثية المقررة بكتاب الرياضيات لطلاب الصف الأول الثانوي بالفصل الاراسي الأول.

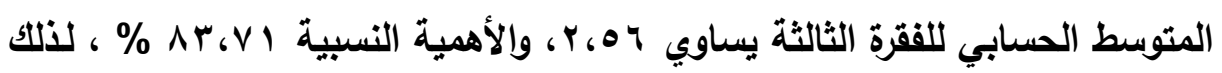

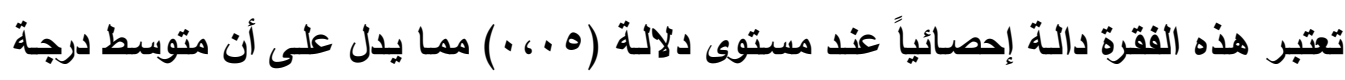

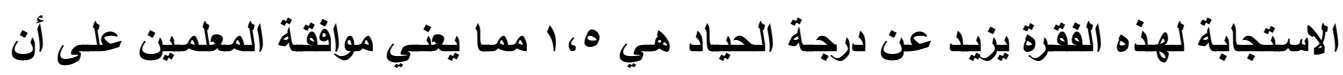

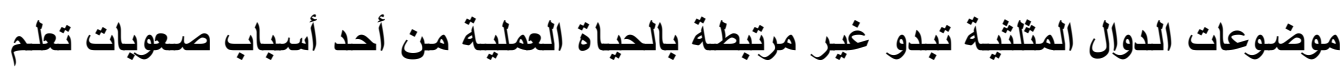

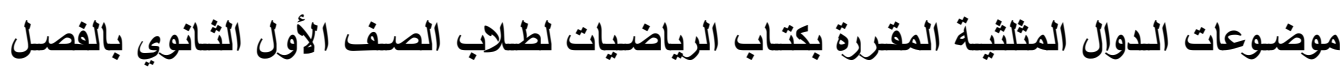

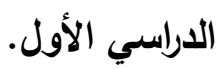

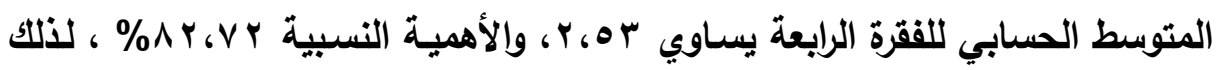

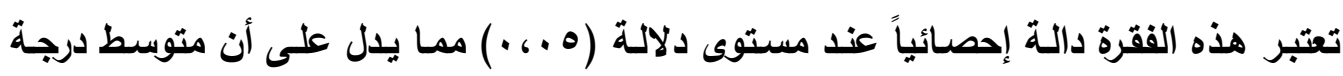

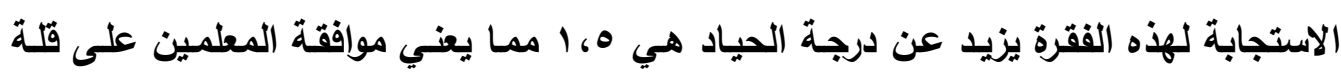

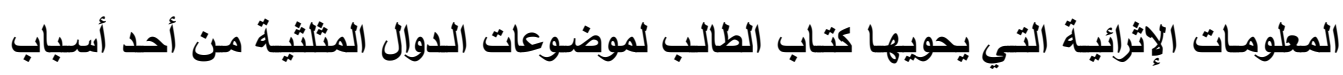

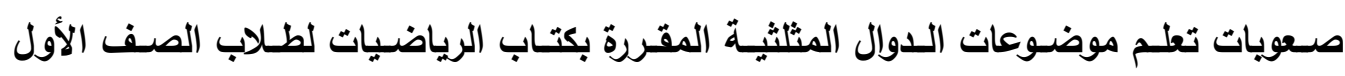
الثانوي بالفصل الاراسي الأول.

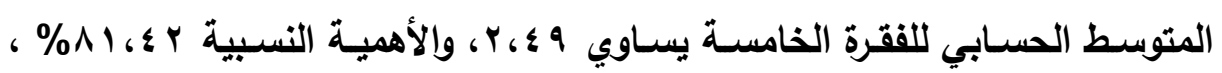

لذلك تعتبر هذه الفقرة دالة إحصائياً عند مستوى دلالة (ه .، . ) مما يدل على أن متوسط

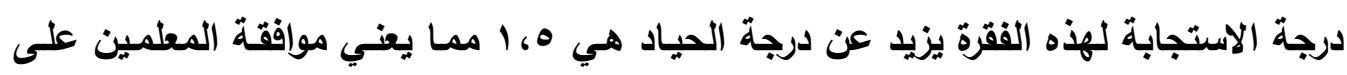

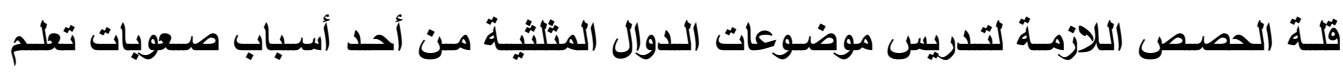
موضـوعات الدوال المثلثيـة المقررة بكتاب الرياضيات لطلاب الصف الأول الثانوي بالفصل

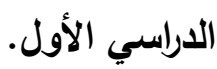
ثالثاً: النتائج المتعلقة بالسؤال الخـامس مـن أسئلة الدراسـة والذذي ينص على "مـا التصـور

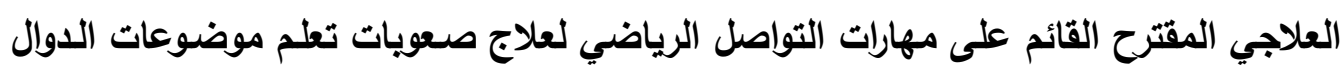
المثلثية المقررة بكتاب الرياضيات لطلاب الصف الأول الثانوي بالفصل الدراسي الأول؟": 


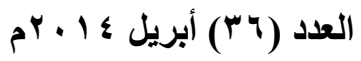

يشمل التصور العلاجي مجموعة من المواقف التعليمية المنظمـة بشكل دروس يمثل كل درس صعوية من الصعويات التي تم التوصل إليها وتتضمن هذه الدروس أهدافاً سلوكية

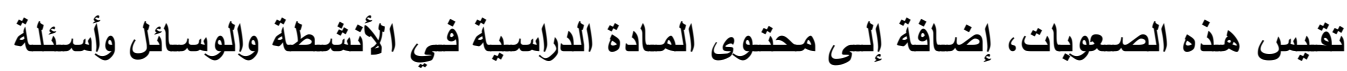
التقويم (*)، ويمكن توضيح ذلك فيما يلي: • إعداد المخطط العام للتصور العلاجي المقترح: تم إعداد مخطط عام للبرنامج المقترح وذلك بإتباع الخطوات التالية: أولاً: تحديد أسس التصور العلاجي. ثانياً: تحديد الهذف العام للتصور العلاجي.

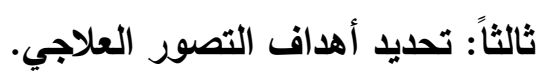
رابعاً: محتوى التصور العلاجي. تُلائ. وفيما عرض للخطوات السابقة:

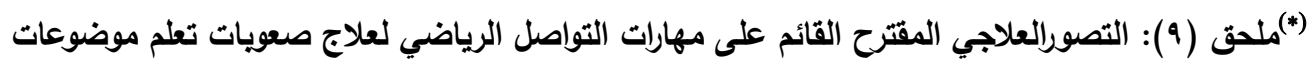
الدوال المثثية المقررة بكتاب الرياضيات لطلاب الصف الأول الثانوي بالفصل الاراسي الأول. 


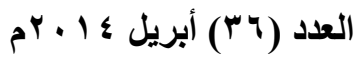

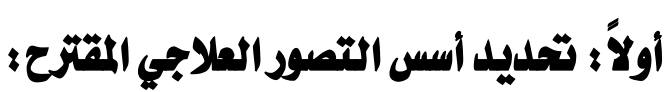

تم تحليد أسس بناء البرنـامج بناء على اعتبار أن كل صعوية من صعويات تعلم

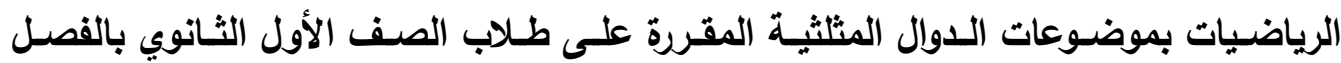
الدراسي الأول هي هدف من أهداف البرنـامج، كما تم تحديد أسس بنـاء البرنامج في ضوء البرامج العالمية الخاصـة بـالمتغيرات ذات العلاقة بالدراسـة الحالية، وقد تم الاعتمـاد في ذلتك على تحديـ مهارات التواصـل الرياضـي الـلازم تضـمينها بموضـوعات الـدوال المثثثية المقررة بكتاب الرياضيات لطلاب الصف الأول الثانوي بالفصل الدراسي الأول لعلاج صعويات التعلم التي تواجه الطلاب أثناء دراستهم لهذه الوحدة.

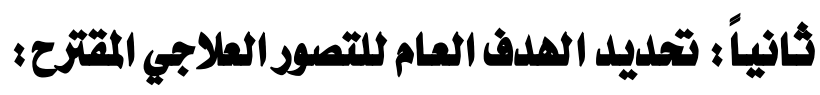
تم تحديد الأهداف العامة للبرنامج في ضوء أهداف الدراسة الحالية ، ولذلك تم تحديد الهدف الرئيس التالي للبرنامج: علاج صعويات التعلم التي تواجه طلاب الصف الأول الثانوي أثناء دراستهم لموضوعات الدوال المثلثية المقررة بكتاب الرياضيات بالفصل الدراسي الأول، وذلك من خلال: - - تيسير فهم الطلاب لمحتوى موضوعات الدوال المثلثية المقرر بكتاب الصف الأول الثانوي بالفصل الدراسي الأول. - - تنمية قدرات الطلاب في التعبير عن الأفكار الرياضية. - - تعميق فهم الطلاب للرياضيات بشكل عام وللاهندة بشكل خاص. - - تنمية مقدرة الطلاب على القراعة الجادة الهادفة. - - تنمية قدرة الطلاب على حسن الاستماع، والتفكير وتحليل ما يسمعوه.

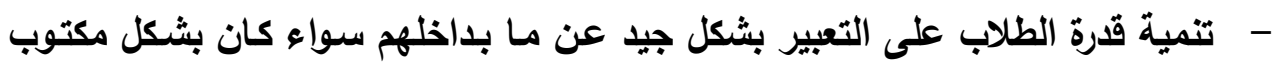
أو شفهي. - - تنمية قدرة الطلاب على استخدام الترميز في تعلم موضوعات الدوال المثلثية. - مساعدة الطلاب على إدراك وفهم ما يتعلموه بشكل أكثر عمقاً. 


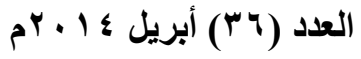

\section{ثالثاً: تُمليد أهداض التصور الملاجي المقتزح:}

1. تحديد إشارة الدوال المثلثية الأساسية.

r. إيجاد قيمة نقطة على دائرة الوحدة الزاوية (هـ) في وضعها القياسي ثم حساب الدوال المثلثية الأساسية للزاوية (هـ). r. تحديد إثارة مقلويات الدوال المثلثية. ع. الربط بين الدوال المثلثية ومقلوياتها. ه. إيجاد قيمة نقطة على دائرة الوحدة لزاوية (هـ) في وضعها القياسي ثم إيجاد مقلويات الاوال المثلثية. - الماد. 7. V. الريط بين الدوال المثلثية ومقلوياتها بنظرية فيثاغورس. ^. حل معادلات الدوال المثلثية بمعلومية زاوية حادة في مثلث قائم الزاوية. 9. إيجاد الدوال المثلثية لأي زاوية. • 1 ـ قياس زاوية معلوم إحدى قيم الدوال المثثية لها. كابعاً: محتوى التصور الملاجي المقترح؛ يشمل محتوى التصور العلاجي على العناصر التالية: 1- المادة التعليمية ( المضموز ):

روعي عند بنـاء التصـور العلاجي الاعتمـاد على كتاب الرياضيات المقرر على طلاب الصف الأول الثانوي بالفصل الاراسي الأول. تمثل التصور العلاجي في مجموعة من الموضوعات التي تم تضمينها مهارات التواصل بالاول

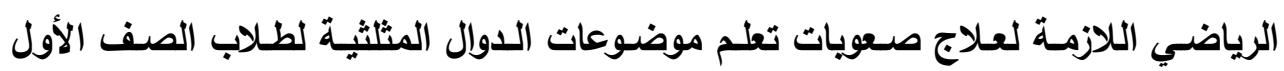

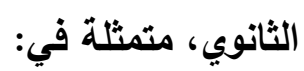
(الدوال المثلثيـة- مقلويـات الـدوال المثلثيـة- الدوال المثلثيـة لبعض الزوايـا الخاصـة-

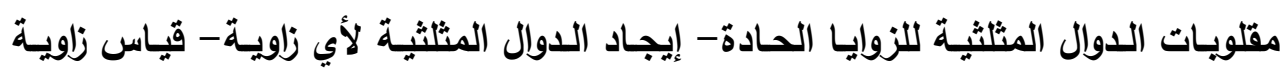
معلوم إحدى قيم الدوال المثثثية لها) وقد تم إعداد الموضوعات وفق لمجموعة من الإجراءات التي تم مراعاتها حتى يمكن من خلالها تحقيق الهدف العام للتصور العلاجي، وتمثلت هذه الإجراءات في: 


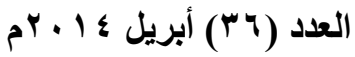

- - العمل في ضوء مهارات التواصل الرياضـي الـلازم تضمينها بموضوعات الدوال المثلثيـة المقررة على طلاب الصف الأول الثانوي بالفصل الدراسي الأول التي إعدادها مسبقاً.

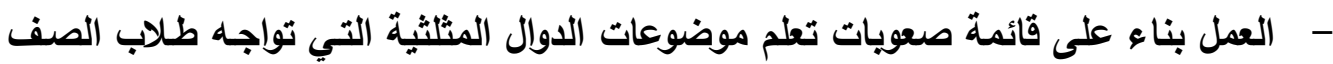

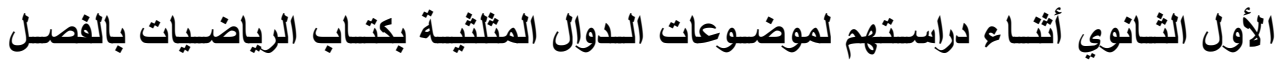

$$
\text { الدراسي الأول. - الأول }
$$

- تعديد أهداف كل موضوع من موضوعات البرنامج. - - تحديد المتطلبات الأساسية لكل موضوع. - - تحديد الخبرات والأنثطة والأساليب التي تحقق أهداف الموضوعات والوحدة بشكل عام. - - تحديد الوسائل التعليمية المناسبة لكل موضوع. - - تحديد استراتيجيات التعليم والتعلم المناسبة لكل موضوع. - تحديد أساليب التقويم المناسبة لكل موضوع.

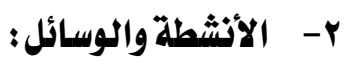

تم تضمين البرنـامج مجموعة مـن الأنشطة المقترحة والوسـائل التعليميـة المختلفة التـي تسـاعد الطلاب على التعلم الفعال، والتي يمكن مـن خلالها تنميـة مهارات التواصل

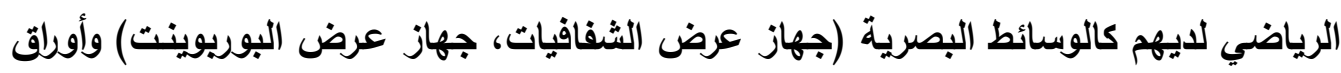

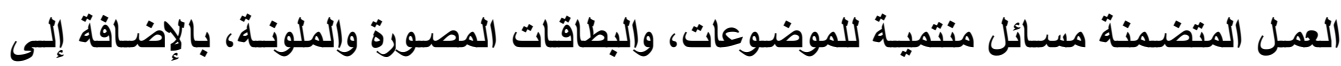
استخدام السبورة العاديـة ووسـائل الإيضـاح المختلفة بما يتلاءم وطبيعة المحتوى المعروض والصعويات المراد علاجها. ب- طرق واستراتيجيات تدريس التصور العلاجي: يتضمن البرنامج مجموعة من الطرق والاستراتيجيات الملائمسة لطبيعة المهارة المراد

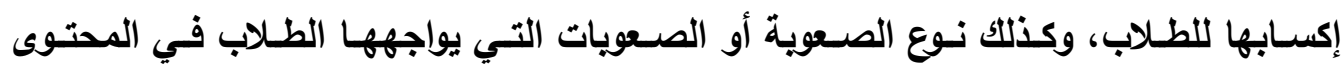
المعروض أمامهم، والتي منها:

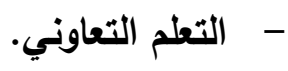
- - التعلم بالاكتشاف. - فكر - زاوج- شارك. ع- أدوات التقويه: 


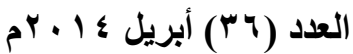

يُعد التقويم الوسيلة التي يمكن من خلالها التأكد من مدى تحقق الأهداف الموضوعة

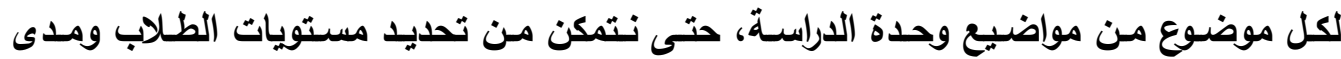
تحقق الأهداف المرجوة من البرنامج، لذلك سيتم اتباع نوعين من التقويم في برنامج الدراسـة هما:

التقويم البنائي:

ويمكن تطبيقه في مجموعة من الإجراءات المتمثلة في:

- تثجيع الطلاب على التحدث عن الجوانب الرياضية التي قاموا بها بالإضـافة إلى قراءة المسائل والتدريبات الرياضية.

- طرح مجموعة من الأسئلة الثفهية التي تثجعهم التحدث وعرض مـا لديهم من أفكار بشكل مسموع.

- عرض مجموعة من الأثكال الهندسية لتحويلها إلى صور رمزية أو العكس.

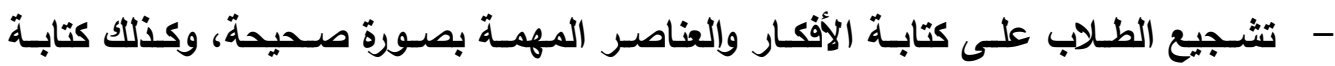
الحلول بشكل مرتب ومنطقي.

التقويم الغتامي؛

ويتم هذا النوع من التقويم بعد الانتهاء من تطبيق التصور العلاجي المقترح لتدريس الدوال المثلثية المقرة بكتاب الرياضيات لطلاب الصف الأول الثانوي بالفصل الدراسي الأول، وذلك لمعرفة مدى التحسن في مستوى الطلاب ومدى تحقى الهذف.

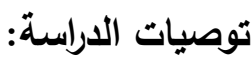

في ضوء مـا توصلت إليـه الاراسـة الحاليـة من نتائج، تقدم الدراسـة الحاليـة بعض التوصيات التي قد تؤدي إلى المساهمة في الحد من صعويات تعلم الدوال المثثيـة لـى طلاب الصف الأول الثانوي، متمثلة في: ا. ضرورة استخدام مهارات التواصل الرياضي في تدريس الرياضيات بشكل عام، وفي تدريس موضوعات الدوال المثلثية بشكل خاص. r. ضرورة إعادة تنظيم كتب الرياضيات باستخدام مهارات التواصل الرياضـي في محاولة لربط المفاهيم والتعميمات والمهارات ببعضهم البعض لإكساب الطلاب مهارات التفكير

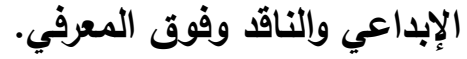


r. ضــرورة الاهتمـام بصـعويات تعــم الرياضـيات لــى الطـلاب واتبـاع الاسـتراتيجيات الملائمة لعلاجها. ع. التأكيا على توضيح المفاهيم والرموز والمصطلحات إبرازها للطلاب حتى يتمكنوا من فئن فهمها والتعامل معها بشكل أفضل.

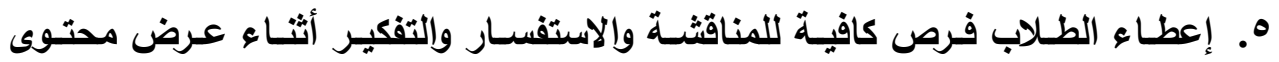

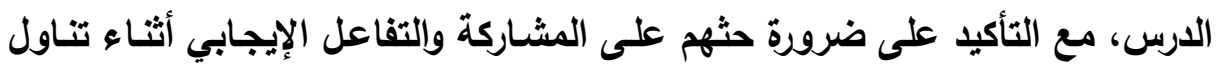
موضوعات الرياضيات المختلفة.

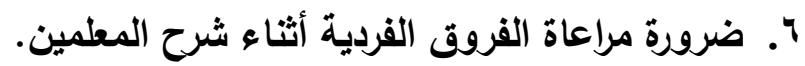

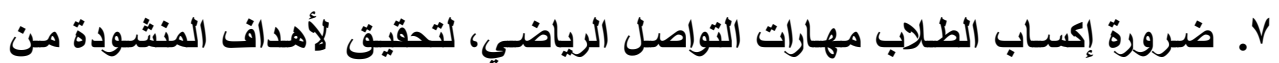
تعليم وتعلم الرياضيات. ^. الاهتمام بتدريب المعلمين أثناء الخدمة على استخدام مهارات التواصل الرياضي مـع طلابهم، والععل على إكسابها لهم من خلال العديد من الدورات التدريبية.

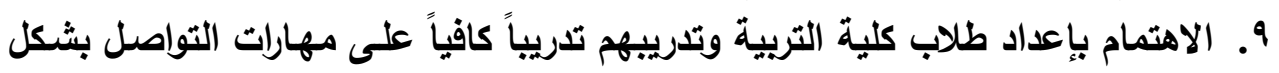

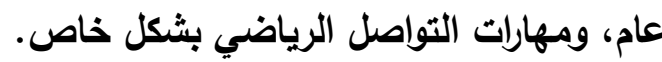

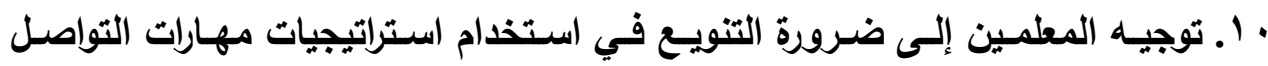

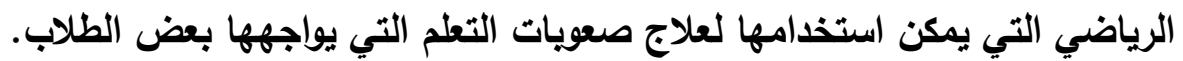

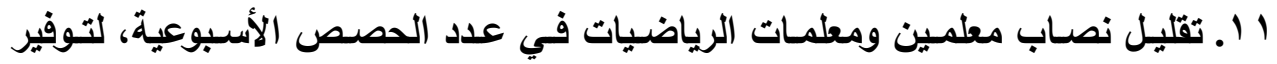
الوقت الملائم لتشخيص صعويات تعلم الرياضيات لاتى الطلاب.

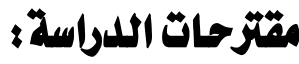

- - - إجراء دراسات مماثلة لعلاج صعويات تعلم الطلابفي مقرات دراسية أخرى.

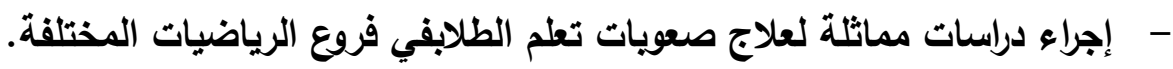

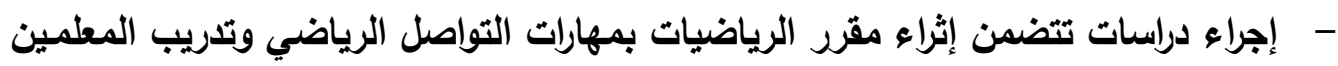
والطلاب على كيفية اكتسابها. - وضـع تصـور مقترح في ضـوء مهـارات التواصـل الرياضسي لعـلاج صـويات التعلم في

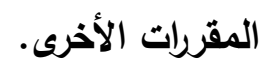
- إجراء دراسـات تتضـمن بـرامج مقترحسة لعـلاج صـويات تعلـم الطلاب بفروع الرياضـيات الأخرى. 


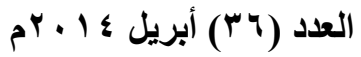

\section{مراجع الدابساند}

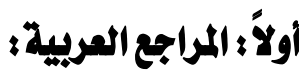

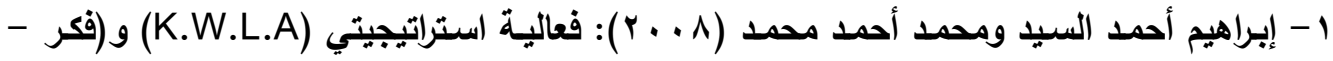
زاوج - شارك) في تدريس الرياضيات على تنمية التواصل والابداع الرياضي لدى تلاميذ المرحلة

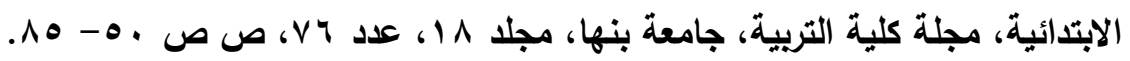

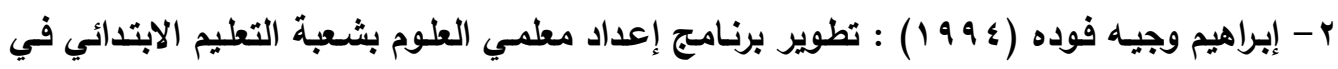

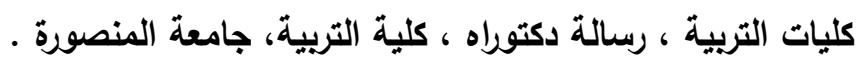

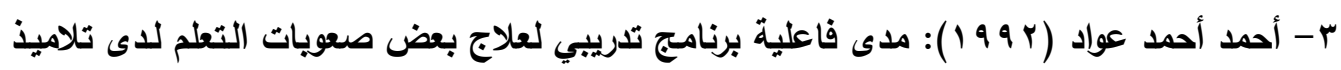

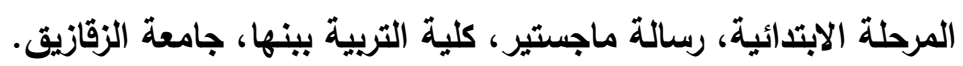

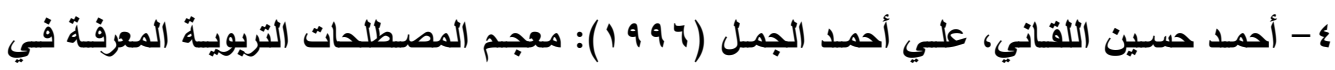
المناهج وطرق التدريس، القاهرة: عالم الكتب.

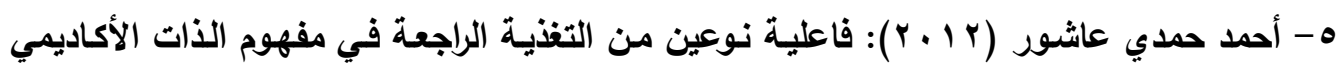

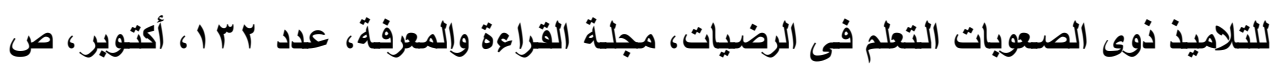

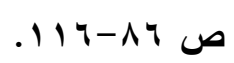
צ- أحمد صادق عبد المجيد، (ه . . r): أثر استخدام الاستراتيجيات المعرفية ومـا وراء المعرفية في

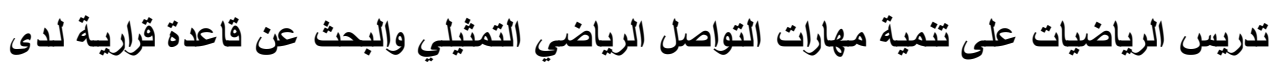

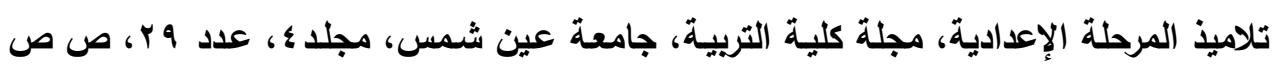
.VY -9

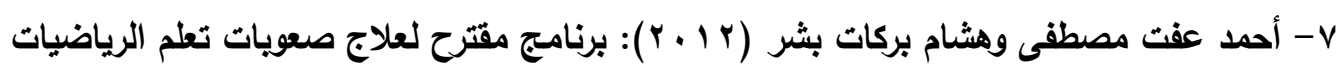

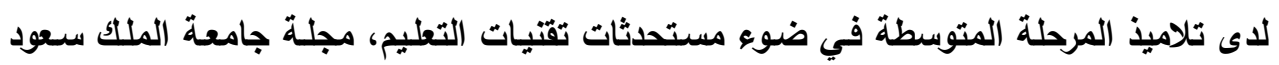

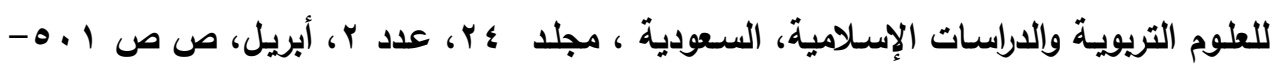

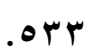

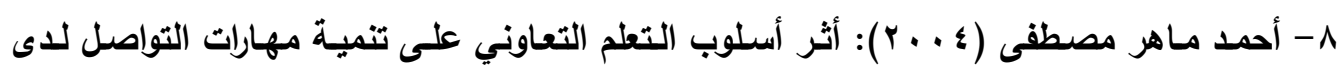

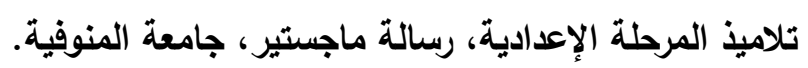

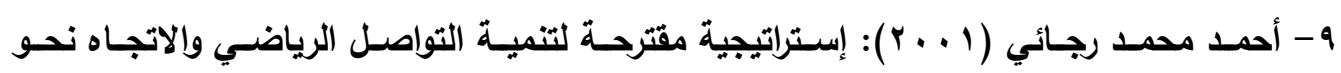
الرياضيات لاى تلاميذ الصف السادس الابتدائي، رسالة ماجستير ، كلية التربية، جامعة طنطا. 


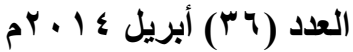

• 1 - أحمد محمود أحمد (^ . . ץ): أثر استخدام إستراتيجية مـا وراء المعرفة على التحصيل وتنمية

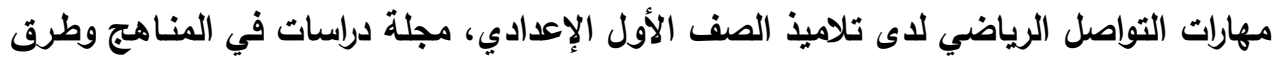

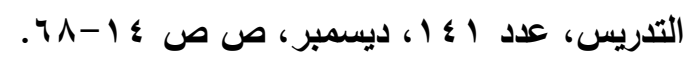

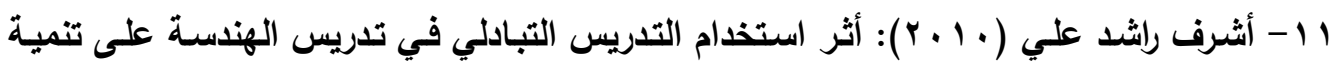

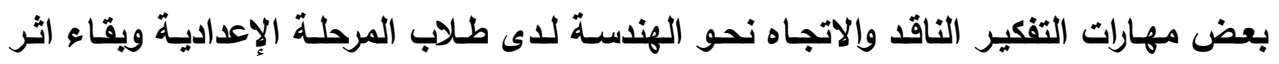

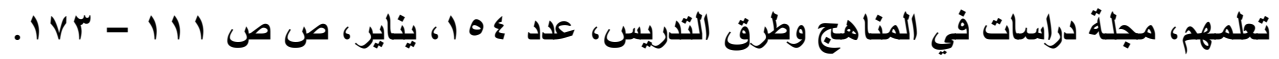

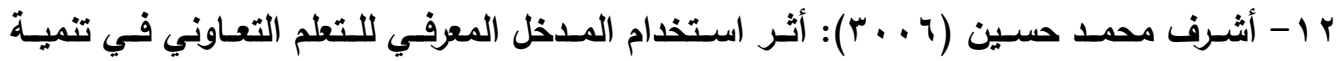

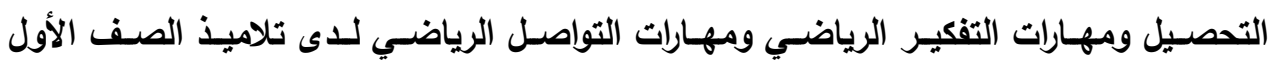
الإعدادي، رسالة دكتوراه، كلية التربية، جامعة الأزهر.

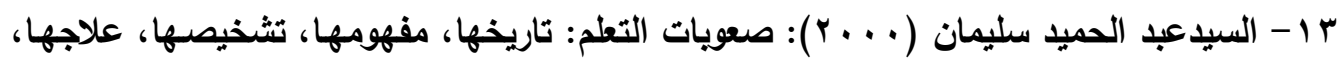
القاهرة، دار الفكر العربي.

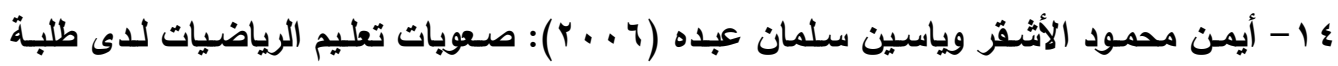

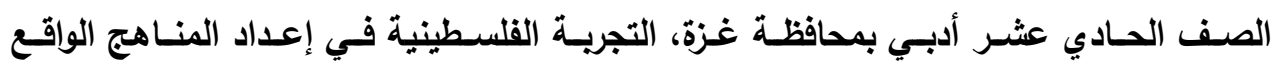

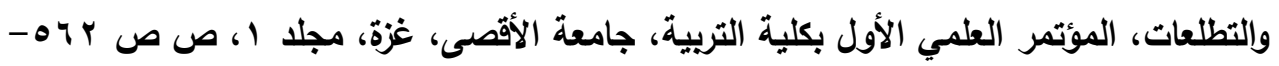
.099

ه 1 - إيهاب عبد العظيم مشالي (^ . + ץ): صعويات تعلم الرياضيات: تشخيصها وعلاجها بالتعزيز، القاهرة: دار النشر للجامعات.

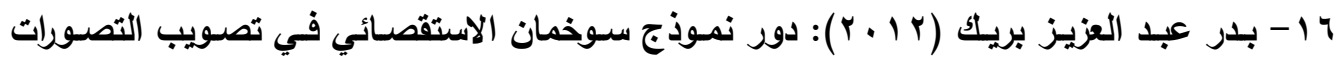
الخطأ في مادة العلوم لاى التلاميذ ذوي صعويات التعلم بالمرحلة الإعدادية، مجلة كلية التربية

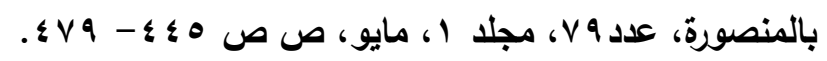

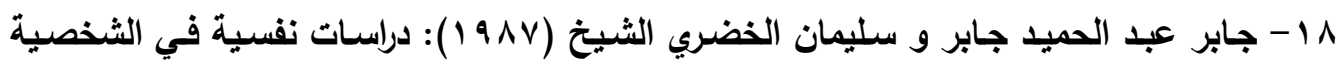
العربية، القاهرة، عالم الكتب.

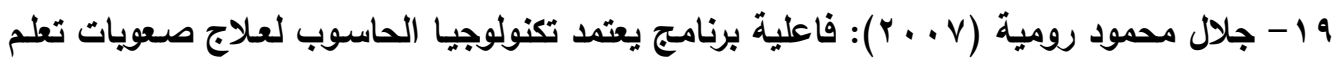

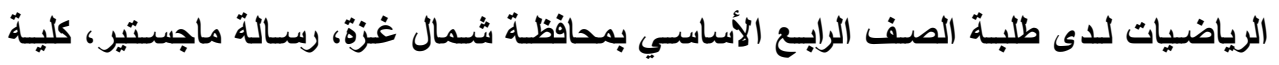
التربية، جامعة الأزهر.

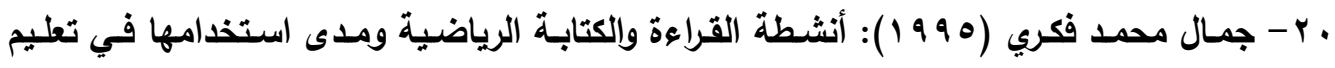

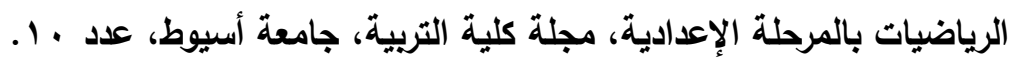
ا Y - رشدي أحمد طعيمة (9Av ( )): تحليل المحتوى في العلوم الإنسانية، القاهرة، دار الفكر العربي. 


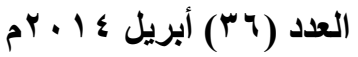

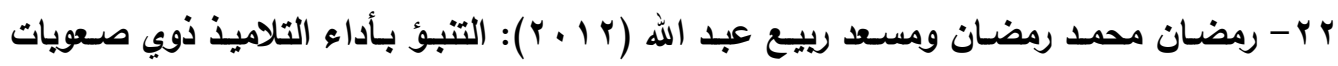
التعلم في اختيار الفهم القرائي من خلال أدائهم في اختبارات الذاكرة العاملة، مجلة كلية التربية بلة،

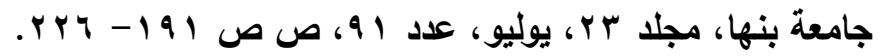

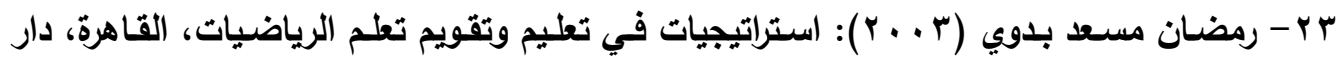

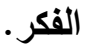

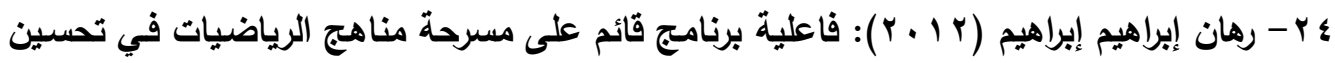
مستوى التحصيل للتلاميذ ذوي صعويات التعلم بالمرحلة الإعدادية، مجلة القراءة والمعرفة، عداند

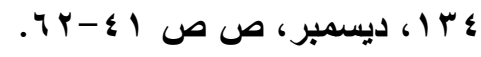

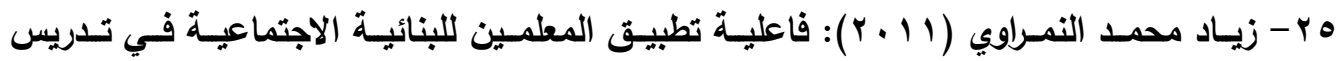
الرياضيات ودورها في تطوير مهارات الاتصال الرياضي لاى طلبة الصف السادس الأساسي في

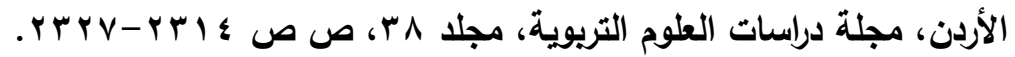

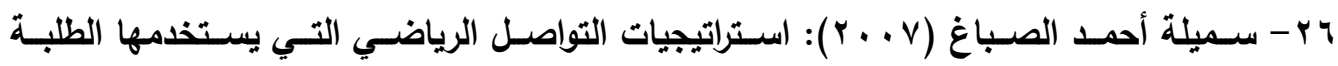

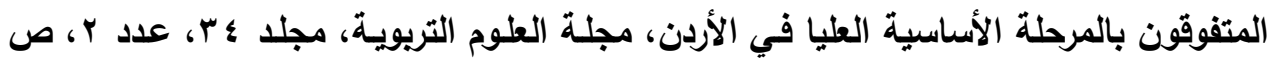

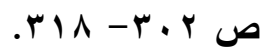

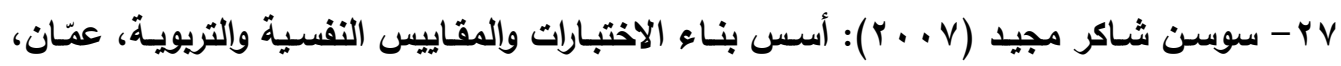
ديبونو للطباعة والنشر والتوزيع. مئر

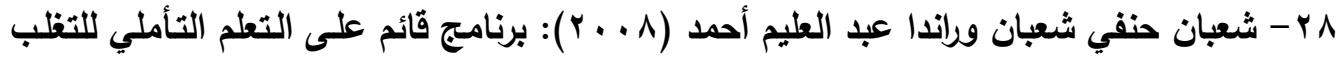

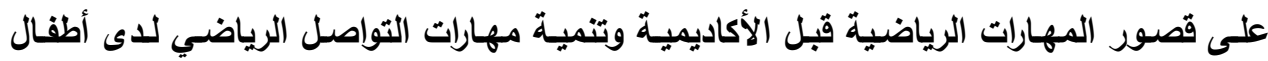

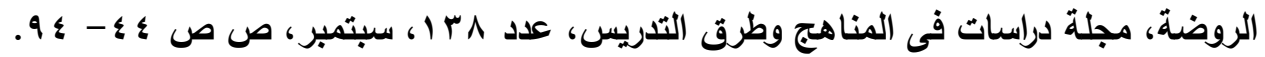

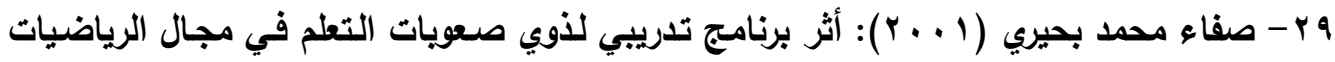

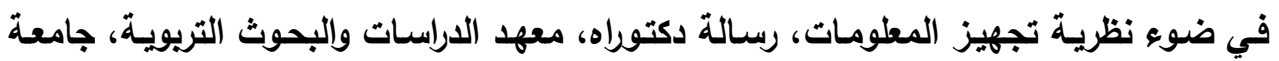
القاهرة.

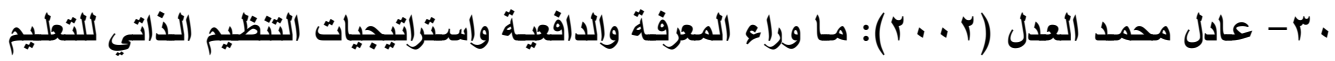

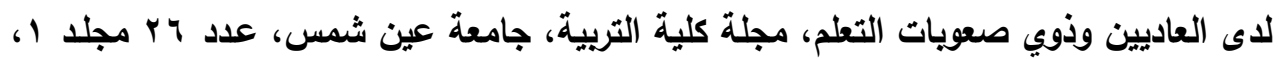

$$
\text { ص ص ص الو العادين ودوي }
$$

اب- عبد الواحد محمد مصطفى (r ا ـ ץ): العلاقة بين الدافع للانجاز وفعالية الذات الأكاديمية لاي

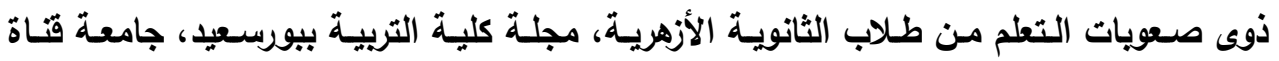

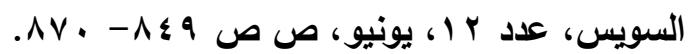




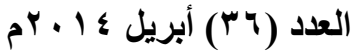

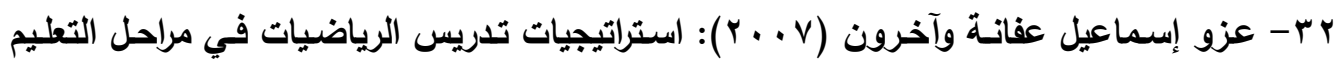
العام، غزة، مكتبة الطالب الجامعي.

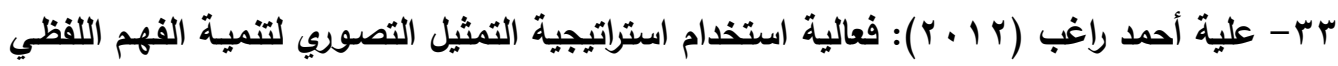

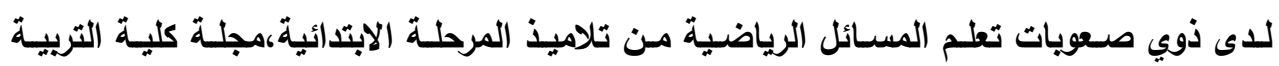

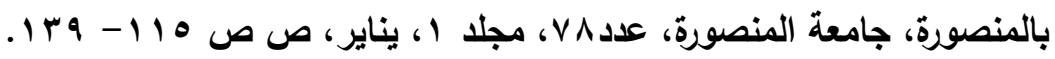

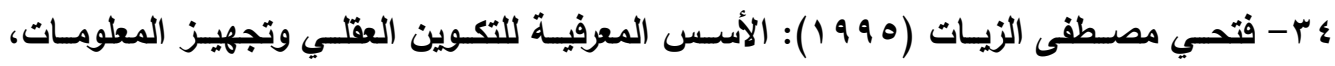
المنصورة، دار الوفاء للطباعة والنشر والتوزيع.

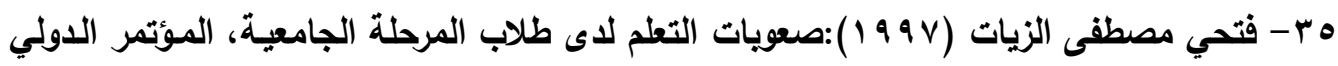

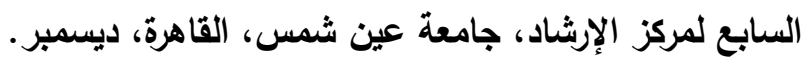

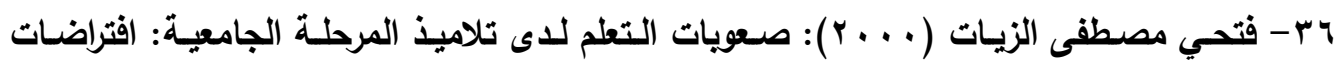

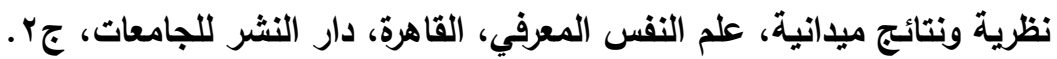

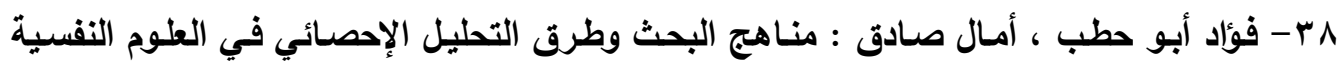

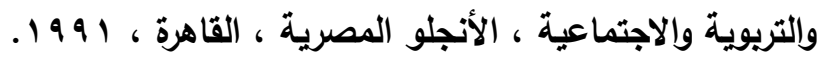

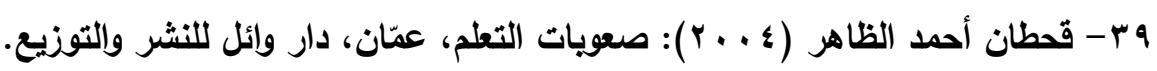

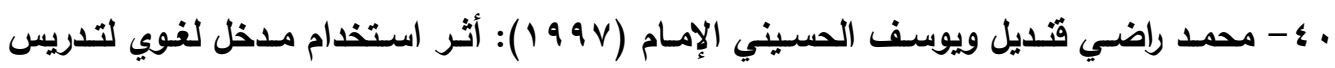
الرياضيات على تحصيل تلاميذ الصف الثاني الإعدادي لموضسوع المسـاحات وعلى تواصلهم الإمام

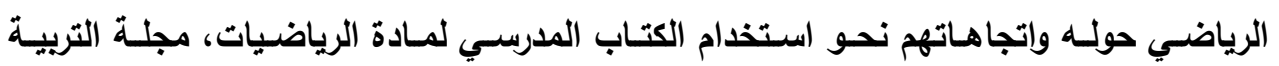

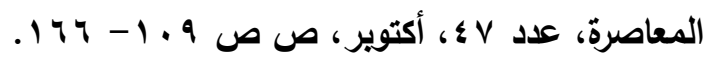

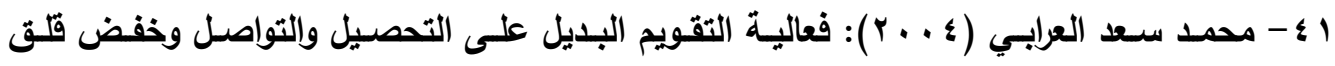

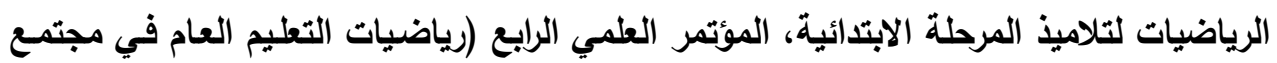

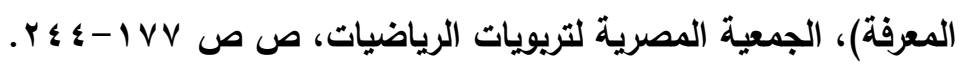

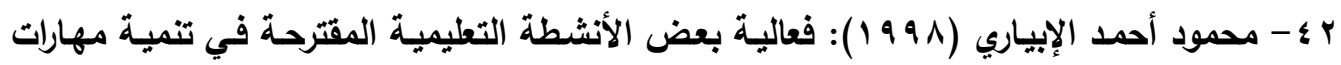

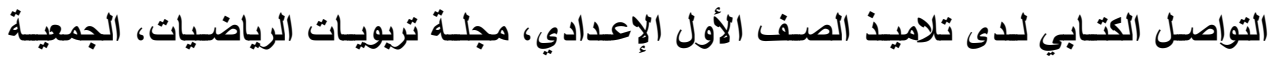

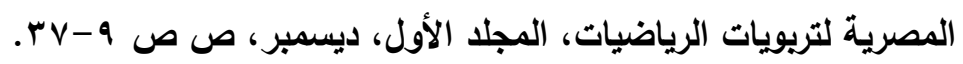

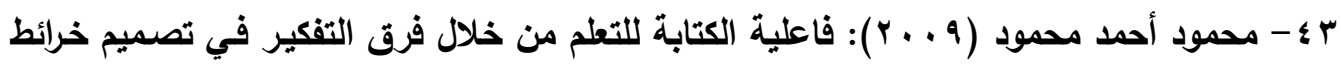

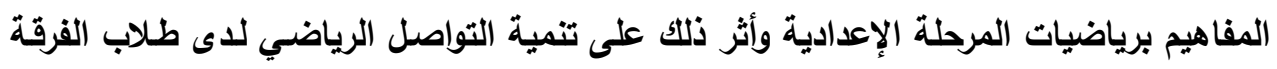

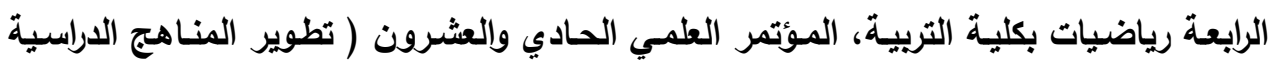

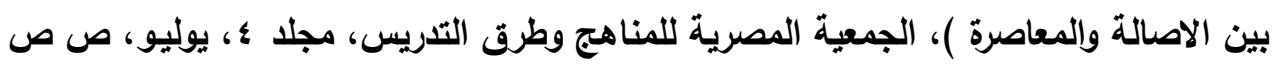




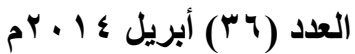

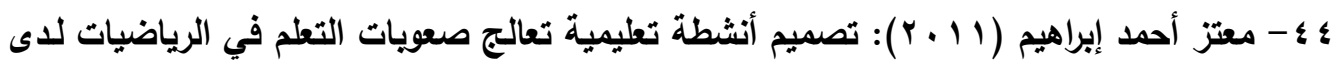

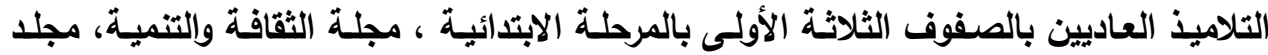

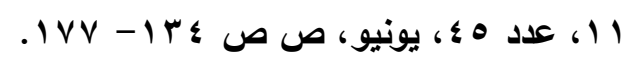

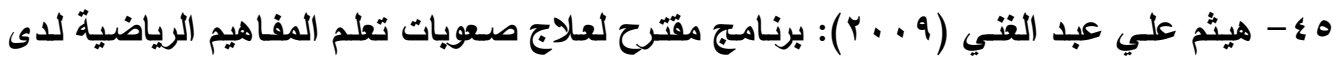

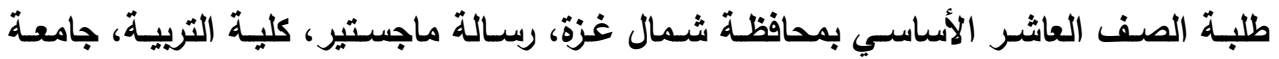
الأزهر.

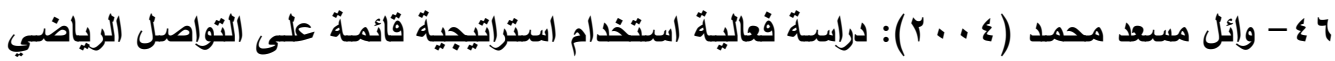

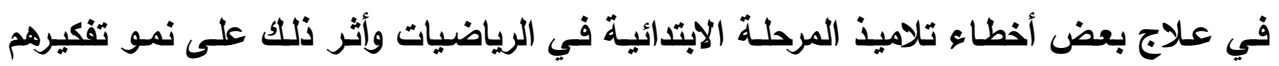

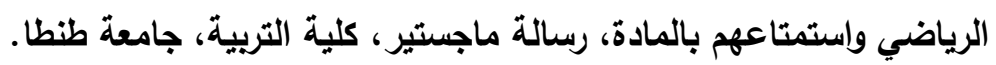

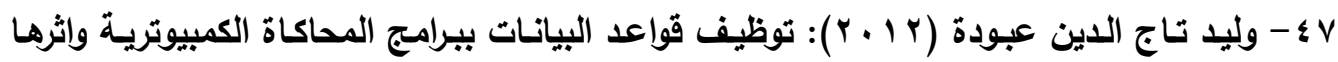
على تتميـة التحصيل لـذوي صـويات تعلـم الفيزيـاء بالمرحلـة الثانويـة، مجلـة كليـة التربيـة

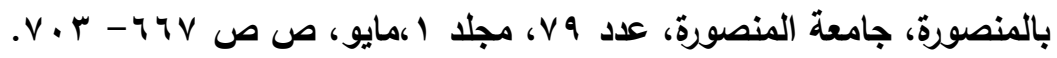

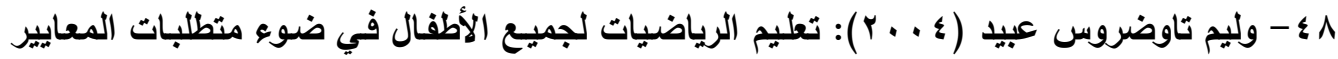

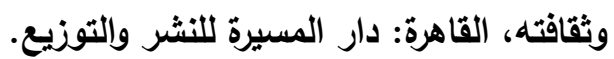

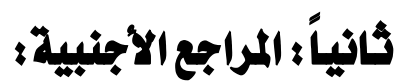

49- Ali, T. (2011): Exploring Students' Learning Difficulties in Secondary Mathematics Classroom in Gilgit-Baltistan and Teachers' Effort to Help Students Overcome These Difficulties, Bulletin of Education and Research. Jun, Vol. 33, No.1, PP.47-69.

50- Anne, N. (2012): Dyscalculia/Specific Learning Difficulty in Mathematics: Identification and Intervention in Irish Primary Schools, Journal of Special Needs Education in Ireland, Vol. 26, No. 1, PP. 3-15.

51- Asha, K. et al., (2013): Understanding and Accessing StandardsBased Mathematics for Students With Mathematics Difficulties, Learning Disability Quarterly, Feb, Vol. 36, No. 1, PP. 4-20.

52- Balas, A. (1997): The Mathematics and Reading Connection, ERIC Document, ERIC NO: ED439017.

53- Baroody A. and Cosnick, R. (1993): Problem Solving Reasoning Communicating (K-8)- Helping Children Think Mathematically, New York, Merrill.

54-Brendefur, J. and Frykholm J., (2000): Promoting Mathematical Communication in the Classroom: Two Preservice Teachers' Conceptions and Practices, Journal of Mathematics Teacher Education, Vol. 3 , No. 2, PP. 125-153. 


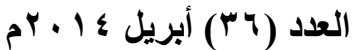

55- Bryant, D. (2005): Commentary on Early Identification and Intervention for Students with Mathematics Difficulties, Journal of Learning Disabilities, Vol. 38, PP. 340- 345.

56- Cawley, J. et al. , (1992): Seeking Excellence in Mathematics Student with Mild Disabilities, Children, Vol. 24, No. 2, PP.40-43.

57- Cooke, B. and Buchholz,D. (2005): Mathematical Communication in the Classroom: A Teacher Makes a Difference, Early Childhood Education Journal, Jun, Vol. 32, No. 6, PP.365-369

58- Cotton, T. (1995): Communicating Mathematics, Mathematics Teaching, Vol. 159, PP. 38-41.

59- Cossey, R. (1997): Mathematical Communication: Lessons of Access AND Equity, Dissertation Abstracts International, Vol. 1, No. 2, PP. 206- 326.

60- Doril, N. and Miriam,A. (2004): "Students preference of NoN-Algebric representation in mathematical communication", proceeding of th 28th conference of the international group for the psychology of Mathematics Education, Vol.3, No.27, PP.409-416.

61- Evans, D. (2007): Developing Mathematical Proficiency in the Australian Context: Implications for Students With Learning Difficulties, Journal of Learning Disabilities, Sep/Oct, Vol. 40, No. 5, p420-426.

62- Fennell, S. and Christiane, C. (1995): Oral and Written Communication for Promoting Mathematical Understanding: Teaching Examples From Grade 3, Journal of Curriculum Studies, Jan, Feb.

63- Fuchs, L. et al., (2008). Effects of Preventative Tutoring on the Mathematical Problem Solving of Third Grade Students With Mat and Reading Difficulties. Exceptional Children, PP.155-173.

64- Gardern, D. and Montague, M. (2003): Visual - Spatial Representation, Mathematical Problem Solving, and Students of Varying Abilities, Learning Disabilities Research and Practice, V.18, No.4, PP.246-254.

65- Good, C. (1973): Dictionary of education $\left(3^{\text {rd }}-\right.$ ED) , Mc Grow Hill , New York.

66- Gearheart, B.(1985): Learning Disabilities, Education Strategies, $4^{\text {th }}$ ed., TIMES Mirror Mosby College Publishing.

67- Gersten, R. et al. (2005): Early Identification and Interventions for Students with Mathematics Difficulties, Journal of Learning Disabilities, Vol. 38, No.4,PP. 293-304.

68- Harding, L. (1986):Learning Disabilities in the Primary Classroom, London Groom Helm L T D. 


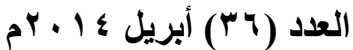

69- Holsti , c. (1969): Content Analysis for Social Science and Humanities, new York · Addison, Wesley.

70- Huggins B. and Maiste T.(1999):Communication in Mathematics, Unpublished master's thesis, Saint Xavier University Chicago.

71- Irvin, B.(1993): Content Analysis of Writing Assignment Contained in The Four Basal Mathematics Textbook Series Adopted By The State Of Texas. DAI, Vol. 54, No. 5, P.1656.

72- Jingzi, H., Bruce ,N. and Sandra ,G. (2005): Talking Math: Integrating Communication and Content Learning in Math ACase Study of Secondary Mathematics Classroom , International Journal ofLearning ,Volume 10,P.3705-3729

73- Kolligian, J. and Sternberg, R. (1987): Intelligence, Information Processing and Specific Learning Disabilities: A Triarchic and Synthesis, Journal of Leering Disabilities, Vol. 20, No. 1, PP.8-18.

74- Kozminski, E. and Konminski, L. (2002): The Dialogue Page: Teachers and Student Dialogues to Improve Learning Motivation, Journal of Intervention in School and Clinic, Vol. 38, No. 2, PP. 88-95.

75- Leikin, R. and Zaslavsky, O. (1997): Facilitating Student Interactions in Mathematics in a Cooperative Learning Setting, Journal for Research in Mathematics education, Vol. 28, No. 3, PP. 331-345.

76- Lexi, W. and Kearney, N. (2009): Communication: A vital Skill of Mathematics, University of Nebraska- Lincolns.

77- Mal, S. and Peter, G. (1998): The Analysis of Student Expository Writing In mathematics, Education Studies in Mathematics, Vol. 36, No. 1, june, PP. 18-33.

78- Miller, L. (1991): Writing to learn Mathematic, Mathematics Teacher, Vol. 84, No. 7, PP. 516- 521.

79- Mantague and Applegate (1993): Mathematical Problems Solving Characteristics of Middle School With Learning Disabilities, Journal of Special Education, Vol. 27, No. 2, PP. 175-201.

80- National Council of Teachers of Mathematics (NCTM) (1989): Curriculum and Evaluation Standers for School Mathematics, Reston, VA: The Council.

81- National Council of Teachers of Mathematics (NCTM) (2000): Principles and Standards for School Mathematics, Reston, VA, USA.

82- Nical, C. (1999): Learning to Teach Mathematics: Questioning, Listening and Responding, Educational Studies in Mathematics, Vol. 37, No. 3, PP. 45-66.

83- Phillips, E. and Crespo, S. (1995): Math Pen pals Developing Written Communication in Mathematics, ERIC Document, ERIC NO: ED 385439. 


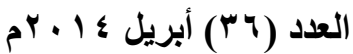

84- Reisman, F. and Kauffman, S. (1980): Teaching Mathematics to children with special Needs, Columbus, Charles E. Merrill.

85- Salle, A. (1997): Children Construction of Knowledge about Fraction Through Writing, Dissertation Abstract International, Vol. 58, No. 1, July. PP. 115-A.

86- Schwarz, J.(1999): Vocabulary and Its Effects on Mathematics Instruction, ERIC, ED 439017.

87- Siegel. L. (1999): Issues in the Definition and Diagnosis of Learning Disabilities, Journal of Learning Disabilities, Vol. 32, No. 4, PP. 304319. 